\title{
THE EXPERIMENTAL EFFECT OF PARENT VERSUS PEER INFLUENCE ON CHILDREN'S PHYSICAL ACTIVITY BEHAVIOR
}

\author{
A dissertation submitted to the \\ Kent State University College \\ of Education, Health, and Human Services \\ in partial fulfillment of the requirements \\ for the degree of Doctor of Philosophy
}

by

Mallory S. Kobak

May 2016 
A dissertation written by

Mallory S. Kobak

B.A., Baldwin-Wallace University, 2011

M.S., The University of Akron, 2013

Ph.D., Kent State University, 2016

Approved by

, Director, Doctoral Dissertation Committee

Jacob E. Barkley

, Member, Doctoral Dissertation Committee

Ellen L. Glickman

, Outside Member, Doctoral Dissertation Committee

Andrew Lepp

Accepted by

, Director, School of Health Sciences

Lynne E. Rowan

, Interim Dean, College of Education, Health, and

Mark Kretovics Human Services 


\section{THE EXPERIMENTAL EFFECT OF PARENT VERSUS PEER INFLUENCE ON CHILDREN'S PHYSICAL ACTIVITY BEHAVIOR (130 pp.)}

Director of Dissertation: Jacob E. Barkley, Ph.D.

Current evidence supports the idea that children's physical activity is highly variable, and may be influenced by a variety of factors. Potential factors known to alter children's physical activity behavior that were examined within this dissertation include the use of mobile, internet-connected devices (e.g., tablet computers) or with whom children play (e.g., parents, peers). Therefore, the purpose of Specific Aim \#1 was to measure physical and sedentary activity with and without the presence of an Apple iPad in a gymnasium. The purpose of Specific Aim \#2 was to measure children's physical and sedentary activity on an outdoor playground during three conditions: playing alone, with their parent participating, and with their friend participating. Twenty children participated in each study where physical and sedentary activity was monitored. Results of Specific Aim \#1 concluded that children accumulated fewer accelerometer counts and increased their sedentary behavior $(p \leq 0.05)$ with the iPad present $(1748 \pm 1321$ counts, $21.6 \pm$ 13.5 min sitting) versus without the iPad present $(3328 \pm 781$ counts, $6.2 \pm 5.0 \mathrm{~min}$ sitting). The results of Specific Aim \#2 concluded that children accumulated fewer sitting minutes and greater physical activity $(p \leq 0.05)$ when playing with their parent ( $2.7 \pm 7$ min sitting, $87503 \pm 37063$ counts) or friend ( $0.9 \pm 1.4$ min sitting, $93363 \pm$ 22608 counts) versus when playing alone (7.8 $\pm 8.2 \mathrm{~min}$ sitting, $70672 \pm 35228$ counts). 
These results provide additional information when creating physical activity interventions with the overall goal of increasing children's physical activity behavior. 


\section{ACKNOWLEDGMENTS}

I would like to thank the members of my dissertation committee, Dr. Jacob E. Barkley, Dr. Andrew Lepp, Dr. Ellen E. Glickman, and Dr. Colleen Novak for your expertise and feedback. More specifically, I would like to thank Dr. Jacob E. Barkley for his mentorship throughout my $\mathrm{PhD}$ career. You have made me a better writing and for that, I am forever grateful. I would also like to thank Rachele Kappler and Dr. Ronald Otterstetter of The University of Akron for their encouragement throughout my graduate experience.

Thank you to my husband, Michael Rebold, not only for his assistance in data collection but also for inspiring me to complete my PhD. Finally, a special thank you to my parents and grandfather for their love and support during my undergraduate and graduate studies; this project is for you. 


\section{TABLE OF CONTENTS}

Page

ACKNOWLEDGMENTS iii

LIST OF FIGURES viii

\section{CHAPTER}

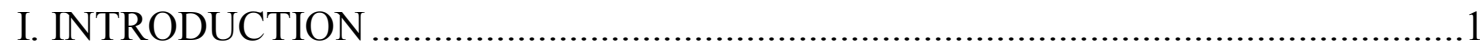

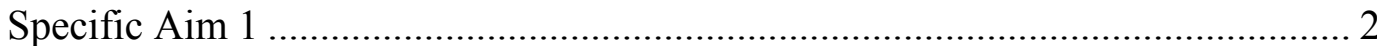

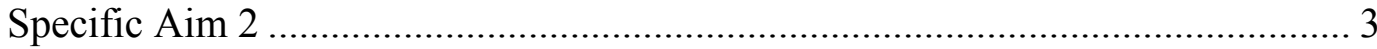

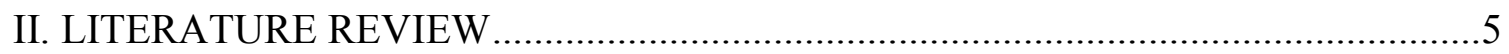

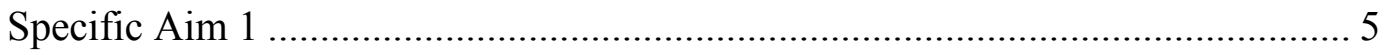

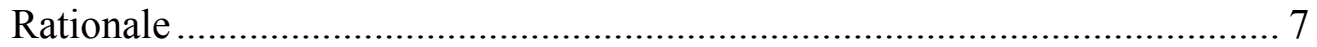

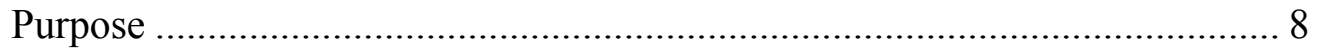

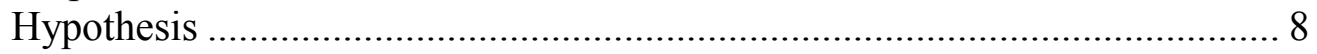

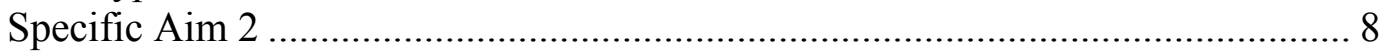

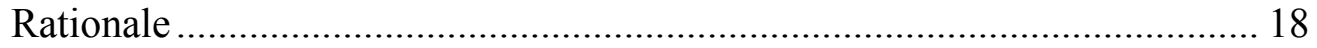

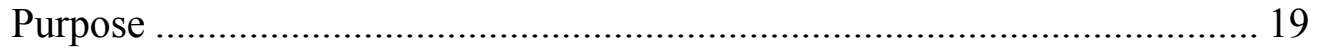

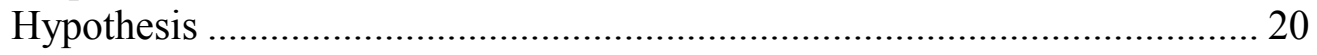

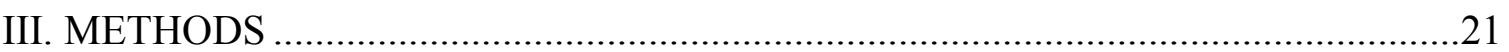

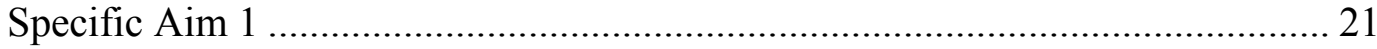

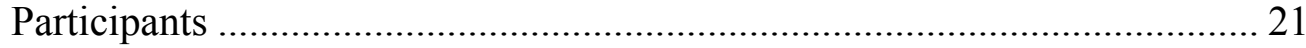

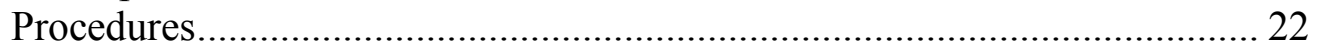

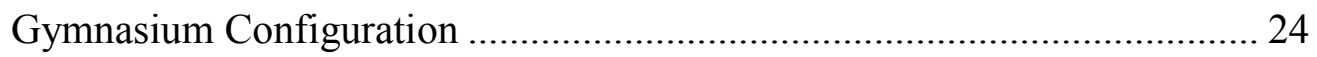

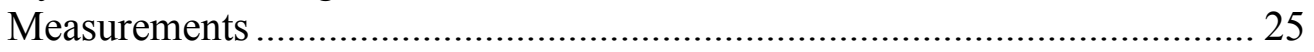

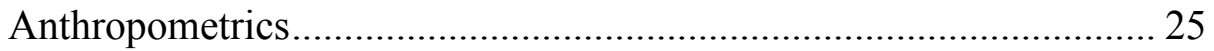

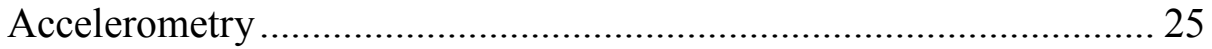

Sedentary activity observation .......................................................... 26

Rating of Perceived Exertion (RPE) .................................................. 26

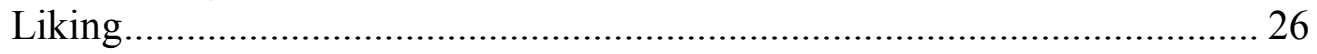

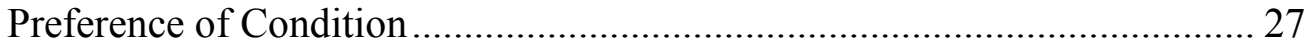

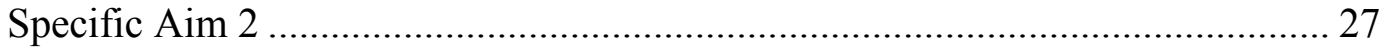

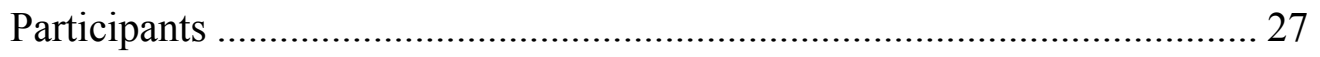

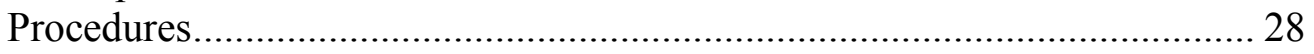

Playground Arrangement.......................................................................... 30

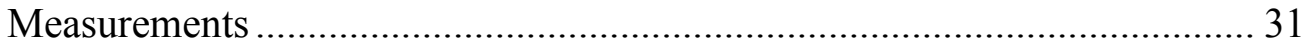

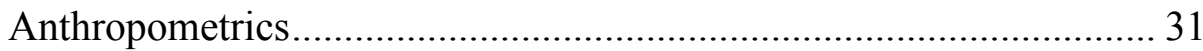

Accelerometry .............................................................................. 31

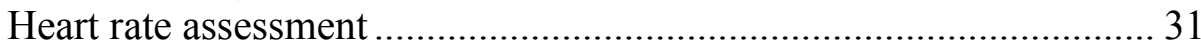

iv 
Sedentary activity observation .......................................................... 32

Rating of Perceived Exertion (RPE) ................................................ 32

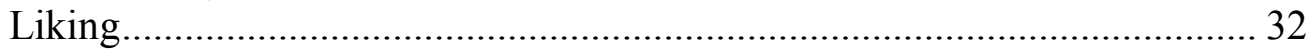

Preference of Condition ......................................................................... 33

IV. THE EFFECT OF THE PRESENCE OF AN INTERNET-CONNECTED, MOBILE, TABLET COMPUTER ON PHYSICAL ACTIVITY BEHAVIOR

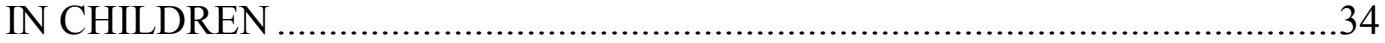

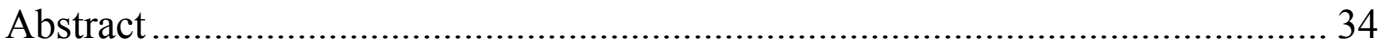

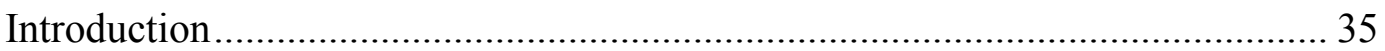

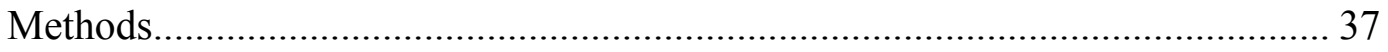

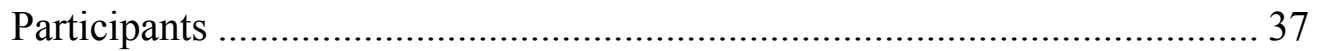

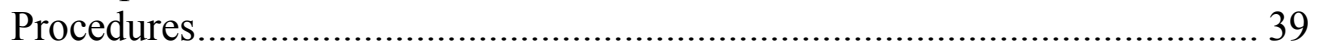

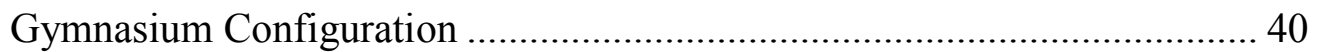

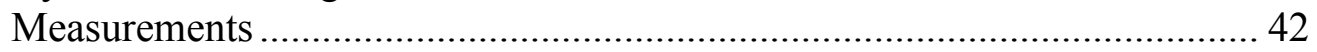

Anthropometrics.......................................................................... 42

Accelerometry ........................................................................... 42

Sedentary activity observation .......................................................... 42

Rating of Perceived Exertion (RPE) .................................................. 43

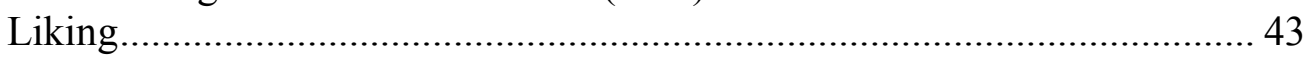

Preference of Condition ........................................................................... 44

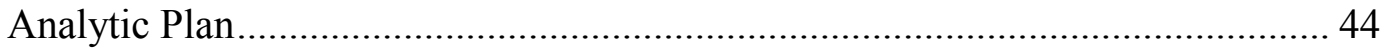

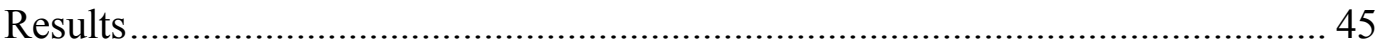

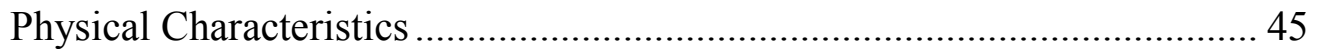

40-Minute Total Accelerometer Counts ......................................................... 45

Time Allocated to Sedentary Activities.......................................................... 46

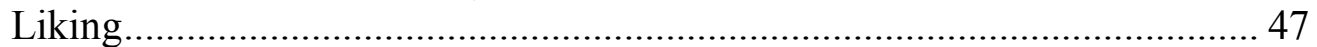

Ratings of Perceived Exertion ................................................................ 47

10-Minute Bonus Period........................................................................ 48

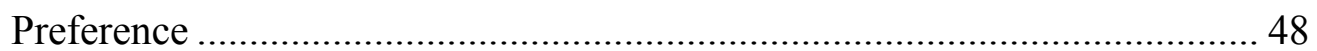

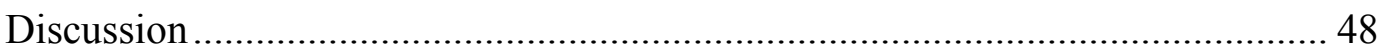

Physical and Sedentary Activity ................................................................ 49

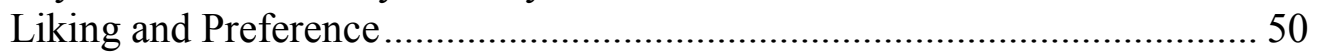

Limitations and Future Directions ............................................................ 51

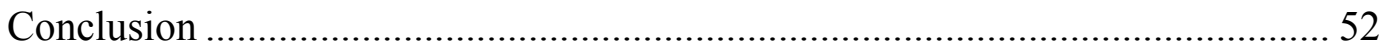

V. THE EXPERIMENTAL EFFECT OF PARENT VERSUS PEER INFLUENCE ON CHILDREN'S PHYSICAL ACTIVITY BEHAVIOR ..................................53

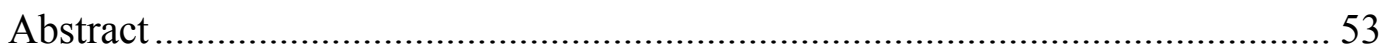

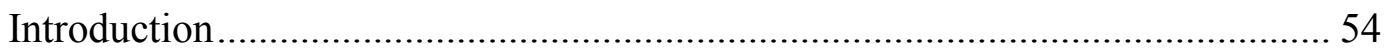

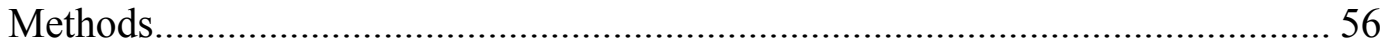

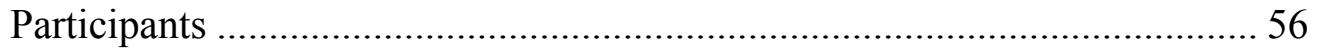

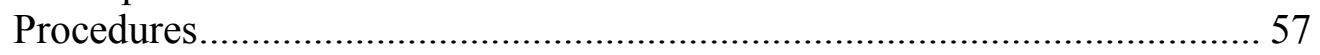

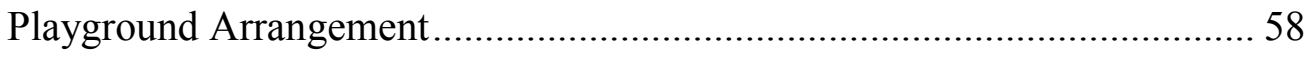




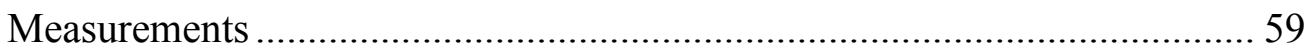

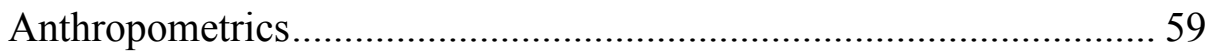

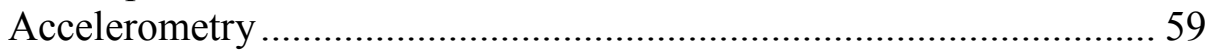

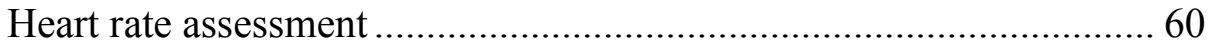

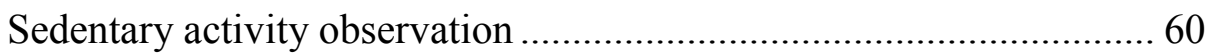

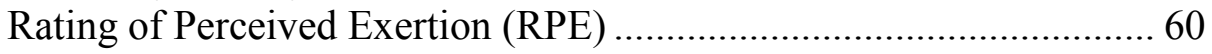

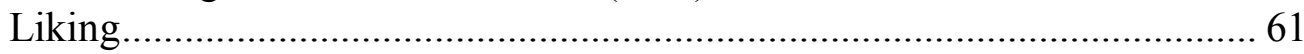

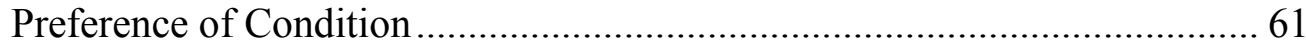

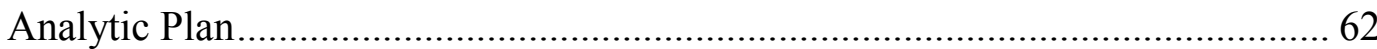

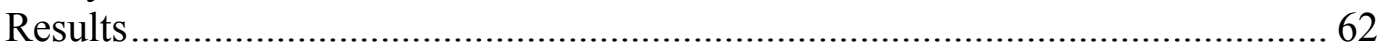

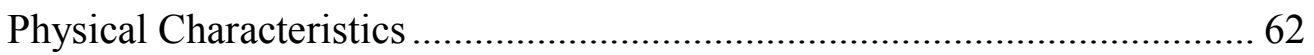

40-Minute Total Accelerometer Counts ........................................................ 63

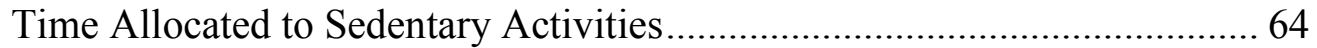

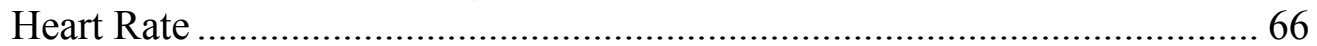

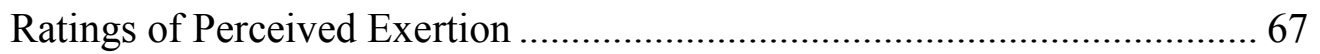

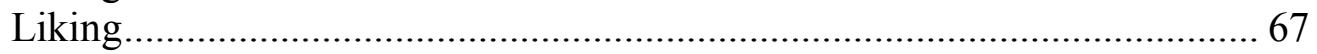

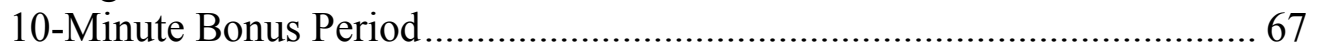

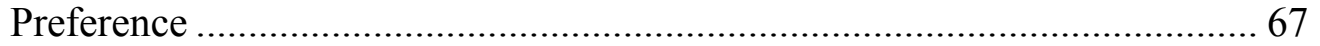

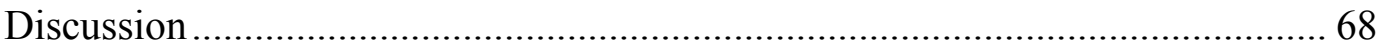

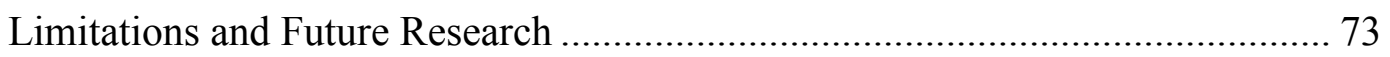

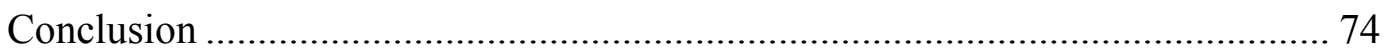

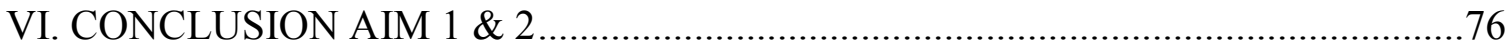

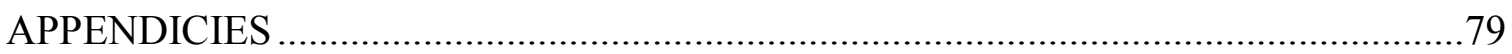

APPENDIX A. SPECIFIC AIM \#1: RECRUITMENT FLYER ............................80

APPENDIX B. SPECIFIC AIM \#1: INFORMED CONSENT FORM .................82

APPENDIX C. SPECIFIC AIM \#1: INFORMED ASSENT FORM ……..............86

APPENDIX D. SPECIFIC AIM \#1: MEDICAL HISTORY FORM ……..............88

APPENDIX E. SPECIFIC AIM \#1: GYMNASIUM CONFIGURATION ...........90

APPENDIX F. SPECIFIC AIM \#1: WORKLOAD DOCUMENTATION

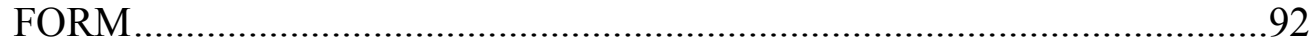

APPENDIX G. SPECIFIC AIM \#1: VISUAL ANALOG SCALE FOR

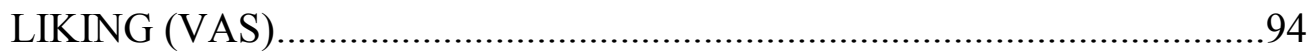

APPENDIX H. SPECIFIC AIM \#1 : OMNI WALK/RUN SCALE OF

PERCIEVED EXERTION FOR CHILDREN …………............................96

APPENDIX I. SPECIFIC AIM \#2: RECRUITMENT FLYER ………................98

APPENDIX J. SPECIFIC AIM \#2: INFORMED CONSENT FORM ...............100

APPENDIX K. SPECIFIC AIM \#2: INFORMED ASSENT FORM....................105

APPENDIX L. SPECIFIC AIM \#2: MEDICAL HISTORY FORM

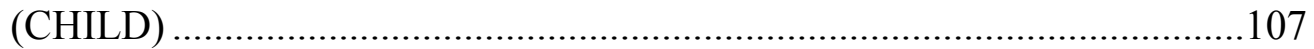

APPENDIX M. SPECIFIC AIM \#2: MEDICAL HISTORY FORM

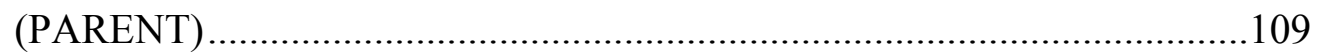

APPENDIX N. SPECIFIC AIM \#2: PRIVATE ACCESS LETTER ...................111 
APPENDIX O. SPECIFIC AIM \#2: VISUAL ANALOG SCALE FOR

LIKING (VAS) ....................................................................................113

APPENDIX P. SPECIFIC AIM \#2: OMNI WALK/RUN SCALE OF

PERCIEVED EXERTION FOR CHILDREN …......................................115

APPENDIX Q. SPECIFIC AIM \#2: PLAYGROUND ARRANGEMENT........117

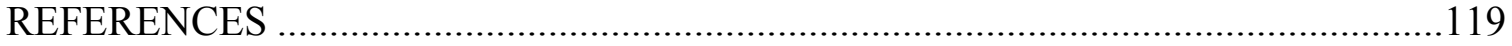




\section{LIST OF FIGURES}

Figure

1. Accelerometer counts for each condition (Mean $\pm \mathrm{SEM}$ ).

2. Sedentary time for each condition (mean \pm SEM).

3. Accelerometer counts for each condition (Mean $\pm \mathrm{SEM}$ ).

4. Time allocated to sedentary activities for boys during each condition (Mean \pm SEM).

5. Time allocated to sedentary activities for girls during each condition (Mean \pm SEM). .66

6. Preference of condition (Data are Mean \pm SEM). .68 


\section{CHAPTER I}

\section{INTRODUCTION}

Participation in prolonged sedentary behavior (i.e., sitting) and inadequate

physical activity have been linked to an increased risk of overweight and obesity in children (Bandura, 1977; Prochaska, Rodgers, \& Sallis, 2002). This fact is the impetus behind the large number of scientific studies that have sought to better understand ways to promote children's physical activity participation and minimize sedentary behavior. Current evidence supports the idea that children's physical activity levels are highly variable, and may be influenced by a multitude of factors including availability of sedentary choices, reinforcing (e.g., motivating) value of physical activity, self-efficacy for physical activity, availability of technology, parental influence, and peer support (Barkley et al., 2014; Beets, Pitetti, \& Forlaw, 2007; Goran \& Reynolds, 1999; Lepp, Barkley, Sanders, Rebold, \& Gates, 2013; Rebold, Lepp, Sanders, \& Barkley, 2015; Rodriguez, Brown, \& Troped, 2005; Sanders, Peacock, et al., 2014; Weiss, 2000). For this project there were two specific aims both designed to experimentally assess differing technological and social factors that may have a causal impact on children's physical and sedentary activity: Specific aim 1 examined the role of a popular portable internet-connected tablet computer (Apple iPad) upon children's physical activity and sedentary behavior. Specific aim 2 examined the differences in physical activity during a simulated, outdoor recess period across three social conditions: a child playing alone, playing with a friend, and playing with a parent. 


\section{Specific Aim 1}

In recent years the advancements of technology have allowed people to engage in traditionally sedentary activities such as watching television, playing video games, or streaming movies using mobile devices (i.e., cell phones, tablet computers). Such devices allow for access to these traditionally sedentary activities almost anywhere and anytime. Unlike the devices used for traditional sedentary activities (e.g., watch television), mobile devices are, by nature, portable thus creating a scenario where watching videos and playing video games can occur during physical activity. However, recent research has shown that heavy use of mobile devices, despite their portability, is positively associated with sedentary behavior in college-aged adults (Barkley \& Lepp, 2015). More specifically, high cell phone users have been shown to sit for 140 minutes more per day than their low use peers. Additionally cell phone use during treadmill exercise has been shown to cause a reduction in overall intensity of exercise (Rebold, Lepp, Sanders, et al., 2015), whereas yet another study reported that high cell phone use was predictive of lower cardiorespiratory fitness (Lepp et al., 2013). Taken together, this mounting evidence suggests that using mobile devices is predictive of many of the same negative consequences as traditional screen time (e.g., television watching). However, these existing studies are limited only to college-aged adults. This is important to note because children have become a growing part of the population who regularly use mobile, internet-connected, electronic devices (e.g., cellular telephones, tablet computers; O'Keeffe, Clarke-Pearson, \& Council on Communications and Media, 2011). Therefore, 
additional research examining the effects of mobile device use upon physical and sedentary behaviors in younger children is needed.

\section{Specific Aim 2}

Parents and peers (e.g., friends) have both been shown to have a particularly strong influence over children's behavioral choices with parents having the largest influence early in life and peer influence becoming increasingly more important as children approach adolescence (Prochaska et al., 2002). Extant evidence supports the notion that children with physically active parents and/or peers are more likely to be physically active themselves (Barkley et al., 2014; Cheng, Mendon, de Farias Junior, 2014; Rebold, Lepp, Kobak, McDaniel, \& Barkley, 2015; Sanders, Peacock, et al., 2014). Several studies have identified parental and peer influence as factors that are associated with physical activity behavior in children though many of these studies have relied on non-experimental techniques (Anderssen \& Wold, 1992; Beets et al., 2007; Cheng et al., 2014; Kirby, Levin \& Inchley, 2011; Prochaska et al., 2002; Sallis, Alcaraz, et al., 1992; Salvy, Bowker, Nitecki, Kluczynski, \& Barkley, 2012; Trost \& Loprinzi, 2011). However, there is recent, albeit limited, experimental research examining the impact of parental and/or peer influence on children's physical activity (Barkley, Salvy, \& Roemmich, 2012; Barkley et al., 2014; Rebold, Lepp, Sanders, et al., 2015; Rittenhouse, Salvy \& Barkley, 2011; Salvy et al., 2012; Sanders, Peacock, et al., 2014). Among those limited existing experimental studies, there are none of which we are aware that have compared the effect of the presence of a peer versus the presence of a parent on children's physical activity simultaneously. This comparison is potentially important 
because children may be more likely to engage in greater amounts of physical activity with a parent than with a peer or vice versa. It is possible that as age increases children are more likely to identify more with their peers rather than their parents. Understanding the potential differences could lead to improved children's physical activity recommendations. 


\section{CHAPTER II}

\section{LITERATURE REVIEW}

\section{Specific Aim 1}

Advancements in computer technology have altered the way in which individuals access modes of communication or digital entertainment. Until recently individuals could only access the internet to stream movies, play video games, access music, or update social media on a television, video gaming consoles (e.g., Playstation), or desktop/laptop computers. There is an abundance of evidence that participation in these traditional forms of screen-based leisure activities is inversely associated with physical activity and positively related to sedentary behavior (Barkley \& Lepp, 2015; Barkley \& Lepp, 2015; Lepp, Li, et al., 2015; Lepp et al., 2013; Rebold, Sheehan, et al., 2015; Rebold, Lepp, Sanders, et al., 2015). However, modern mobile device (e.g., cell phone) technology allows one to access these same activities (e.g., watching videos, playing video games) almost anytime or anyplace right in the palm of the user's hand. Recently, emerging research has sought to examine how the use of cell phones can impact physical activity and sedentary behavior in college-aged adults. Lepp and colleagues (2013) assessed the relationship between that cell phone use and cardiorespiratory fitness in healthy, college-aged adults. Results indicated that cell phone use was significantly and negatively associated with cardiorespiratory fitness, meaning that college-aged individuals who used their cell phones heavily were less physically fit then college aged individuals who used their cell phones less frequently. The researchers offer a possible explanation for this relationship in that high cell phone users are more likely to sacrifice 
opportunities to be physically active to participate in sedentary alternatives such as accessing social media applications, playing video games, or surfing the internet. This decreased physical activity and increased sedentary behavior may not only explain the inverse relationship between cell phone use and fitness but it likely places the high cell users at an elevated risk of developing hypokinetic diseases such as Obesity or Type 2 diabetes (Cox et al., 2012).

Since the previous investigation only used self-report data regarding quantity of cell phone use on how it may impact cardiorespiratory fitness, further studies were needed to investigate the causal impact cell phone use during physical activity and its impact on cardiorespiratory fitness. Rebold and colleagues (2015) conducted a study where college-aged adults participated in four separate 30-minute exercise conditions (texting, talking, music, and control). During all conditions, each participant was allowed to self-select his or her pace of walking though all speed and elapsed time displays were covered so he or she was blinded to the actual intensities. Results of this study indicated that while using the cell phone for talking and texting, participants reduced their walking speed. A second study using a similar research design similarly demonstrated that when college aged adults used their cell phone for texting purposes during treadmill exercise, participants spent significantly more time at lower intensities while using their cell phone compared to greater intensities when not using their cell phones (Rebold, Sheehan, Dirlam, Maldonado, \& O'Donnell, 2015). These combined findings indicate that certain cell phone functions (e.g., texting) during a planned bout of exercise lower the intensity of that bout of exercise. 
Being that previous research has investigated cell phone use and its affect on physical activity behavior, sedentary behavior, and cardiorespiratory fitness in the adult population, it is imperative that the same is investigated in children. Since the use of mobile, internet-connected devices is becoming more popular with children, research is needed to identify how physical activity behavior is affected when utilizing those devices (Barkley \& Lepp, 2015; Barkley \& Lepp, 2016; Lepp et al., 2013; Lepp, Li, Barkley, \& Salehi-Esfahani, 2015; Rebold, Lepp, Sanders, et al., 2015; Rebold, Sheehan, et al., 2015). Moreover, with more research indicating that the use of cell phones, which are mobile devices that can be used to access the internet or play video games (among other uses), promote sedentary behavior and reduce exercise intensity, it is reasonable to question mobile-internet connected tablet computers do the same.

\section{Rationale}

The use of mobile devices has rapidly increased in the past decade with emerging research suggesting that the high use of these devices is associated with a decrease in physical activity and increase in sedentary activity. Studies indicate a significant negative relationship between cell phone use and cardiorespiratory fitness and that utilizing a cell phone can reduce exercise intensity while exercising in college-aged adults. However, the current research examining this topic is limited to college-aged adults. Because the use of mobile devices has also increased in children, investigating how these devices affect their physical activity behavior, sedentary behavior, and enjoyment is also warranted. 


\section{Purpose}

The purpose of this study was to experimentally assess physical and sedentary activity behavior and preference of two separate simulated recess conditions: with (iPad) and without (no $\mathrm{iPad}$ ) the presence of a mobile, internet-connected tablet computer (i.e., Apple iPad) in a controlled gymnasium environment.

\section{Hypothesis}

We hypothesized that children's physical activity would be greater in the condition with no iPad present than with an iPad present. Recent investigations in an adult population noted that heavy mobile device (i.e., cell phone) use was predictive of greater sedentary behavior, decreased exercise intensity, and decreased free-living walking speed, and a greater likelihood to use the device during exercise (Lepp et al., 2013; Penko \& Barkley, 2010; Rebold, Lepp, Sanders, et al., 2015; Rebold, Sheehan, et

al., 2015; Sanders et al., 2012). We also hypothesized that children would prefer the $i P a d$ recess condition versus the no iPad condition. This was hypothesized because results from previous research indicated that college-age adults reported greater liking for a bout of treadmill exercise when they were able to use a cell phone during that time (Rebold, Lepp, Sanders, et al., 2015).

\section{Specific Aim 2}

Several non-experimental studies have suggested that parental influence plays a crucial role in the amount and type of physical activity accumulated by their children (Beets, Cardinal, \& Alderman, 2010; Dunton et al., 2012; Prochaska et al., 2002). Parental influence on children's physical activity behavior can occur directly, though 
social support, transportation, paying fees, and playing with the child, and/or indirectly, through behavior modeling (Beets et al., 2010; Wu \& Pender, 2002). Prior studies that have examined parental social support, behavioral modeling, and co-participation are further explained. Several studies examining parental social support have demonstrated that the association between parental social support and children's physical activity level is mediated by self-efficacy, or one's own belief in their abilities to complete certain tasks (Cheng et al., 2014; Dishman, Saunders, Motl, Dowda, \& Pate, 2009; Peterson, Lawman, Wilson, Fairchild, \& Van Horn, 2013; Shields et al., 2009). Children who perceive more social support from their parents feel more capable of engaging in more physical activity (Rebold, Lepp, Kobak, et al., 2015). When parents provide more social support this leads to an increase in children's self-efficacy to complete certain physical activities (Cheng et al., 2014; Dishman, Saunders, Motl, Dowda, \& Pate, 2009; Peterson, Lawman, Wilson, Fairchild, \& Van Horn, 2013; Shields et al., 2009). Additionally, research examining children who received positive social support versus those who did not receive positive social support has found that when parents provided positive social support and rewards (e.g., in the form of praise) for their children's participation in physical activity, they had children who were more likely to engage in more physical activities than those who did not receive positive social support and rewards (Eccles, 1999; Weiss, 2000).

The Social Learning Theory may also serve as an important theory for understanding how parents can influence children's behavior. It assumes that human behavior is acquired and modified from the observation of socially important people 
(Pugliese \& Tinsley, 2007; Trost \& Loprinzi, 2011). Children, for example, are highly influenced by the behavior of others and seek praise and acceptance from those same people, especially with those closest to them, such as their parents. Parents are considered the primary role model for younger children (3-6 years old) and they play an important role in influencing their children's behaviors, since children have minimal behavioral influences from other sources such as peers or social media until a later age (Bandura, 1977; Sallis \& Nader, 1988; Zecevic, Tremblay, Lovsin, \& Michel, 2011). Behavioral modeling, learning primarily by observing and imitating the actions of others, is a central concept of the Social Learning Theory and can be easily connected between parent and child (Ormrod, 1999). When taking both the Social Learning Theory and behavioral modeling into consideration, parents convey information to their children through modeling and reinforcing behaviors (Trost et al., 2003; Weiss, McCullagh, Smith, \& Berlant, 1998). This phenomenon has been supported by several correlation-based studies, which have indicated that children's physical activity levels are positively associated with their parent's physical activity levels. In other words, physically active parents are more likely to have physically active children, and parents that engage in more sedentary-related activities are more likely to have children that engage in more of these sedentary-related activities (Edwardson \& Gorely, 2010; Prochaska et al., 2002; Rodriguez et al., 2005; Seabra, Mendonca, Thomis, Anjos, \& Maia, 2008). Therefore, it can be understood that parental physical activity can act as a model for the practice of that same behavior in children. 
Parents may also influence children's physical activity behaviors through a process known as gender socialization. Through the process of gender socialization, boys and girls learn behaviors and attitudes that are deemed appropriate for acceptance within perceived societal norms such as some classical examples of boys playing with cars, wearing the color blue, and playing outdoors, whereas on the other hand girls playing with dolls, wearing the color pink, and doing household related-activities such as learning how to cook (Elkin \& Handel, 1988). Cheng and colleagues (2014) reported that the physical activity levels of fathers are positively associated to that of the son, and the physical activity levels of the mothers are positively associated to that of the daughter. A possible explanation for these associations may be due to the fact that male adolescents usually identify more with their fathers and their behaviors, whereas female adolescents are more inclined to identify with their mothers (Cheng et al., 2014). This evidence suggests that the presence of parents may not have the same influence on boys and girls as it pertains to physical activity behavior.

Tangible support provided by parents is considered the most effective type of parental support said to increase the physical activity behavior of children (Beets et al., 2010; Sallis, Alcaraz, et al., 1992; Trost et al., 2003). This support involves physical aid provided by the parents such as providing transportation to and from sport practices or games, overseeing and facilitating play dates with other children, as well as actively participating in physical activity with their child. Since children do not have the means to drive, it is necessary that parents transport them to provide access to places where they can be physically active (e.g., playgrounds, parks, practice fields). This is especially 
important when these places to engage in physical activity are further away from their home. In a review completed by Beets and colleagues (2010), cross-sectional analyses indicated parental transportation as a key component to children accessing these places and are linked to greater levels of physical activity. Since transportation alone does not require parents to be active themselves, it is not reasonable to conclude that if children have access to these places they will always be more active than children who do not have access to transportation. Active parental participation, for example, is another key component that may lead to an increase in physical activity in children. Within that same review, $27 \%$ of the studies reported associations between active participation by a mother or father and increased levels of physical activity and reduced sedentary behaviors of their child (Beets et al., 2010). The more time parents spend participating in physical activity with their child the less likely their child is to suffer from overweight or obesity since they are engaging in more physical activity while reducing sedentary behaviors. This may have favorable effects on the parent's weight status as well since they are engaging in physical activity as well.

Prior non-experimental studies mentioned previously have indicated that when children are young (3-6 years old), parents likely have a significant impact on their physical activity behaviors by providing support, modeling behavior, being active with their children, and also providing opportunities for their children to be active (Beets et al., 2010; Dunton et al., 2012; Prochaska et al., 2002). However, these prior, non-experimental studies do not allow for causal inference. Presently there is only one study we are aware of that has examined the causal impact of parental interaction on children's physical activity. 
Rebold, Lepp, Kobak, et al. (2015) examined free choice physical activity and sedentary behavior of children (3-6 years old) in a controlled environment, under three separate 30 minute conditions: while the children were playing alone, with their parent watching, and with their parent participating. Physical activity behavior was objectively monitored using an accelerometer. As well, motivation to engage in additional physical activity was assessed by offering them the option to play for an additional 10-minutes (bonus period) after completing their initial 30-minute activity session. Results indicated that children's physical activity levels were greatest when their parents were participating in physical activities with them versus when they played alone or while their parent was watching them play, which in turn caused a $58 \%$ reduction in time allocated to sedentary activities when the parent was participating relative to the alone condition. In terms of preference, $80 \%$ of the children indicated that the parent participating condition was their favorite condition. Furthermore, $89 \%$ of children elected to participate in the 10 -minute bonus activity when their parent was participating versus only $55 \%$ and $22 \%$ in the parent watching and alone conditions, respectively. This suggests that parental involvement may increase the liking (i.e., enjoyment) of that activity which may, in turn, lead to increased physical activity behavior of children (Rebold, Lepp, Kobak, et al., 2015). Overall, since parental interaction was manipulated in this study and the effects on children's physical activity behavior were assessed objectively, it can be concluded that parental participation can cause an overall increase in children's physical activity behavior, their liking of the activity, their motivation to be active, and decrease sedentary behavior. These results are in agreement with several non-experimental studies that have also indicated that parental 
influence (e.g., co-participation) is an important factor in regards to children's physical activity behavior (Beets et al., 2010; Sallis, Simons-Morton, et al., 1992; Trost et al., 2003).

While those results suggest that parental involvement plays a crucial role in children's physical activity behavior, it is unclear if those results are similar in older age groups. Emerging evidence has suggested children aged 6 years and older may be greatly influenced by other outlets such as their peers (Kirby et al., 2011; Verloigne et al., 2014). Previous research has demonstrated when examining peers versus parents, peers have a greater influence on children's behavior as they approach adolescence (Kirby et al., 2011; Verloigne et al., 2014). Peers have been shown to influence behaviors such as food choices, drug and alcohol use, and physical activity participation (Bahr, Hoffmann \& Yang, 2005; Epstein, Roemmich, Cavanaugh, \& Paluch, 2011; Salvy et al., 2009; Salvy, Romero, Paluch, \& Epstein, 2007). Much like the research examining the impact of parental influence on children's physical activity, the majority of the evidence examining the effect of peers on childhood physical activity has been non-experimental and relied upon self-report measures (Anderssen \& Wold, 1992; Hills, Andersen, \& Byrne, 2012; Sallis, 2001; Sallis, Prochaska, Taylor, Hill, \& Geraci, 1999; Sallis, Taylor, Dowda, Freedson, \& Pate, 2002; Salvy et al., 2007; Weiss, 2000). However, the experimental assessments of parental influence upon children's physical activity are not limited to a single study. Recently, several experimental studies have been conducted allowing for the assessment of the casual impact of peer influence on physical activity behavior in children (Barkley et al., 2014; Salvy et al., 2012; Sanders, Peacock, et al., 2014; Sigmund, Naylor, Santo, \& Barkley, 2014). These studies are all in agreement that the 
presence, versus the absence, of a peer or peers contributes to increased physical activity participation in children (Anderssen \& Wold, 1992; Barkley et al., 2011; Epstein \& Goldfield, 1999; Hills et al., 2012; Jago et al., 2010; Macdonald-Wallis, Jago, Page, Brockman, \& Thompson, 2011; Rittenhouse et al., 2011; Sallis, 2001; Sallis, Alcaraz, McKenzie, \& Hovell, 1999; Sallis et al., 2002; Sallis, Simons-Morton et al., 1992; Salvy et al., 2012; Salvy et al., 2009; Salvy et al., 2007; Sanders, Peacock, et al., 2014; Weiss, 2000).

More specifically, Rittenhouse et al. (2011) found that the presence of an unfamiliar peer decreased the amount of time overweight/obese boys ( $8-12$ years old) allocated to sedentary activities and also increased their physical activity behavior to a level that was similar to that of non-overweight boys. However, the presence of an unfamiliar peer did not alter physical activity, relative to an alone condition, in the non-overweight boys. Salvy et al. (2009) found that in a sample of overweight/obese and non-overweight children, motivation to be physically active and actual physical activity levels increased in the presence of a friend versus an alone condition. These results are favorable; however, the exercise equipment (i.e., cycle ergometers) and simulated environment did not replicate a free-choice environment in which children can choose from a variety of physical and/or sedentary activity options. Some subsequent studies however did utilize a gymnasium with activities that children are more likely to participate in on a daily basis (e.g., running, jumping, activities with sports balls, etc.; Barkley et al., 2014; Sanders, Peacock, et al., 2014). During these studies, overweight and non-overweight children had the option to participate in any physical and/or 
sedentary activities in the gymnasium that they desired for a total of 30 minutes. Barkley et al. (2014) found that young children (3-6 years old) increased their physical activity levels by $54 \%$ when playing with a friend versus an alone condition. Furthermore, all children (i.e., 100\%) chose to participate in an optional, additional 10-minute session after their initial 30-minute session was completed while in the presence of a friend. Conversely only $43 \%$ elected to participate in this bonus activity while alone. Taken together, while the presence of an unknown peer causes an increase in physical activity in overweight children only, the presence of a friend causes increased physical activity behavior in both overweight and non-overweight children.

Though Barkley, Salvy and colleagues provide insight on the presence of a peer on the physical activity behavior of children, they only examined the effect of the presence of a single peer or friend on physical activity. Recently Sanders, Peacock, et al. (2014) examined the impact of playing alone, with a single friend, and playing with a group of friends on children's physical activity participation and intensity of that activity while utilizing objective measures. Results from Sanders, Peacock, et al.’s study revealed children accumulated significantly more physical activity and were more motivated to engage in physical activity when playing with a single friend and a group of friends compared to when playing alone. Like Rebold, Lepp, Kobak, et al. (2015), children's motivation was assessed by offering them the option to play for an additional 10 minutes (bonus period) after completing their initial 30-minute activity session. Results demonstrated that a significantly greater proportion of children chose to participate in a 10-minute bonus period during the friend (92\%) and group (100\%) 
conditions than the alone condition (33\%) suggesting that children are more motivated to engage in additional physical activity when a friend is present (Sanders, Peacock, et al., 2014). Playing with one or more friends, relative to playing alone, is more motivating and can increase physical activity and simultaneously reduce the amount of time 6-10 year old children allocate to sedentary activities when given the option for additional time.

However, it is important to note that peer influence does not always provide positive effects on physical activity behavior in young children. Researchers have reported that when children are treated negatively or ostracized by their peers, they exhibit decreases in physical activity behavior (Barkley et al., 2012; Rittenhouse \& Barkley, 2013). Barkley et al. (2012) conducted a study involving 19 children who completed 2 experimental sessions. During each session children played a virtual ball-toss computer game called Cyberball. In one session, children played Cyberball where they experienced inclusion, where in the other session, they experienced ostracism. After playing the game, children were then taken to a gymnasium where they had the opportunity to engage in physical or sedentary activities in any pattern they chose for a total of 30 minutes. Results demonstrated that when children experienced simulated ostracism they exhibited a $22 \%$ decrease in physical activity behavior and a $41 \%$ increase in sedentary behavior. Rittenhouse and Barkley (2013) further explored this topic using a sample of 24 overweight/obese and non-overweight boys who first completed a validated peer victimization questionnaire and then were taken to a gymnasium individually where they had the opportunity to play with a variety of physical and sedentary activity options 
in any pattern they wished for a total of 30 minutes. From this study it was concluded that the overweight/obese boys reported greater peer victimization, and had lower average physical activity intensity and allocated more time to sedentary activity than the non-overweight boys. Moreover, the peer victimization questionnaire was positively correlated with the amount of time allocated to sedentary behaviors, possibly suggesting that there is a dangerous link between peer victimization and decreased physical activity behavior in boys (Rittenhouse et al., 2013).

Although these studies provide pertinent evidence in support of the idea that parental and peer activity is associated with children's physical activity behavior, it is unknown what the causal impact of each is on that behavior. More specifically, it is unknown if parental or peer presence can increase physical activity participation more than the other in a sample of children. These previously mentioned studies provide some insight into the relationship between parental and peer influence on children's physical activity; however, we feel studies that actually manipulate both parental and peer influence simultaneously and assess the effects on children's physical activity behavior may yield new information that could aid in the development of more effective physical activity interventions and recommendations for children.

\section{Rationale}

Parents and peers have been shown to have a particularly strong influence over children's behavioral choices with parents having the largest influence early in life whereas peer influence is believed to increase as children approach adolescence. Multiple studies support the notion that children with physically active parents and/or 
friends are more likely to be more active themselves. However, the majority of this evidence supporting the link between parent and/or peer and child physical activity relies on non-experimental research. Also, among these existing non-experimental and limited experimental studies there are none that we are aware of which have compared the effect of the presence of a peer versus the presence of a parent on children's physical activity. For that reason, we examined the impact of the presence of a parent or peer on children's physical activity participation and intensity of that activity while utilizing experimental techniques.

\section{Purpose}

The primary purpose of this study was to assess the amount and intensity of children's physical and sedentary activity behavior during three separate simulated recess conditions: playing alone, with their parent participating, and with their friend participating. Another purpose of this study was to assess children's enjoyment (i.e., liking) and preference of children's physical activity in each of the three separate simulated recess conditions. It is our understanding that this is the first study to experimentally examine the effects of parental influence as well as peer influence on children's physical activity behavior simultaneously while utilizing objective measures of physical activity and activities that are similar to what children are likely to participate in while playing on a playground (e.g., running, climbing, crawling, jumping, throwing, catching, and sedentary activities). Unlike similar investigations, this study is novel in a way that an actual playground was the setting for data collection that allowed researchers to measure and observe physical activity behavior in a setting where children most 
commonly play instead of a "simulated" research condition where most children would not have access to other than when recruited for research purposes.

\section{Hypothesis}

We hypothesized that children's physical activity behavior would be greater in the condition with their friend participating than in the conditions where they were playing with their parent or playing alone. We also hypothesized that children would prefer the condition where they were playing with their friend than the conditions where they were playing with their parent or playing alone. We believed this to be true, as research has suggested that among all other social influences, peers are said to serve as the most important behavioral role models for children ages 6-14 years old. As age increases into adolescents, friends naturally become the closest people with whom they share attitudes and physical activity behavior (Eccles, 1999; Wu \& Pender, 2002. 


\section{CHAPTER III}

\section{METHODS}

\section{Specific Aim 1}

\section{Participants}

Twenty children ( $n=10$ boys and 10 girls) between the ages of five to 10 years old, with no contraindications to physical activity (e.g., orthopedic injury, cardiovascular disorder, uncontrolled asthma, etc.) were recruited to participate in this study via fliers posted on campus and a database of potential participants who contacted the principal investigator for separate, unrelated studies. Each child and one of his or her parents or a legal guardian came to the Applied Physiology Laboratory at Kent State University (Kent, $\mathrm{OH}$ ) to participate in two simulated recess conditions on separate days; playing with an internet-connected tablet computer (Apple iPad) present, and without an iPad present. Before any activity took place, the parent or legal guardian of each child filled out a health history questionnaire assessing the child's ability to participate in physical activity safely. Upon completion, research personnel reviewed their health history and approved of their ability to participate. Once a child was deemed eligible they provided verbal assent and the parent provided written consent.

Each child came to the gymnasium on two separate visits in a random order to complete the following simulated recess conditions: playing with an iPad present, and without an iPad present. During these conditions the gymnasium was private, with only research personnel and a single participant being present per session. No other child was present in the gymnasium because it is possible that if there were more than one child 
playing in each condition those children would respond differently to the active and sedentary options accessible (Barkley et al., 2014; Sanders, Peacock, et al., 2014; Rebold, Lepp, Kobak, et al., 2015). Participants were compensated with a gift card to a local store. The Kent State University Institutional Review Board approved this study.

\section{Procedures}

During each of the separate laboratory visits, children were taken to a 4,360 square foot gymnasium located within the same building as the Laboratory where they were shown a variety of age-appropriate physical activity options (e.g., balls, hoops, targets, cones, obstacle courses, etc.) and a table of sedentary activities (e.g., books, Lego blocks, coloring sheets, pencils, crayons, etc.). While all 20 participants reported having an iPad or similar device in their home, all participants completed a 10-minute familiarization period at the beginning of each session in which they were shown how to utilize the iPad (e.g., navigating through each screen, returning to the "home" screen, accessing the internet, and finding various games on the iPad that were pre-loaded). The iPad was pre-loaded with popular, age-appropriate game applications (i.e., Despicable Me: Minon Rush, Angry Birds, LEGO ${ }^{\circledR}$ Star Wars ${ }^{\mathrm{TM}}$ : The Complete Saga, Girl Dress Up Makeover, MADDEN NFL Mobile, Temple Run, \& Subway Surfers) along with access to two video-streaming application (i.e., Netflix \& Disney Movies Anywhere).

After being shown the physical and sedentary options and undergoing iPad familiarization (e.g., sampling games, etc.) each child was fitted with an accelerometer (ActiGraph GT1M, Pensacola, FL) that fit comfortably around his or her waist. The ActiGraph is a valid and reliable device for quantifying physical activity behavior in 
children and adolescents (Trost et al., 1998). After being fitted with the accelerometer, children were given permission to participate in any of the sedentary and/or physical activities in the gymnasium they wish, in any pattern, for a total of 30 minutes.

During the condition with the iPad present, the iPad was placed on the sedentary table and was available to play with. If the child decided to play with the iPad they had to stay sitting at the sedentary table and could not walk around the gymnasium. During the condition without the iPad present, children had access to all of the physical activity and sedentary activities; as the condition with the iPad present, however, there was no iPad present on the table of sedentary activities.

In addition to accelerometry data, the time children allocated to the sedentary and physical activities during each 30-minute activity session was recorded via a stopwatch (Champion Sports Stopwatch, Marlboro, NJ). At the end of each 30-minute session, each child was asked to indicate his or her liking of the activity and rating of perceived exertion (RPE), using a visual analog scale (VAS) and OMNI walk/run RPE, respectively (Robertson et al., 2005; Roemmich et al., 2008; Rebold, Lepp, Kobak, McDaniel, \& Barkley, 2015; Sanders, Peacock, et al., 2014). Children were then asked if they would like to play for an additional 10 minutes or if they wished to be finished for the session. If a child decided to participate in the additional 10 minutes of activity they followed identical procedures to their initial 30 minutes for that day. After all conditions were completed, each child was asked to indicate which condition (with the iPad present or without the iPad present) they preferred. 


\section{Gymnasium Configuration}

Equipment in the gymnasium consisted of one jump rope, one Wilson ${ }^{\circledR}$ indoor/outdoor basketball, five 6 inch $(0.153 \mathrm{~m})$ hurdles (SKLZ® Speed Hurdles), one Nerf ${ }^{\mathrm{TM}}$ Pro Grip ${ }^{\mathrm{TM}}$ football (Hasbro ${ }^{\circledR}$, Pawtucket, RI), one Franklin ${ }^{\circledR}$ soccer ball to kick through five cones separated by two feet, and two obstacle courses consisting of gymnastic/soft-play equipment (UCS Inc. Lincolnton, NC). The first obstacle course consisted of foam gymnastic/soft-play equipment arranged in order, one $60 "(1.52 \mathrm{~m})$ long by 48 " $(1.22 \mathrm{~m})$ wide ramp climbing to a peak height of $15 "(0.38 \mathrm{~m})$ to a 34 " $(0.86$ $\mathrm{m})$ long by $24 "(0.61 \mathrm{~m})$ diameter octagonal cylinder laid flat on the gymnasium floor. Immediately after the cylinder there was a $60 "(1.52 \mathrm{~m})$ long by $36 "(0.91 \mathrm{~m})$ wide ramp climbing to a peak height of $15 "(0.38 \mathrm{~m})$ to an upright, 48 " $(1.22 \mathrm{~m})$ tall octagonal ring with a 28 " $(0.71 \mathrm{~m})$ diameter opening and another $60 "(1.52 \mathrm{~m})$ long by $36 "(0.91 \mathrm{~m})$ wide ramp placed in a down-hill fashion, after the octagonal ring. The second obstacle course consisted of one $24 "(0.61 \mathrm{~m})$ long by $24 "(0.61 \mathrm{~m})$ wide ramp climbing to a peak height of 5 " $(0.13 \mathrm{~m})$ next to a 34 " $(0.86 \mathrm{~m})$ long by 24 " $(0.61 \mathrm{~m})$ diameter octagonal cylinder laid flat on the gymnasium floor. After the cylinder, there were two octagonal rings. The first ring had a 48 " $(1.22 \mathrm{~m})$ total diameter with a 28 " $(0.71 \mathrm{~m})$ diameter opening and a height of 12 " $(0.31 \mathrm{~m})$. The second ring had a 48 " $(1.22 \mathrm{~m})$ total diameter with a 28 " $(0.71 \mathrm{~m})$ diameter opening and a height of 24 " $(0.61 \mathrm{~m})$. Lastly, next to the second ring, there was one more 24 " $(0.61 \mathrm{~m})$ long by 24 " $(0.61 \mathrm{~m})$ wide ramp placed in a downhill fashion. 
The sedentary activity area was outfitted with one table and one chair. The age-appropriate sedentary alternatives included four different Transformer $^{\mathrm{TM}}$ action figures (Hasbro®, Pawtucket, RI), four different MOXIE Gurlz ${ }^{\mathrm{TM}}$ toy dolls (MGA Entertainment Inc., Van Nuys, CA), four reading books, Crayola ${ }^{\circledR}$ crayons, markers, and colored pencils with coloring sheets, the block stacking game called Jenga ${ }^{\circledR}\left(\right.$ Hasbro ${ }^{\circledR}$, Pawtucket, RI), and the matching game called Perfection ${ }^{\mathrm{TM}}$ (Milton Bradley Company, East Longmeadow, MA). The Apple iPad (Apple, Inc., Cupertino, CA) was also placed on this table if the child was participating in that condition on that day.

\section{Measurements}

Anthropometrics. Children were measured for height to the nearest $\mathrm{cm}$ via a stadiometer and weight to the nearest kg using a balance beam scale (Health O Meter, Chicago, IL). In addition to height and weight, gender and age were recorded.

Accelerometry. Children were fitted with an accelerometer (ActiGraph GT1M Monitor, Pensacola, FL) that comfortably wrapped around their waist. The accelerometer recorded the number of physical activity counts per session for each child. Epoch length was set to 60 -seconds per-minute with accelerometer counts averaged over each 30-minute session. For children who chose to participate in the optional, additional 10-minute activity session, identical procedures were implemented as the previous 30 minutes of activity. Accelerometer data were also converted to metabolic equivalents (METs, $1 \mathrm{MET}=3.5 \mathrm{ml} \cdot \mathrm{kg}^{-1} \cdot \mathrm{min}^{-1}$ of oxygen consumption) based on each child's age. The Actigraph accelerometer has been shown to be a valid and reliable instrument for quantifying physical activity levels in children and adolescents (Trost et al., 1998). 
Sedentary activity observation. During each 30-minute activity session, the amount of time each child allocated to sedentary activities was recorded from direct observation of research personnel by using a stopwatch (Champion Sports Stopwatch, Marlboro, NJ). Time started when the child sat down at the sedentary table and stopped when they left the sedentary table. If a child returned to the sedentary table multiple times, identical procedures were followed and the time allocated to sedentary activities during the entire 30 -minute activity session was totaled.

Rating of Perceived Exertion (RPE). At the completion of each session, children were asked for their rating of perceived exertion (RPE) using the OMNI walk/run Scale of Perceived Exertion (Dishman, Sallis, \& Orenstein, 1985). To do so, research personnel described the OMNI walk/run RPE scale to each child using age appropriate language. While the scale was being explained, the child viewed a pictorial description of it which showed an illustration of a boy standing at the number " 0 " (not tired at all) and as the numbers increase the pictures of the boy depict him running up a hill to the number "10" (very, very tired) indicating that as the numbers get higher so does the difficulty of the activity session. Each child then circled the number in which he or she felt represented how tired he or she was after the activity session. The OMNI walk/run Scale of Perceived Exertion (category range: 0 to 10) has been previously validated for use in children (Robertson et al., 2005).

\section{Liking}

At the end of each 30-minute session, children were asked to indicate their liking of the activity using the visual analog scale (VAS) by marking on a 10-cm line anchored 
by "like it very much" on the left and "do not like it at all" on the right. Research personnel described the VAS to each child while they viewed a pictorial description of the scale that illustrates a "happy" face on the left above "like it very much" and as the VAS proceeds to the right the faces progressively become "sadder" with the last face on the right above "do not like it at all" being very unhappy (i.e., crying). A lower score indicated a higher liking for the activity session. Assessing liking in using this scale has been shown to predict actual physical activity behavior (Roemmich et al., 2008).

\section{Preference of Condition}

Upon completion of the two social conditions, children were asked by research personnel to indicate which condition (with the iPad, or without the iPad) was their favorite. For example, "Did you have more fun when you were playing with the iPad or without the iPad?"

\section{Specific Aim 2}

\section{Participants}

Twenty Caucasian children ( $n=10$ girls) with a mean age of $8.2 \pm 1.7$ years old, with no contraindications to physical activity (e.g., orthopedic injury, cardiovascular disorder, uncontrolled asthma, etc.), along with one parent or legal guardian $(n=20)$ between the ages of 30-50 years old, were recruited to participate in this study. Five boys were recruited to participate and chose one friend of the same biological sex to play with them in the friend condition. Once the friend was chosen, research personnel contacted the friend's parent to ask if he would agree to participate in the study. If so, that friend then became a participant in the study. The same recruiting procedure was performed for 
the girls. One parent or legal guardian for each child was also recruited to participate in the parent participating condition. These initial participants (five boys, five girls) were recruited via fliers posted in the local community and a database of potential participants who contacted the principal investigator for separate, unrelated studies. Before the start of the first activity session each child, along with his or her parent, filled out a health history questionnaire assessing each of his or her abilities to safely participate in physical activity. Upon completion, research personnel reviewed their health history and approved their ability to participate. Each child came to the Independence Fire Station Playground (Independence, $\mathrm{OH}$ ) on three separate visits in a random order to complete the following social conditions; playing alone, with his or her parent participating, and with his or her friend participating. During all three social conditions the playground was private, with only research personnel and participants being present. Each child earned one $\$ 10$ gift card to a local store per session completed. After their final session was finished, they were paid with three gift cards worth $\$ 10$ each. The Kent State University Institutional Review Board approved this study.

\section{Procedures}

Upon arrival of the first visit, parental consent and child assent were obtained. Each child had anthropometric assessments measured (age, height, weight, and BMI). During each of the three separate visits, children were introduced to the playground and shown a variety of age-appropriate physical activity options (e.g., monkey bars, slides, crawl tubes, climbers, and balls) and a table of sedentary activity options (e.g., books, Lego blocks, coloring sheets, crayons, sidewalk chalk, etc.). After being shown the 
physical activity options and sedentary alternatives, each child was fitted with an accelerometer (ActiGraph GT1M, Pensacola, FL) that was comfortably strapped around his or her waist. The ActiGraph is a valid and reliable device for quantifying physical activity behavior in children and adolescents (Trost et al., 1998). Each child was also fitted with a Polar heart rate monitor (Polar V800, Lake Success, NY) that fit comfortably around his or her chest at the level of his or her zyphoid process. After being fitted with the accelerometer and heart rate monitor, children were given permission to play on the playground and participate in any of the physical and/or sedentary activities they wished, in any pattern for 30 minutes.

During the playing alone social condition children played on the playground participating in the physical and/or sedentary activities alone with no other children or parents present. The parent participating social condition consisted of the parent actively participating with his or her child in the physical and/or sedentary activities options in which his or her child chose to participate. Parents were instructed to follow their child and play in the activities in which the child chose to participate. The parent was instructed not to select the activities nor instruct his or her child what activities to utilize. Instead the parent let the child dictate the activities in which he or she wished to participate. During the friend participating social condition both children had free access to the playground and the physical and sedentary activities.

In addition to accelerometry data, the time children allocated to sedentary and physical activities during each 30-minute activity session was recorded via a stopwatch. At the end of each 30-minute session, each child was asked to indicate his or her liking of 
the activity and rating of perceived exertion (RPE), using a visual analog scale (VAS; Roemmich et al., 2008) and OMNI walk/run RPE, respectively (REF for the Omni). Children were then asked if they would like to play for an additional 10 minutes or if they wished to be finished for the session. If a child decided to participate in the additional 10 minutes of activity, they followed identical procedures to their initial 30 minutes for that day. During the friend condition, both the child and his or her friend were informed that if they do not both agree, they would be done for the day. After all three conditions were completed, each child was asked privately to indicate which condition (alone, with a parent participating, or with a friend participating) he or she preferred.

\section{Playground Arrangement}

Physical activities and equipment consisted of monkey bars, swings, slides, crawl tubes, climbers, and a merry-go-round. Auxiliary items placed around the playground consisted of five 6 inch $(0.153 \mathrm{~m})$ tall hurdles (SKLZ® ${ }^{\circledR}$ Speed Hurdles), one Nerf ${ }^{\mathrm{TM}}$ Pro Grip $^{\mathrm{TM}}$ football, one Franklin ${ }^{\circledR}$ soccer ball to kick around a series of seven cones separated three feet apart. The sedentary activity area was equipped with one table and two chairs to accommodate both the child and parent or friend (depending on the social condition being completed at the time). The age-appropriate sedentary alternatives included on the table were four different Transformer ${ }^{\mathrm{TM}}$ action figures (Hasbro ${ }^{\circledR}$, Pawtucket, RI), four different MOXIE Gurlz ${ }^{\mathrm{TM}}$ toy dolls (MGA Entertainment Inc., Van Nuys, CA), four reading books, Crayola ${ }^{\circledR}$ crayons and colored pencils with blank paper for drawing, coloring sheets, the block stocking game called Jenga ${ }^{\circledR}$ (Hasbro®, 
Pawtucket, RI), and the matching game called Perfection ${ }^{\mathrm{TM}}$ (Milton Bradley Company, East Longmeadow, MA).

\section{Measurements}

Anthropometrics. At the playground, children were measured for height and weight using a balance beam scale (Health O Meter, Chicago, IL). In addition to height and weight, gender and age were recorded.

Accelerometry. Children were fitted with an accelerometer (ActiGraph GT1M Monitor, Pensacola, FL) that comfortably wrapped around their waist. The accelerometer recorded the number of physical activity counts per session for each child. The accelerometer counts were totaled for each 30-minute session. For children who chose to participate in the optional, additional 10-minute activity session, identical procedures were implemented as the previous 30 minutes of activity. Accelerometer data were also converted to metabolic equivalents (METs, $1 \mathrm{MET}=3.5 \mathrm{ml} \cdot \mathrm{kg}^{-1} \cdot \mathrm{min}^{-1}$ of oxygen consumption) based on each child's age and using validated equations (REF). The Actigraph accelerometer has been shown to be a valid and reliable instrument for quantifying physical activity levels in children and adolescents (Trost et al., 1998).

Heart rate assessment. Children's physical activity intensity level was assessed via a Polar heart rate monitor (Polar V800, Lake Success, NY). The heart rate monitor was comfortably fitted around their chests at the level of their zyphoid process. Heart rate was monitored throughout the entire 30-minute session (and 10-minute session if elected) via Bluetooth capabilities. After the completion of each session, data were downloaded to the compatible software and the average heart rate was recorded. 
Sedentary activity observation. During each 30-minute activity session, the amount of time each child allocated to sedentary activities was recorded from direct observation of research personnel by using a stopwatch (Champion Sports Stopwatch, Marlboro, NJ). Time started when the child sat down at the sedentary table and stopped when he or she left the sedentary table. If a child returned to the sedentary table multiple times, identical procedures were followed and the time allocated to sedentary activities during the entire 30-minute activity session was totaled.

Rating of Perceived Exertion (RPE). At the completion of each session, children were asked for their rating of perceived exertion (RPE) using the OMNI walk/ run Scale of Perceived Exertion (Dishman et al., 1985). To do so, research personnel described the OMNI walk/run RPE scale to each child using age appropriate language. While the scale was being explained, the child viewed a pictorial description of it which showed an illustration of a boy standing at the number "0" (not tired at all) and as the numbers increase the pictures of the boy depict him running up a hill to the number " 10 " (very, very tired) indicating that as the numbers get higher so does the difficulty of the activity session. Each child then circled the number in which he or she felt represented how tired he or she was after the activity session. The OMNI walk/run Scale of Perceived Exertion (category range: 0 to 10 ) was validated in a study involving 8-12 year old children (Robertson et al., 2005).

\section{Liking}

At the end of each 30-minute session, children were asked to indicate their liking of the activity using the visual analog scale (VAS) by marking on a 10-cm line anchored 
by "like it very much" on the left and "do not like it at all" on the right. Research personnel described the VAS to each child while he or she viewed a pictorial description of the scale that illustrates a "happy" face on the left above "like it very much" and as the VAS proceeds to the right the faces progressively become "sadder" with the last face on the right above "do not like it at all" being very unhappy (i.e., crying). Assessing liking in using this scale has been shown to predict actual physical activity behavior (Roemmich et al., 2008).

\section{Preference of Condition}

Upon completion of all three social conditions children were asked by research personnel to indicate which condition (alone, playing with a parent, or playing with a friend) was their favorite. For example, "Did you have more fun when you were playing by yourself, while you were playing with you parent, or while you were playing with your friend?" All children were asked privately so their answer was not influenced by with whom they played (i.e., parent or friend). 


\title{
CHAPTER IV
}

\section{THE EFFECT OF THE PRESENCE OF AN INTERNET-CONNECTED, MOBILE, TABLET COMPUTER ON PHYSICAL ACTIVITY BEHAVIOR IN CHILDREN}

\begin{abstract}
Current evidence supports the notion that children's physical activity levels are highly variable, and may be influenced by a variety of factors. One potential factor may be the use of mobile, internet-connected devices (e.g., tablet computers, cellular telephones). These devices provide access to activities (e.g., playing video games, watching videos) that have traditionally been associated with sedentary behavior. Because they are portable, these devices can be utilized in any environment. Therefore, providing access to these devices to children in environments that typically promote physical activity (e.g., parks, gymnasiums) may impede physical activity behavior. PURPOSE: The purpose of this study was to assess physical and sedentary activity with and without the presence of a mobile, internet-connected tablet computer (Apple iPad). METHODS: Twenty children $(6.7 \pm 1.9$ years old $)$ were recruited to participate in two simulated recess conditions on separate days. Each child completed these two conditions with no other children present. During each condition, children were taken to a 4,360 square foot gymnasium where they had free-choice access to age-appropriate physical activity options (e.g., balls, hoops, obstacle courses, etc.) and a table of sedentary activities (e.g., books, toys, coloring sheets, etc.) for 40 minutes. During one session the iPad was present on the sedentary table and in the other session it was not. The iPad was
\end{abstract}


internet-connected and pre-loaded with popular, age-appropriate video game applications and a popular video streaming application. Physical activity was monitored via an accelerometer and time allocated to the sedentary options was monitored via a stopwatch. RESULTS: Children accumulated significantly $(p \leq 0.05)$ fewer accelerometer counts and increased their sedentary behavior with the iPad present $\left(1748 \pm 1321\right.$ counts $\cdot \min ^{-1}$, $21.6 \pm 13.5$ min sitting) versus the condition without the iPad present $(3328 \pm 781$ counts $\cdot \min ^{-1}, 6.2 \pm 5.0$ min sitting). CONCLUSION: Introducing an internet-connected mobile tablet computer into a gymnasium setting reduced children's physical activity by $28 \%$ and increased sedentary behavior by $45 \%$. These devices may impede children's physical activity even in environments specifically designed to encourage physical activity.

\section{Introduction}

Participation in sedentary behavior over physical activity options has been linked to an increased risk of overweight and obesity in children (Bandura, 1977; Center for Disease Control [CDC], 2015; Hills et al., 2012; Himes \& Dietz, 1994; Pradinuk, Chanoine, \& Goldman, 2011). This fact is the impetus behind the large number of scientific studies that have sought to better understand children's physical activity behavior. Current evidence supports the notion that children's physical activity levels are highly variable, and may be influenced by a multitude of factors including physiological ability, psychological wellbeing, and the availability and/or use of technology (Beets et al., 2007; Eccles, 1999; Epstein et al., 2011; Goran \& Reynolds, 1999; Rodriguez et al., 2005; Weiss, 2000). In recent years, young children have become a growing part of the 
population who utilize mobile, internet-connected, electronic devices (e.g., cellular telephones, tablet computers) for purposes such as talking/texting, accessing social media applications, watching videos, and playing video games, and so forth (O'Keeffe et al., 2011). Unlike traditional electronic devices (e.g., television, desktop computers), mobile devices are, by design, portable allowing the user to access activities that have historically been considered sedentary (e.g., watching videos, playing video games) at any time. The portable nature of these devices also makes it possible to use them while participating in moderate physical activity (e.g., walking). Therefore, the use of mobile devices does not have to be a sedentary activity.

While there is no research examining the impact of mobile, internet-connected devices on physical activity, exercise and sedentary behavior in children, there is emerging evidence linking the use of these mobile devices with decreased exercise intensity and fitness as well as an increased sedentary behavior in college-aged adults. In this group of individuals, Lepp and colleagues (2013) demonstrated an inverse relationship between cell phone use and cardiorespiratory fitness as assessed via indirect calorimetry. In the same study, high cell phone users reported greater participation in sedentary activities and fewer physical activities than their low cell use peers. In multiple subsequent studies cell phone use has also been shown to reduce exercising intensity as well as reduce average walking speed during free-living walking (Barkley \& Lepp, 2015; Rebold, Lepp, Sanders, et al., 2015; Rebold, Sheehan, et al., 2015). Finally, this group has also repeatedly demonstrated a significant positive relationship between cell phone use and sedentary behavior in college-aged adults with the heaviest cell phone users 
reporting an average of 80-145 minutes more sitting per day than their lower use peers (Barkley \& Lepp, 2016; Barkley, Lepp, \& Salehi-Esfahani, 2015).

Investigating cell phone use particularly in college age adults has become incredibly prevalent because they are considered to be the first cohort of individuals to grow up entirely in the digital age (Lepp et al., 2013). However, with the use of mobile internet-connected devices on the rise in children, it is crucial to understand how these devices may affect their physical activity behavior. Additionally, since children are more likely then college aged adults to engage in physical activity as a form of play, investigating how these devices affect their physical and social behavior is warranted. Therefore, the purpose of this study was to assess physical and sedentary activity behavior and preference of two separate simulated recess conditions: with and without the presence of a mobile, internet-connected tablet computer (i.e., Apple iPad). We hypothesized that children's physical activity would be greater in the condition with no $i P a d$ present than with an $i P a d$ present. We also hypothesized that children would prefer the $i P a d$ recess condition versus the no iPad condition.

\section{Methods}

\section{Participants}

Twenty children ( $n=10$ boys and 10 girls) between the ages of five to 10 years old, with no contraindications to physical activity (e.g., orthopedic injury, cardiovascular disorder, uncontrolled asthma, etc.) were recruited to participate in this study via fliers posted on campus and a database of potential participants who contacted the principal investigator for separate, unrelated studies. Each child and one of his or her parents or a 
legal guardian came to the Applied Physiology Laboratory at Kent State University (Kent, $\mathrm{OH}$ ) to participate in two simulated recess conditions on separate days; playing with an internet-connected tablet computer (Apple iPad) present, and without an iPad

present. Before any activity took place, the parent or legal guardian of each child filled out a health history questionnaire assessing the child's ability to participate in physical activity safely and each parent was asked if his or her child had access to an internetconnected tablet computer (iPad or similar device) at home. All 20 participants reported having access to such a device at home. Upon completion of these surveys, research personnel reviewed their health history and approved of their ability to participate. Once a child was deemed eligible he or she provided verbal assent and the parent provided written consent.

Each child came to the gymnasium on two separate visits in a random order to complete the following simulated recess conditions: playing with an iPad present, and without an iPad present. During these conditions the gymnasium was private, with only research personnel and a single participant being present per session. No other child was present in the gymnasium because the presence of additional peers has been shown to impact physical activity and sedentary behaviors in children (Barkley et al., 2014; Rittenhouse, Salvy, \& Barkley, 2011; Sanders, Rebold, et al., 2014). Participants were compensated with a gift card to a local store. The Kent State University Institutional Review Board approved this study. 


\section{Procedures}

During each of the separate laboratory visits, children were taken to a 4,360 square foot gymnasium located within the same building as the Laboratory where they were shown a variety of age-appropriate physical activity options (e.g., balls, hoops, targets, cones, obstacle courses, etc.) and a table of sedentary activities (e.g., books, Lego blocks, coloring sheets, pencils, crayons, etc.). At the beginning of each session a 10-minute familiarization period took place where the children were shown how to work the iPad itself (e.g., navigating through each screen, returning to the "home" screen, accessing the internet and finding various games on the iPad that were pre-loaded). Once the child was familiar with the iPad itself, research personnel explained how to play each game. The iPad was pre-loaded with popular, age appropriate game applications (i.e., Despicable Me: Minon Rush, Angry Birds, LEGO ${ }^{\circledR}$ Star Wars ${ }^{\mathrm{TM}}$ : The Complete Saga, Girl Dress Up Makeover, MADDEN NFL Mobile, Temple Run, \& Subway Surfers) along with access to two video steaming applications (i.e., Netflix \& Disney Movies Anywhere). These were all applications that children could easily access if they had an internet-connected tablet computer at their home.

After being shown the physical and sedentary options and undergoing iPad familiarization (e.g., sampling games, etc.), each child was fitted with an accelerometer (ActiGraph GT1M, Pensacola, FL) that fit comfortably around his or her waist. The ActiGraph is a valid and reliable device for quantifying physical activity behavior in children and adolescents (Trost et al., 1998). After being fitted with the accelerometers, 
children were given permission to participate in any of the sedentary and/or physical activities in the gymnasium they wish, in any pattern, for a total of 30 minutes.

During the condition with the iPad present, the iPad was placed on the sedentary table and was available to play with. If the child decided to play with the iPad they had to stay sitting at the sedentary table and could not walk around the gymnasium. During the condition without the iPad present, children had access to all of the physical activity and sedentary activities, as the condition with the iPad present however, there was no iPad present on the table of sedentary activities.

In addition to accelerometry data, the time children allocated to the sedentary and physical activities during each 30-minute activity session was recorded via a stopwatch (Champion Sports, Rural Hall, NC). At the end of each 30-minute session, each child was asked to indicate his or her liking of the activity and rating of perceived exertion (RPE), using a visual analog scale (VAS) and OMNI walk/run RPE respectively (Robertson et al., 2005; Roemmich et al., 2008; Rebold, Lepp, Sanders, et al., 2015; Sanders, Peacock et al., 2014). Children were then asked if they would like to play for an additional 10 minutes or if they wished to be finished for the session. If a child decided to participate in the additional 10 minutes of activity they followed identical procedures to their initial 30 minutes for that day. After all conditions were completed, each child was asked to indicate which condition (with the iPad present, or without the iPad present) he or she preferred.

\section{Gymnasium Configuration}

Equipment in the gymnasium consisted of one jump rope, one Wilson ${ }^{\circledR}$ indoor/outdoor basketball, five 6 inch $(0.153 \mathrm{~m})$ hurdles (SKLZ® Speed Hurdles), one 
Nerf $^{\mathrm{TM}}$ Pro Grip ${ }^{\mathrm{TM}}$ football (Hasbro ${ }^{\circledR}$, Pawtucket, RI), one Franklin ${ }^{\circledR}$ soccer ball to kick threw five cones separated by two feet, and two obstacle courses consisting of gymnastic/soft-play equipment (UCS Inc. Lincolnton, NC). The first obstacle course consisted of foam gymnastic/soft-play equipment arranged in order, one 60" (1.52 m) long by 48 " $(1.22 \mathrm{~m})$ wide ramp climbing to a peak height of $15 "(0.38 \mathrm{~m})$ to a 34 " $(0.86$ m) long by 24 " $(0.61 \mathrm{~m})$ diameter octagonal cylinder laid flat on the gymnasium floor. Immediately after the cylinder there was a $60 "(1.52 \mathrm{~m})$ long by $36 "(0.91 \mathrm{~m})$ wide ramp climbing to a peak height of $15 "(0.38 \mathrm{~m})$ to an upright, 48 " $(1.22 \mathrm{~m})$ tall octagonal ring with a $28 "(0.71 \mathrm{~m})$ diameter opening and another $60 "(1.52 \mathrm{~m})$ long by $36 "(0.91 \mathrm{~m})$ wide ramp placed in a down-hill fashion, after the octagonal ring. The second obstacle course consisted of one $24 "$ ( $0.61 \mathrm{~m})$ long by 24 " $(0.61 \mathrm{~m})$ wide ramp climbing to a peak height of 5" $(0.13 \mathrm{~m})$ next to a $34 "(0.86 \mathrm{~m})$ long by $24 "(0.61 \mathrm{~m})$ diameter octagonal cylinder laid flat on the gymnasium floor. After the cylinder there were two octagonal rings. The first ring had a 48" $(1.22 \mathrm{~m})$ total diameter with a 28 " $(0.71 \mathrm{~m})$ diameter opening and a height of 12 " $(0.31 \mathrm{~m})$. The second ring had a 48 " $(1.22 \mathrm{~m})$ total diameter with a $28 "(0.71 \mathrm{~m})$ diameter opening and a height of $24 "(0.61 \mathrm{~m})$. Lastly, next to the second ring there was one more 24 " $(0.61 \mathrm{~m})$ long by 24 " $(0.61 \mathrm{~m})$ wide ramp placed in a downhill fashion.

The sedentary activity area was outfitted with one table and one chair. The age-appropriate sedentary alternatives included four different Transformer $^{\mathrm{TM}}$ action figures (Hasbro ${ }^{\circledR}$, Pawtucket, RI), four different MOXIE Gurlz ${ }^{\mathrm{TM}}$ toy dolls (MGA Entertainment Inc., Van Nuys, CA), four reading books, Crayola ${ }^{\circledR}$ crayons, markers, and 
colored pencils with coloring sheets, the block stacking game called Jenga ${ }^{\circledR}\left(\right.$ Hasbro ${ }^{\circledR}$, Pawtucket, RI), and the matching game called Perfection ${ }^{\mathrm{TM}}$ (Milton Bradley Company, East Longmeadow, MA). The Apple iPad (Apple, Inc., Cupertino, CA) was also placed on this table if the child was participating in that condition on that day.

\section{Measurements}

Anthropometrics. Children were measured for height to the nearest $\mathrm{cm}$ via a stadiometer and weight to the nearest kg using a balance beam scale (Health O Meter, Chicago, IL). In addition to height and weight, gender and age were recorded.

Accelerometry. Children were fitted with an accelerometer (ActiGraph GT1M

Monitor, Pensacola, FL) that comfortably wrapped around their waist. The accelerometer recorded the number of physical activity counts per session for each child. Epoch length was set to 60-seconds per-minute with accelerometer counts averaged over each 30-minute session. For children who chose to participate in the optional, additional 10-minute activity session, identical procedures were implemented as the previous 30 minutes of activity. The Actigraph accelerometer has been shown to be a valid and reliable instrument for quantifying physical activity levels in children and adolescents (Trost et al., 1998).

Sedentary activity observation. During each 30 -minute activity session, the amount of time each child allocated to sedentary activities was recorded from direct observation of research personnel by using a stopwatch (Champion Sports Stopwatch, Marlboro, NJ). Time started when the child sat down at the sedentary table and stopped when he or she left the sedentary table. If a child returned to the sedentary table multiple 
times, identical procedures were followed and the time allocated to sedentary activities during the entire 30-minute activity session was totaled.

Rating of Perceived Exertion (RPE). At the completion of each session, children were asked for their rating of perceived exertion (RPE) using the OMNI walk/ run Scale of Perceived Exertion (Dishman et al., 1985). To do so, research personnel described the OMNI walk/run RPE scale to each child using age appropriate language. While the scale was being explained, the child viewed a pictorial description of it which showed an illustration of a boy standing at the number "0" (not tired at all) and as the numbers increase the pictures of the boy depict him running up a hill to the number " 10 " (very, very tired) indicating that as the numbers get higher so does the difficulty of the activity session. Each child then circled the number in which he or she felt represented how tired he or she was after the activity session. The OMNI walk/run Scale of Perceived Exertion (category range: 0 to 10 ) has been validated in for use in eight to12 year old children (Robertson et al., 2005; Roemmich et al., 2006).

\section{Liking}

At the end of each 30-minute session, children were asked to indicate their liking of the activity using the visual analog scale (VAS) by marking on a 10-cm line anchored by "like it very much" on the left and "do not like it at all" on the right. Research personnel described the VAS to each child while he or she viewed a pictorial description of the scale that illustrates a "happy" face on the left above "like it very much" and as the VAS proceeds to the right the faces progressively become "sadder" with the last face on the right above "do not like it at all" being very unhappy (i.e., crying). A lower score 
indicated a higher liking for the activity session. Assessing liking in using this scale has been shown to predict actual physical activity behavior (Roemmich et al., 2008).

\section{Preference of Condition}

Upon completion of the two social conditions children were asked by research personnel to indicate which condition (with the iPad, or without the iPad) was their favorite. For example, "Did you have more fun when you were playing with the iPad or without the iPad?"

\section{Analytic Plan}

Independent samples $t$-tests was used to examine any sex (boys, girls) differences in physical characteristics (age, height, weight).

Multiple, two sex (male, female) by two social condition (playing with the iPad present, and playing without the iPad present) analysis of variance (ANOVA) with repeated measures on social condition were utilized to assess differences in accelerometer counts, sedentary minutes, and liking.

Wilcoxon signed rank test was used to examine the differences in children's decision to or not to participate in the optional 10-minute bonus period of activity across the two social conditions. In addition, a Chi-square analysis was performed to assess any differences in the number of children indicating their preference of the two social conditions. All statistics were analyzed using IBM SPSS Statistics 21.0 (International Business Machines Corp., 2012). 


\section{Results}

\section{Physical Characteristics}

An independent samples $t$-test revealed no significant difference ( $p>0.05$ for all) between boys' and girls' physical characteristics for age, weight, or height (Table 1).

Table 1

Children's Physical Characteristics (Data are Means $\pm S D$ )

\begin{tabular}{lcc}
\hline & Boys $(n=10)$ & Girls $(n=10)$ \\
\hline Age $(\mathrm{yrs})$ & $6.5 \pm 1.78$ & $6.9 \pm 2.08$ \\
Weight $(\mathrm{kg})$ & $26.65 \pm 8.0$ & $24.01 \pm 7.4$ \\
Height $(\mathrm{cm})$ & $124.77 \pm 23.0$ & $119.79 \pm 16.3$ \\
\hline
\end{tabular}

\section{0-Minute Total Accelerometer Counts}

A total of 40 minutes of accelerometry counts were measured within this analysis.

This was done because there were no significant differences in the number of children who chose to participate in both conditions. There was a significant main effect of condition for accelerometer counts $(\mathrm{F}=5.0, p=0.04$, Figure 1). Children accumulated significantly $(t=2.293, p=0.033)$ more physical activity counts when playing without the iPad present $\left(101732.75 \pm 60015\right.$ counts $\left.\cdot \mathrm{min}^{-1}\right)$ versus when playing with the iPad present $\left(72812 \pm 58448\right.$ counts $\left.\cdot \mathrm{min}^{-1}\right)$. There were no significant main or interaction effects for $\operatorname{sex}(\mathrm{F}=0.2, p=0.7)$. 


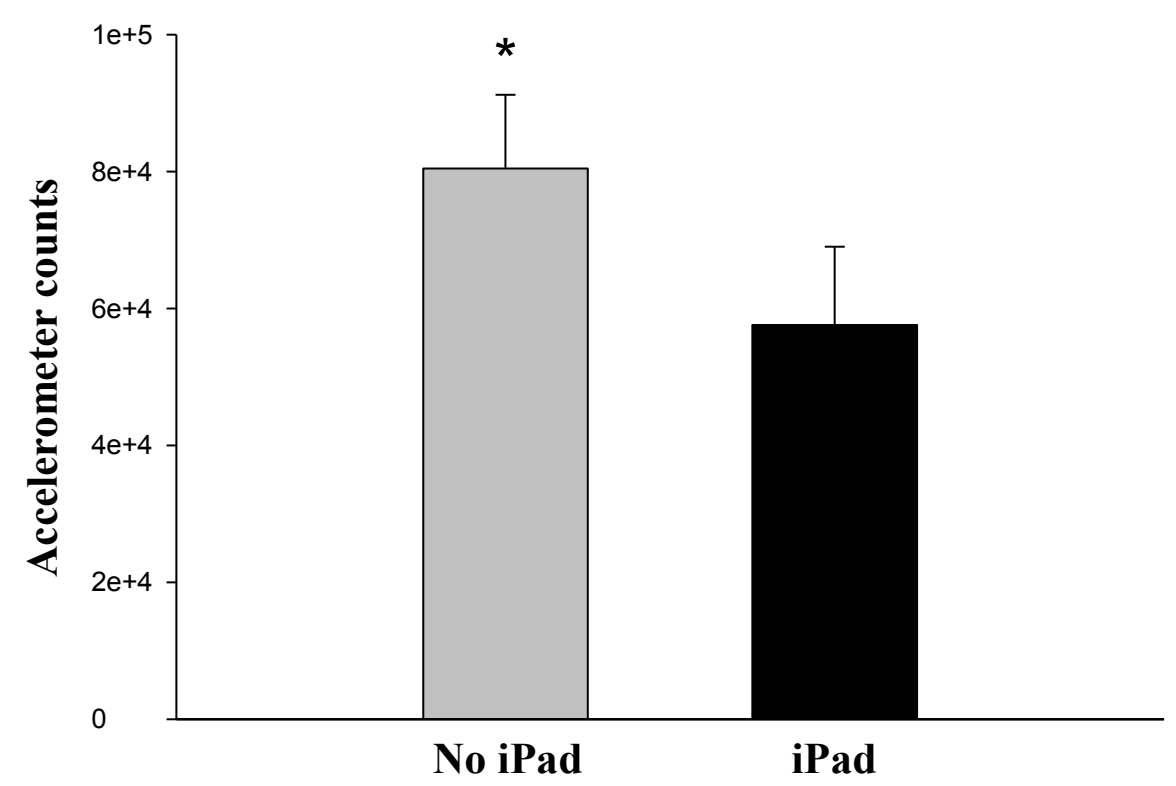

Figure 1. Accelerometer counts for each condition (Mean \pm SEM). The level of significance was set a priori at $p \leq 0.05$.

*Without iPad condition was significantly greater than with iPad condition.

\section{Time Allocated to Sedentary Activities}

There was a significant main effect of condition for time allocated to sedentary activities $(\mathrm{F}=4.7, p=0.04$, Figure 2$)$. Children accumulated significantly more sedentary minutes in the condition with the iPad present $(16.29 \pm 11.3)$ than without the iPad present $(11.76 \pm 11.05)$. There were no significant main or interaction effects for $\operatorname{sex}(\mathrm{F}=0.5, p=0.5)$. 


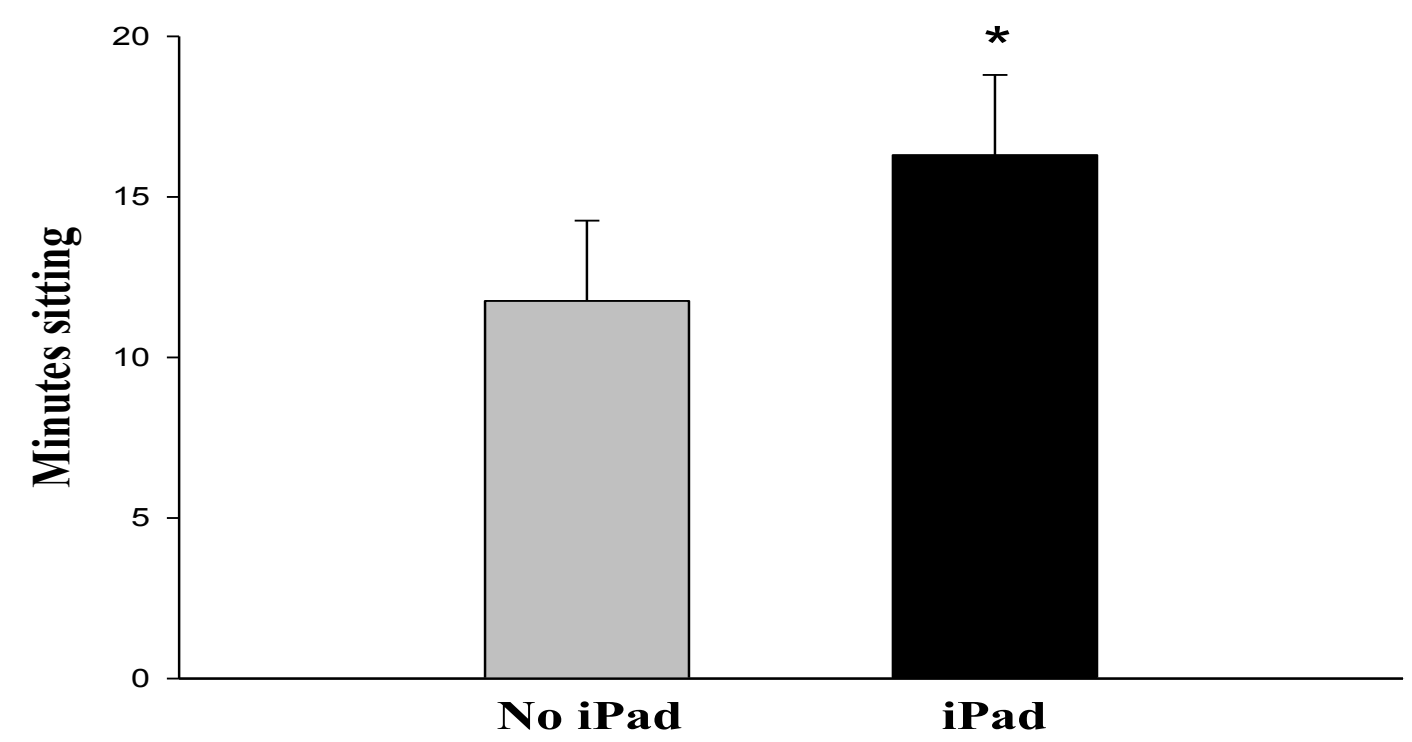

Figure 2. Sedentary time for each condition (mean \pm SEM). *The level of significance was set a priori at $p \leq 0.05$.

*With iPad condition was significantly greater than without iPad condition.

\section{Liking}

There were no significant main or interaction effects of condition or sex for liking of recess condition $(\mathrm{F} \leq 0.4, p \geq 0.6$ ). Children reported similar liking in the condition with the iPad $(9.5 \pm 1.0)$ to the condition without the iPad $(9.5 \pm 1.2)$.

\section{Ratings of Perceived Exertion}

There were no significant main or interaction effects $(\mathrm{F} \leq 1.2, p \geq 0.3)$ of condition or sex for ratings of perceiving exertion (RPE). Children reported similar RPE in the condition with the iPad $(2.7 \pm 2.6)$ to the condition without the iPad $(3.2 \pm 3.3)$. 


\section{0-Minute Bonus Period}

A Wilcoxin Signed Rank test revealed no significant difference $(Z \geq-1.0, p=0.3)$ in the proportion of children who chose to participate in the 10 -minute bonus period in the condition with the iPad $(n=16)$ versus the number of children who chose to participate in the 10-minute bonus period in the condition without the iPad $(n=14)$.

\section{Preference}

Chi-square analysis revealed no significant difference $\left(x^{2}=0.8, p=0.371\right)$ in the number of children who preferred the with iPad condition $(n=12)$ versus the number of children who preferred the without iPad condition $(n=8)$.

\section{Discussion}

The purpose of this study was to assess children's physical and sedentary activity with and without the presence of a mobile, internet-connected tablet computer (i.e., Apple iPad). To our knowledge this is the first experimental study utilizing objective measures to evaluate children's physical activity and sedentary behavior in the presence and absence of a mobile, internet-connected tablet. The results of this study indicated that children accumulated $40 \%$ greater accelerometer counts and $28 \%$ fewer sedentary minutes in the condition without the iPad present versus the condition with the iPad. Though there was a significant increase in physical activity and a reduction in sedentary time in the condition without the iPad present, children did not report a greater perceived effort in that recess condition than the condition with the iPad present. Furthermore, children did not report greater liking nor did they prefer one recess versus the other. Although there does not appear to be a difference in liking or preference, our results 
indicate that the introduction of a mobile, internet-connected device into a traditionally active environment decreases physical activity behavior and increases sedentary behavior, meaning that these devices have the potential to reduce energy expenditure in children between the ages of five and 10 years old.

\section{Physical and Sedentary Activity}

It was hypothesized that children's physical activity would be greater in the condition without the iPad present than with an iPad present. Presently, children accumulated significantly more accelerometer counts and less sedentary minutes in the condition without the iPad relative to the condition with the iPad. Overall, children accumulated $40 \%$ more accelerometer counts in the condition without the iPad present compared to the condition with the iPad. Additionally, children sat an average of 11.8 minutes in the condition without the iPad and 16.3 minutes in the condition with the iPad. Previous research has suggested that high levels of television viewing or video game play may affect preschool children's weight status through displacement of physical activity and an increase in sedentary behavior (Cox et al., 2012; Penko \& Barkley, 2010), meaning that since watching television and playing video games are predominantly sedentary activities, as children increase the number of hours spent participating in these activities the less physical activity they participate in, thus increasing their risk for overweight and obesity. However, since the modern tablet computers are portable it is now possible for children to have access to these traditionally sedentary activities (playing video games, watching videos) at virtually any time and in any environment. Therefore, it is possible that this could make an environment that traditionally promotes 
physical activity (e.g., a gymnasium) into one that can more easily become sedentary. The results gathered from the current study are similar to previous investigations in college-aged adults that reported greater sedentary behavior, decreased exercise intensity, decreased walking speed, and a greater likelihood to use the device during exercise in high cell phone users (Lepp et al., 2013; Penko \& Barkley, 2010; Rebold, Lepp, Sanders, et al., 2015; Rebold, Sheehan et al., 2015; Sanders et al., 2012).

\section{Liking and Preference}

Physical activity participation is influenced by one's "liking" of that physical activity. Prior evidence indicates that children may be more likely to engage in physical activities they like or perceive as enjoyable (Roemmich et al., 2008). The results from our present study indicated that children did not like or prefer one condition more than the other. To the best of our knowledge there are no studies investigating liking or preference of condition in children while utilizing a mobile, internet-connected tablet computer; however, other studies involving college-aged students and cell phone use have been investigated. Rebold, Lepp, Sanders, et al. (2015) investigated three different modes of cell phone use (listening to music, talking, and texting) during treadmill exercise. Results among college-aged participants indicated that two of the cell phone functions tested (talking and listening to music) increased the liking of a bout of treadmill exercise; texting did not increase liking. Therefore, the relationship between cell phone use and liking appears to be specific to the function being utilized on the phone. Since this study involved college-aged participants it is difficult to generalize these results to other populations, such as children. However, since the children equally liked both 
conditions and children accumulated more physical activity in the condition without the iPad, it is reasonable to conclude that keeping the iPad out of a physically active environment may increase physical activity behavior without reducing the child's liking of that environment.

\section{Limitations and Future Directions}

Despite the fact that this was the first experimental study examining the use of a mobile, internet-connected tablet computer on children's physical activity behavior and liking for that behavior, it was not without limitations. In the condition where the iPad was present and the child was operating it, they were not allowed to move from the sedentary table. This was done to reduce the likelihood that the $i P a d$ would not be dropped or damaged during the duration of the study. If the children were allowed to walk around the gymnasium while using the iPad, it is feasible that they may have accumulated more accelerometer counts within that condition. Though, the only time the rule was mentioned to the child was if they tried to move from the sedentary table in which only two children attempted to do. Furthermore, in a separate study of college-aged adults, the vast majority $(87 \%)$ of cell phone use was reportedly performed while sitting (Barkley \& Lepp, 2016). Therefore, it is unlikely that accelerometry data would have significantly changed in this study had children been given the option to use the $i P a d$ while mobile. Additionally, children only had the opportunity to play for 30 minutes with the option of playing for an additional 10 minutes in each condition. Thus, it is reasonable to question whether children would have been more active or sedentary in each condition if they were allotted a longer amount of time (i.e., $>40$ minutes) to play in 
the gymnasium. Further research is needed to examine how children's physical activity and sedentary behavior may change in the presence of other children and/or with the addition of more time in a condition where an iPad is present versus a condition where an iPad is not present.

\section{Conclusion}

Previous investigations have reported greater use of mobile internet-connected devices is associated with decreased fitness, reduced exercise intensity and greater sedentary behavior in college-aged adults (Barkley \& Lepp, 2016; Lepp et al., 2013;

Rebold, Lepp, Sanders, et al., 2015; Rebold, Sheehan, et al., 2015). However, to the best of our knowledge the current investigation is the first experimental study examining the influence of a mobile, internet-connected tablet computer (i.e., Apple iPad) on children's physical activity and sedentary behavior. Results from the current study are in agreement with previous research demonstrating that the use of mobile, internet-connected technology increases sedentary behavior and reduces physical activity behavior. Results from the current study also indicated that children did not like nor prefer one condition over the other. Therefore, since children accumulated less physical activity counts and greater sedentary minutes in the condition with the iPad present and there were no differences in the liking of the conditions with and without the iPad present, it is reasonable to conclude that mobile internet-connected devices should not be introduced into children's physically active environments. 


\title{
CHAPTER V
}

\section{THE EXPERIMENTAL EFFECT OF PARENT VERSUS PEER INFLUENCE ON CHILDREN'S PHYSICAL ACTIVITY BEHAVIOR}

\begin{abstract}
Parents and friends have been shown to have a significant influence over a variety of children's behavioral choices including physical activity and sedentary behavior. However, while there are studies assessing the role of parents and peers on youth physical activity, we are aware of no students that have directly compared the effect of parent versus peer influence upon children's physical activity and sedentary behavior. PURPOSE: To assess children's physical and sedentary activity behavior, enjoyment (i.e., liking), and preference of condition during three separate simulated recess conditions: playing alone, with their parent participating, and with their friend participating. METHODS: Twenty children ( $8.2 \pm 1.7$ years old) participated in three simulated recess conditions on separate days. During each of the conditions, children had free access to an outdoor playground (e.g., slides, crawl tubes, etc.) and a chair with a table of sedentary activity options (e.g., books, toys, coloring sheets, crayons, etc.) situated within the playground property for 40 minutes. Physical activity was monitored via an accelerometer and time allocated to the sedentary options was monitored via a stopwatch. Children reported their liking of each condition via visual analog scale and identified their preferred condition. RESULTS: Children accumulated significantly $(p \leq$ 0.05) fewer sitting minutes and greater physical activity counts when playing with their parent $\left(2.7 \pm 7 \mathrm{~min}\right.$ sitting, $87503 \pm 37063$ counts $\left.\cdot \mathrm{min}^{-1}\right)$ or friend $(0.9 \pm 1.4 \mathrm{~min}$ sitting,
\end{abstract}


$93363 \pm 22608$ counts $\left.\cdot \mathrm{min}^{-1}\right)$ versus playing alone $(7.8 \pm 8.2 \mathrm{~min}$ sitting, $70672 \pm 35228$ counts $\left.\cdot \min ^{-1}\right)$. Children reported greater $(p \leq 0.05)$ liking of the friend $(9.8 \pm 0.6 \mathrm{~cm})$ and parent $(9.4 \pm 1.1 \mathrm{~cm})$ conditions versus playing alone $(7.0 \pm 3.5 \mathrm{~cm})$. Twelve children reported preferring the friend condition, seven preferred the parent condition, and only one child preferred the alone condition $\left(x^{2}=9.1, p \leq 0.01\right)$. CONCLUSION: Playing with a friend or parent significantly increased children's physical activity and reduced sedentary behavior versus playing alone. Children also preferred playing with their friend versus all other conditions. Therefore, the presence of either a friend or a parent enhances physical activity behavior and enjoyment while simultaneously reducing sedentary behavior.

\section{Introduction}

Lack of physical activity in children is linked to the later development of a variety of diseases such as obesity, Type 2 diabetes, and coronary (Kimm, Glynn, \& Kriska, 2000; Kvaavik, Tell, \& Kleep, 2003; Sallis, Berry, Broyles, McKenzie, \& Nader, 1995; Trost, Pate, Freedson, Sallis, \& Taylor, 2000). For this reason, current studies have focused on creating interventions that promote physical activity in children by creating situations where the children are able to play with a peer or playing with a parent (Barkley et al., 2014; Rebold, Lepp, Kobak, et al., 2015; Rittenhouse et al., 2011; Sanders, Peacock, et al., 2014). Prior non-experimental studies have indicated that when children are young (3-6 years old), parents likely have a significant impact on their physical activity behaviors by providing support, modeling behavior, being active with their children, and also providing opportunities for their children to be active (Beets et al., 
2010; Dunton et al., 2012; Prochaska et al., 2002). However, these prior, nonexperimental studies do not allow for causal inference. Emerging experimental studies have demonstrated that the children are more physically active in a controlled gymnasium setting in the presence of a friend, and to a lesser extent an unknown peer, versus a condition where they are playing alone (Barkley et al., 2014; Rebold, Lepp, Kobak, et al., 2015; Rittenhouse et al., 2011; Sanders, Peacock, et al., 2014). However, among the existing experimental studies there are none that we are aware of which have compared the effect of the presence of a peer versus the presence of a parent on children's physical activity behavior. Therefore, the purpose of this study was to assess children's physical and sedentary activity behavior, and preference of condition in three separate simulated recess conditions: playing alone, with their parent participating, and with their friend participating. Research has suggested that among all other social influences, peers are said to serve as the most important behavioral role models for children ages 6-14 years old. As age increases and children progress towards adolescence, it has been suggested that friends supplant parents as the stronger influence upon a child's physical activity behavior (Eccles, 1999; Wu \& Pender, 2002). For that reason, we hypothesized that children's physical activity behavior would be greater in the condition with their friend participating than in the conditions where they were playing with their parent or playing alone. We also hypothesized that children would prefer the condition where they were playing with their friend than the conditions where they were playing with their parent or playing alone. 


\section{Methods}

\section{Participants}

Twenty Caucasian children ( $n=10$ girls) with a mean age of $8.2 \pm 1.7$ years old, with no contraindications to physical activity (e.g., orthopedic injury, cardiovascular disorder, uncontrolled asthma, etc.), along with one parent or legal guardian $(n=20)$ between the ages of 30-50 years old, were recruited to participate in this study. Five boys were recruited to participate who chose one friend of the same biological sex to play with them in the friend condition. Once the friend was chosen, research personnel contacted the friend's parent to ask if they would agree to participate in the study. If so, that friend then also became a participant in the study. The same recruiting procedure was performed for the girls. One parent or legal guardian for each child was also recruited to participate in the parent participating condition. These initial participants (five boys, five girls) were recruited via fliers posted in the local community and a database of potential participants who contacted the principal investigator for separate, unrelated studies. Before the start of the first activity session, each child, along with his or her parent, completed a health history questionnaire assessing his or her ability to safely participate in physical activity. Upon completion, research personnel reviewed their health history and approved their ability to participate. Each child came to the Independence Fire Station Playground (Independence, $\mathrm{OH}$ ) on three separate visits in a random order to complete the following social conditions; playing alone, with his or her parent participating, and with his or her friend participating. During all three social conditions the playground was private, with only research personnel and participants being present. Each child earned one \$10 gift card 
to a local store per completed session ( $\$ 30.00$ for completing all three session). The Kent State University Institutional Review Board approved this study.

\section{Procedures}

Upon arrival of the first visit, parental consent and child assent were obtained. Each child had anthropometric assessments measured (age, height, weight, and BMI). During each of the three separate visits, children were introduced to the playground and shown a variety of age-appropriate physical activity options (e.g., monkey bars, slides, crawl tubes, climbers, and balls) and a table of sedentary activity options (e.g., books, Lego blocks, coloring sheets, crayons, sidewalk chalk, etc.). After being shown the physical activity options and sedentary alternatives each child was fitted with an accelerometer (ActiGraph GT1M, Pensacola, FL) that was comfortably strapped around his or her waist. The ActiGraph is a valid and reliable device for quantifying physical activity behavior in children and adolescents (Trost et al., 1998). Each child was also fitted with a Polar heart rate monitor (Polar V800, Lake Success, NY) that fit comfortably around his or her chest at the level of his or her zyphoid process. After being fitted with the accelerometer and heart rate monitor, children were given permission to play on the playground and participate in any of the physical and/or sedentary activities they wished, in any pattern for 30 minutes.

During the playing alone social condition, children played on the playground participating in the physical and/or sedentary activities alone with no other children or parents present. The parent participating social condition consisted of the parent actively participating with his or her child in the physical and/or sedentary activities options in 
which his or her child chose to participate. Parents were instructed to follow their child and play in the activities in which the child chose to participate. The parent was instructed not to select the activities nor instruct his or her child what activities to utilize. Instead the parent let the child dictate the activities in which he or she wished to participate. During the friend participating social condition both children had free access to the playground and the physical and sedentary activities.

In addition to accelerometry data, the time children allocate to sedentary and physical activities during each 30-minute activity session was recorded via a stopwatch (Champion Sports Stopwatch, Marlboro, NJ). At the end of each 30-minute session, each child was asked to indicate his or her liking of the activity and rating of perceived exertion (RPE), using a visual analog scale (VAS; Roemmich et al., 2008) and OMNI walk/run RPE, respectively (REF for the Omni). Children were then asked if they would like to play for an additional 10 minutes or if they wished to be finished for the session. If a child decided to participate in the additional 10 minutes of activity he or she followed identical procedures to his or her initial 30 minutes for that day. During the friend condition, both the child and his or her friend were informed that if they do not both agree, they would be done for the day. After all three conditions were completed, each child was asked privately to indicate which condition (alone, with a parent participating, or with a friend participating) he or she preferred.

\section{Playground Arrangement}

Physical activities and equipment consisted of monkey bars, swings, slides, crawl tubes, climbers, and a merry-go-round. Auxiliary items placed around the playground 
consisted of five 6 inch $(0.153 \mathrm{~m})$ tall hurdles (SKLZ® Speed Hurdles), one Nerf ${ }^{\mathrm{TM}}$ Pro Grip $^{\mathrm{TM}}$ football, one Franklin ${ }^{\circledR}$ soccer ball to kick around a series of seven cones separated three feet apart. The sedentary activity area was equipped with one table and two chairs to accommodate both the child and parent or friend (depending on the social condition being completed at the time). The age-appropriate sedentary alternatives included on the table were four different Transformer ${ }^{\mathrm{TM}}$ action figures (Hasbro ${ }^{\circledR}$, Pawtucket, RI), four different MOXIE Gurlz ${ }^{\mathrm{TM}}$ toy dolls (MGA Entertainment Inc., Van Nuys, CA), four reading books, Crayola ${ }^{\circledR}$ crayons and colored pencils with blank paper for drawing, coloring sheets, the block stocking game called Jenga ${ }^{\circledR}\left(\right.$ Hasbro ${ }^{\circledR}$, Pawtucket, RI), and the matching game called Perfection ${ }^{\mathrm{TM}}$ (Milton Bradley Company, East Longmeadow, MA).

\section{Measurements}

Anthropometrics. At the playground, children were measured for height and weight using a balance beam scale (Health O Meter, Chicago, IL). In addition to height and weight, gender and age were recorded.

Accelerometry. Children were fitted with an accelerometer (ActiGraph GT1M Monitor, Pensacola, FL) that comfortably wrapped around their waist. The accelerometer recorded the number of physical activity counts per session each child accumulated. The accelerometer counts for each 30-minute session. For children who chose to participate in the optional, additional 10-minute activity session, identical procedures were implemented as the previous 30 minutes of activity. The Actigraph accelerometer has 
been shown to be a valid and reliable instrument for quantifying physical activity levels in children and adolescents (Trost et al., 1998).

Heart rate assessment. Children's physical activity intensity level was assessed via a Polar heart rate monitor (Polar V800, Lake Success, NY). The heart rate monitor was comfortably fitted around their chest at the level of their zyphoid process. Heart rate was monitored throughout the entire 30-minute session (and 10-minute session if elected) via Bluetooth capabilities. After the completion of each session data was downloaded to the compatible software and the average heart rate was recorded.

Sedentary activity observation. During each of the 30 -minute activity sessions, the amount of time each child allocated to sedentary activities was recorded via direct observation of research personnel by using a stopwatch (Champion Sports Stopwatch, Marlboro, NJ). Sedentary time started when the child sat down at the sedentary table and stopped when he or she left the sedentary table. If a child returned to the sedentary table multiple times, the same procedures were followed. The time allocated to sedentary activities during the entire 30-minute activity session was then totaled.

Rating of Perceived Exertion (RPE). At the completion of each session, children were asked to verbally indicate their whole-body, undifferentiated ratings of perceived exertion (RPE) using the OMNI walk/ run Scale of Perceived Exertion (Dishman et al., 1985). To do so, research personnel described the OMNI walk/run RPE scale to each child using age appropriate language. While the scale was being explained, the child viewed a pictorial description of it which showed an illustration of a boy standing at the number " 0 " (not tired at all) and as the numbers increase the pictures of 
the boy depict him running up a hill to the number "10" (very, very tired) demonstrating that as the numbers get higher so does the difficulty of the activity session. Each child circled the number he or she felt represented how tired he or she was after the activity session. The OMNI walk/run Scale of Perceived Exertion (category range: 0 to 10) was validated in a study involving 8-12 year old children (Robertson, Goss, Andreacci, Dube, Rutkowski \& Snee, 2005).

\section{Liking}

At the end of each 30-minute session, children were asked to indicate their liking of the activity using the visual analog scale (VAS) by marking on a $10-\mathrm{cm}$ line anchored by "like it very much" on the left and "do not like it at all" on the right. Research personnel explained the VAS to each child while they viewed a pictorial description of the scale that illustrates a "happy" face on the left above "like it very much" and as the VAS continues to the right the faces gradually become "sadder" with the last face on the right above "do not like it at all" being very unhappy (i.e., crying). This scale has been shown to predict actual liking for physical activity behavior (Roemmich et al., 2008).

\section{Preference of Condition}

After all three sessions were completed, children were asked by research personnel to specify which condition (alone, playing with a parent, or playing with a friend) was their favorite. For example, "Did you have more fun when you were playing by yourself, while you were playing with you parent, or while you were playing with your friend?" All children were asked privately so their answer was not influenced by the person with whom they played (i.e., parent or friend). 


\section{Analytic Plan}

Independent samples $t$-tests was used to examine any differences between sex (boys, girls) in physical characteristics (age, height, weight).

Two sex (male, female) by three social condition (alone, playing with a parent, and playing with a friend) analyses of variance (ANOVAs) with repeated measures on social condition were utilized to assess differences in accelerometer counts, sedentary minutes, average heart rate, and liking.

Post-hoc analyses for all significant main and interaction effects were completed by using $t$-tests with the Benjamini and Hochberg False Discovery Rate correction (Benjamini \& Hochberg, 1995).

Wilcoxon signed rank test was used to examine the differences in children's decision to or not to participate in the optional 10-minute bonus period of activity across the three social conditions. In addition, a Chi-square analysis was performed to assess any differences in the number of children indicating their favorite of the three social conditions. All statistics were analyzed using IBM SPSS Statistics 21.0 (International Business Machines Corp., 2012).

\section{Results}

\section{Physical Characteristics}

An independent samples $t$-test revealed no significant difference $(p<0.05)$ between boys' and girls' physical characteristics for age, weight, and height. 
Table 2

Children's Physical Characteristics (Data are Means \pm SD)

\begin{tabular}{lcc}
\hline & Boys $(n=10)$ & Girls $(n=10)$ \\
\hline Age $(\mathrm{yrs})$ & $8.5 \pm 1.95$ & $7.8 \pm 1.32$ \\
Weight $(\mathrm{kg})$ & $31.78 \pm 8.76$ & $29.2 \pm 5.9$ \\
Height $(\mathrm{cm})$ & $131.6 \pm 12.50$ & $133.3 \pm 10.3$ \\
\hline
\end{tabular}

\section{0-Minute Total Accelerometer Counts}

A total of 40 minutes of accelerometry counts were measured within this analysis. This was done because there were no significant differences in the number of children who chose to participate in each of the recess conditions. There was a significant main effect of condition for accelerometer counts $(\mathrm{F}=4.39, p=0.02$, Figure 3$)$. A paired samples $t$-test revealed children accumulated significantly $(t=3.766, p=0.001)$ more physical activity counts when playing with their peer $\left(93363 \pm 22608\right.$ counts $\left.\cdot \min ^{-1}\right)$ versus when playing alone $\left(70672 \pm 35228\right.$ counts $\left.\cdot \min ^{-1}\right)$. There was no significant difference $(t=1.718, p=0.102)$ in accelerometer counts when comparing the alone condition to the parent condition $\left(87503 \pm 37063\right.$ counts $\left.\cdot \mathrm{min}^{-1}\right)$. There was also no significant difference $(t=0.764, p=0.454)$ when comparing the parent condition to the peer condition. There were no significant main or interaction effects for sex $(\mathrm{F}=1.149$, $p=0.328)$. 


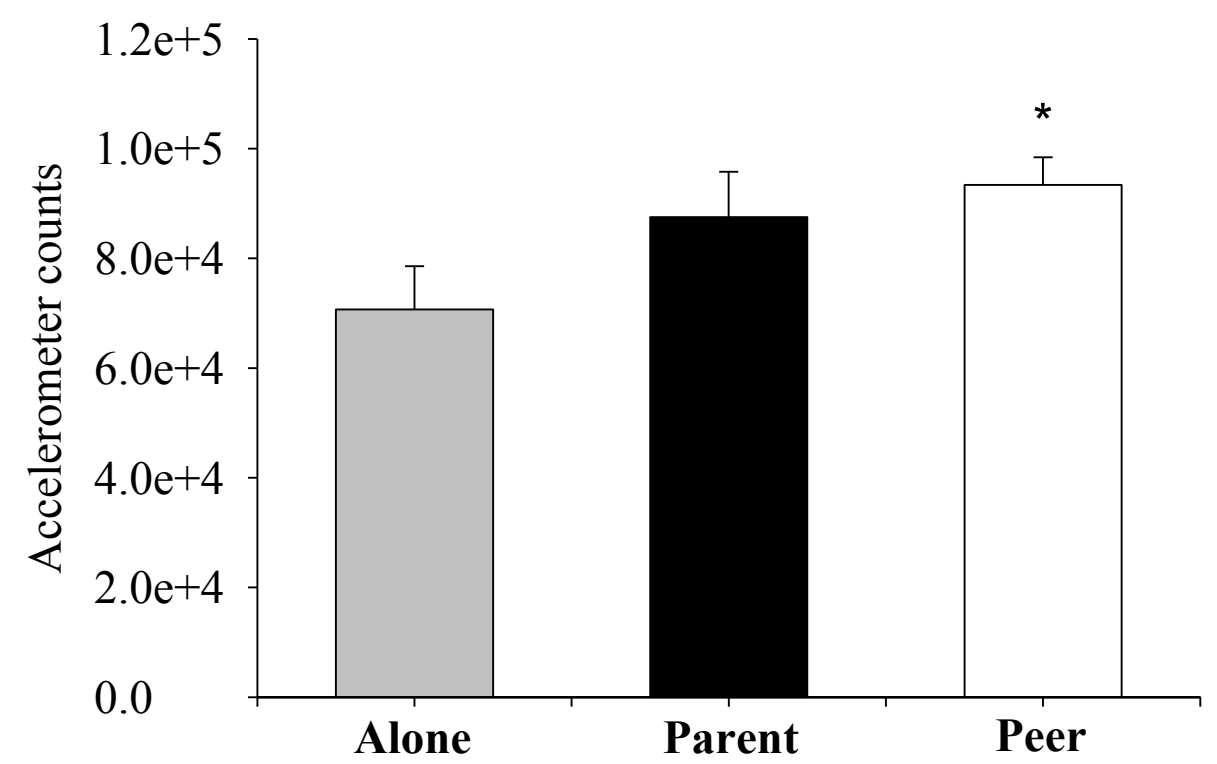

Figure 3. Accelerometer counts for each condition (Mean $\pm \mathrm{SEM})$.

*condition was significantly greater than alone $p \leq 0.05$.

\section{Time Allocated to Sedentary Activities}

There was a significant social condition by biological sex interaction for sedentary time $(\mathrm{F}=3.32, p=0.048)$. Boys allocated significantly $(t=3.368, p=0.008)$ more time to sedentary activities during the alone condition $(9.7 \pm 9.1$ minutes $)$ than the parent $(0.00 \pm 0.00$ minutes $)$ and peer $(1.07 \pm 1.4$ minutes $)$ conditions (Figure 4$)$.

Additionally, boys accumulated significantly $(t=2.353, p=0.043)$ more minutes sitting during the peer condition $(1.1 \pm 1.4$ minutes $)$ than the parent condition $(0 \pm 0.0$ minutes $)$ (Figure 2). For girls, there was no significant $(t=0.079, p=0.939)$ difference in time allocated to sedentary activity between the alone ( $5.8 \pm 6.9$ minutes) condition and the parent $(5.5 \pm 9.4$ minutes) condition (Figure 5). There was also no significant difference 
$(t=1.761, p=0.112)$ in time allocated to sedentary activities between the parent and peer $(0.72 \pm 1.5$ minutes $)$ conditions (Figure 3$)$. There was a trend towards a significant difference $(t=2.113, p=0.064)$ in time allocated to sedentary activities between the alone and peer conditions (Figure 5). There were also significant main effects of condition and sex for time allocated to sedentary activities $(\mathrm{F} \geq 3.32, p \leq 0.048)$. On average the alone condition $(7.8 \pm 8.2$ minutes $)$ was greater than the parent $(2.75 \pm 7$ minutes $)$ and friend $(0.9 \pm 1.4$ minutes $)$ conditions. Overall girls $(4.0 \pm 2.8$ minutes $)$ allocated more time to sedentary behavior than boys $(3.6 \pm 5.3$ minutes $)$.

\section{Boys}

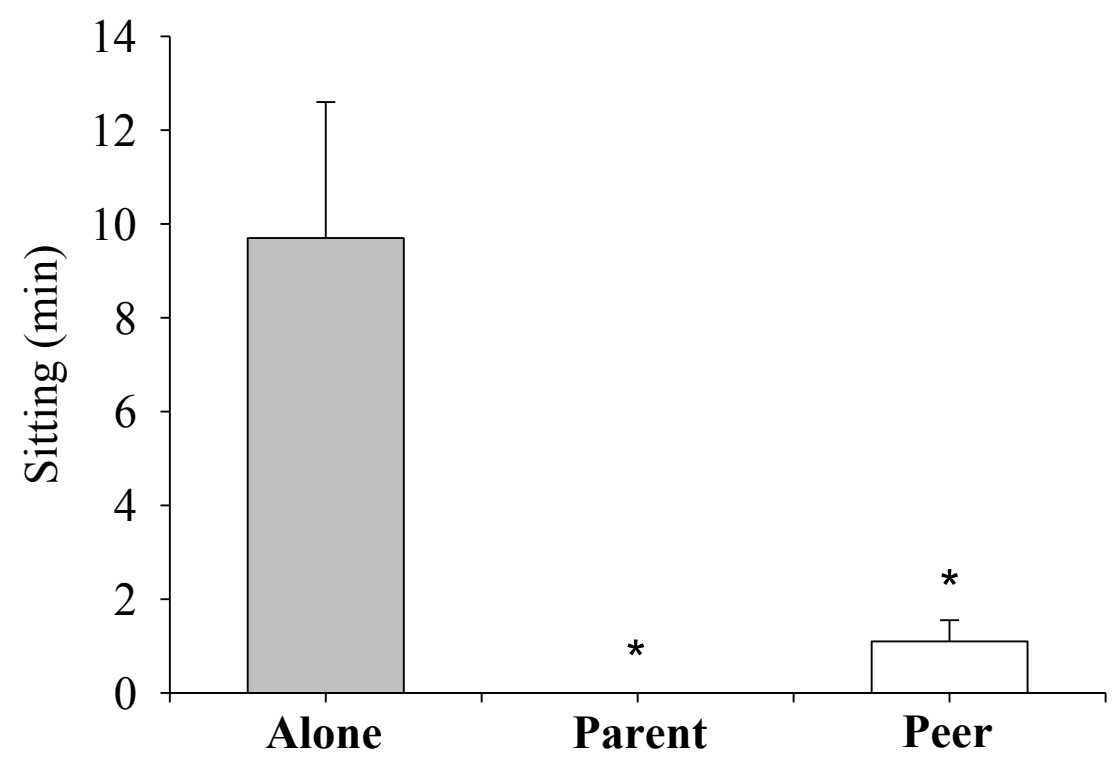

Figure 4. Time allocated to sedentary activities for boys during each condition (Mean \pm SEM). The level of significance was set a priori of $p \leq 0.05$.

*condition was significantly greater than alone $p \leq 0.05$. 


\section{Girls}

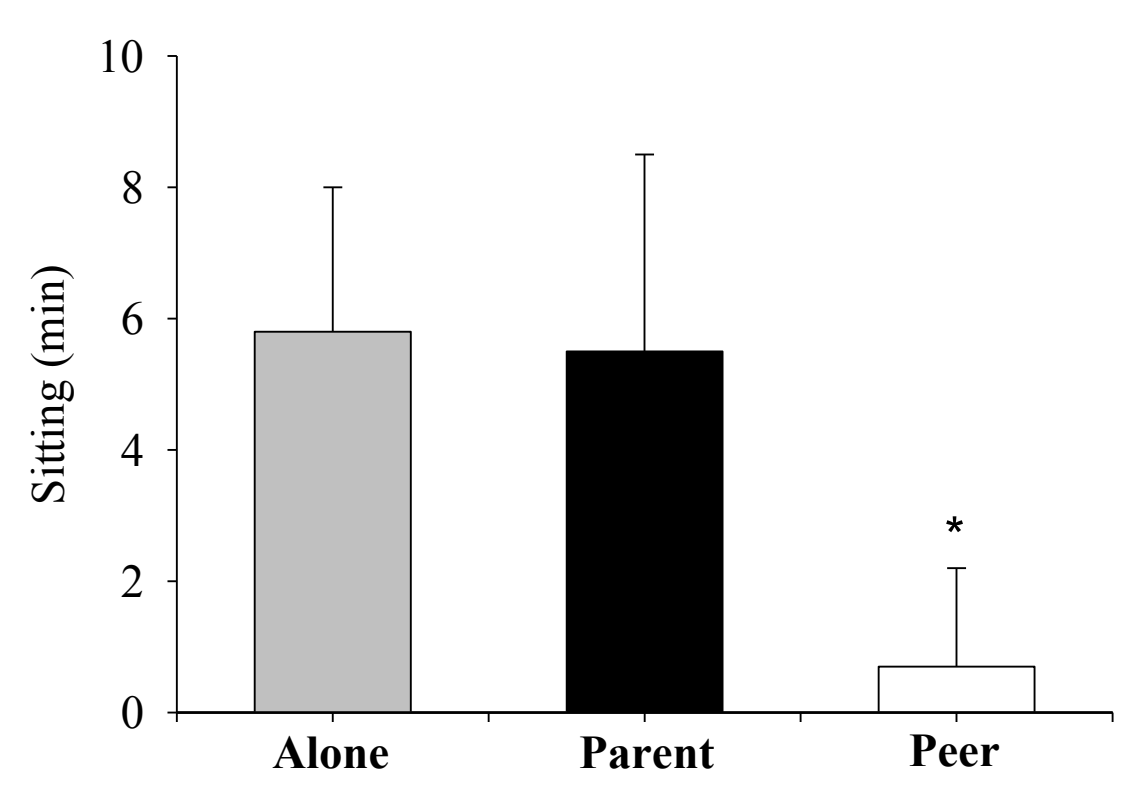

Figure 5. Time allocated to sedentary activities for girls during each condition (Mean \pm SEM).

*condition was significantly greater than alone $p \leq 0.05$.

\section{Heart Rate}

There was a significant main effect of condition for average heart rate $(F=5.641$, $p=0.007)$. Post-hoc analysis revealed that children achieved a significantly $(t=2.5, p=$ $0.022)$ higher average heart rate in when playing with their peer $(145.8 \pm 18.9$ beats $\cdot$ $\left.\mathrm{min}^{-1}\right)$ and with their parent $\left(145.7 \pm 18.7\right.$ beats $\left.\cdot \mathrm{min}^{-1}\right)$ condition versus playing alone $\left(132.5 \pm 19.4\right.$ beats $\left.\cdot \min ^{-1}\right)$. There was no significant difference between the parent and peer social conditions $(t=0.017, p=0.987)$. There were no main or interaction effects of $\operatorname{sex}(\mathrm{F}=0.753, p=0.478)$. 


\section{Ratings of Perceived Exertion}

There were no significant main or interaction effects of condition $(\mathrm{F}=0.217, p=$ $0.806)$ or sex for RPE $(\mathrm{F}=0.058, p=0.944)$. Children reported similar RPE in the alone (2.4 \pm 2.4$)$, parent $(2.7 \pm 2.6)$, and peer $(2.8 \pm 3.1)$ conditions.

\section{Liking}

There was a significant main effect of condition for liking $(\mathrm{F}=5.649, p=0.007)$. Post hoc analysis revealed that children reported significantly $(\mathrm{F}=3.65, p=0.002)$ greater liking of the parent condition $(9.4 \pm 1.1 \mathrm{~cm})$ and peer $(9.8 \pm 0.6 \mathrm{~cm})$ condition versus the alone condition $(7.0 \pm 3.5 \mathrm{~cm})$. Liking was not significantly different between the parent and peer social conditions $(t=1.325, p=0.201)$. There were no significant main or interaction effects for biological sex $(\mathrm{F}=0.07, p=0.933)$.

\section{0-Minute Bonus Period}

A Wilcoxon Signed Rank test revealed that a significantly greater $(\mathrm{Z} \geq-2.449, p \leq$ 0.014) proportion of children chose to participate in the additional 10-minute bonus period during the peer condition (100\%) than both the alone (35\%) and parent (70\%) conditions. There was a trend toward significant difference $(\mathrm{Z}=-1.897, p=0.058)$ between the proportion of children who chose to participate in the additional 10-minute bonus period between the parent and alone conditions.

\section{Preference}

Chi-square analysis revealed a significantly greater $\left(x^{2}=9.1, p \leq 0.011\right.$, Figure 6$)$ number of children preferred the peer condition $(n=12)$ condition versus the parent ( $n=$ 7) and alone $(n=1)$ conditions (Figure 6). 


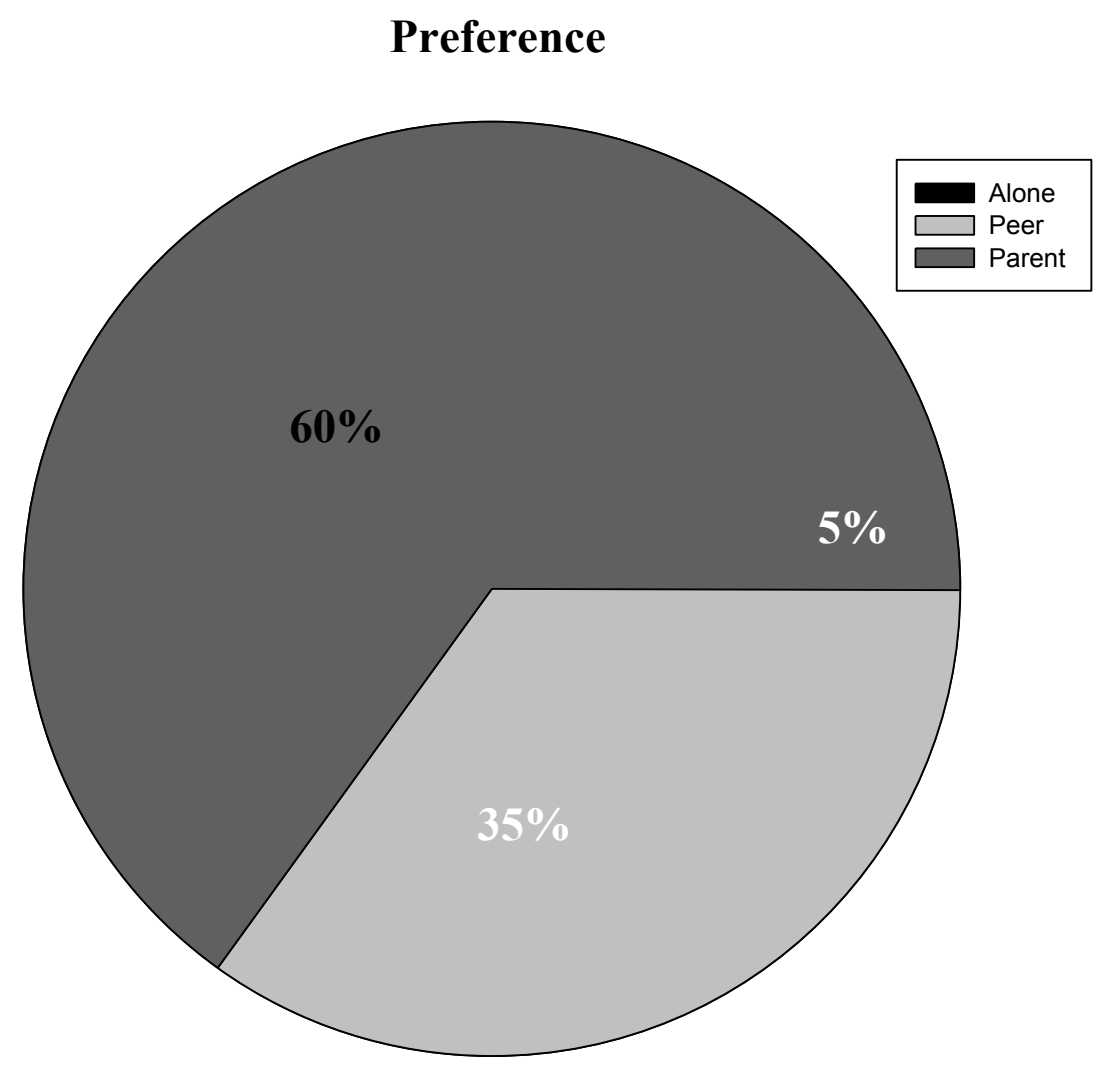

Figure 6. Preference of condition (Data are Mean \pm SEM).

*condition was significantly greater than alone $p \leq 0.05$.

\section{Discussion}

To the best of our knowledge this is the first experimental study examining the effects of parent versus peer interaction upon children's physical activity behavior in a natural environment (i.e., playground). The results of the current study indicate that children were more physically active when playing with their parent or friend versus when playing alone. Based on accelerometer counts, children were $32 \%$ more active when playing with their friend versus when playing alone. While not statistically significant, 
children also accumulated 24\% more accelerometer counts during the parent participating condition versus the alone condition. Relative to the alone condition, children also allocated $65 \%$ and $88 \%$ less time to sedentary activity during the parent and peer conditions, respectively. Children also reported a $34 \%$ and $40 \%$ greater liking in the parent and friend conditions versus the alone condition, respectively. While children may have equally liked both parent participating and friend conditions more than the alone condition, $60 \%$ of the children rated the friend condition as their most preferred, followed by $35 \%$ preferring the parent condition, and only $5 \%$ preferring the alone condition. Additionally, $100 \%$ of children elected to participate in the 10 -minute bonus period of activity when their friend was participating with them versus only $70 \%$ and $35 \%$ in the parent participating and alone conditions, respectively. These results indicate that children are likely to accumulate more accelerometer counts, have less sedentary minutes, and achieve a greater average heart rate in the friend and parent participating conditions when compared to the alone condition. Additionally, in the friend condition children reported greater liking, preference, and motivation (assessed via the decision to participate in the bonus 10 minutes) for physical activity when compared to having a parent participating or when playing alone.

It was hypothesized that children's physical activity behavior would be greater in the friend participating condition than in either the parent participating or alone conditions. We believed that children would have accumulated more accelerometer counts and less sedentary minutes in the friend conditions relative to the alone condition because previous research has suggested that among all other social influences, peers are 
said to begin to serve as the most important behavioral role models for children as they age from 6 to 14 years old (Eccles, 1999; Salvy et al., 2012; Wu \& Pender, 2002). The results of our study indicated that children accumulated significantly more accelerometer counts in the parent participating and friend conditions versus the alone condition. Our results are in agreement with previous studies where children's physical activity was greatest and sedentary behavior lowest when they were playing with their parents or peers versus when playing alone (Barkley et al., 2014; Rebold, Lepp, Kobak, et al., 2015; Salvy et al., 2009). Exercise intensity, which was evaluated by heart rate in the current study, followed the same pattern as accelerometer counts. However, as was the case with accelometer counts, there was no significant difference between the parent and peer social conditions. Therefore, when looking at activity as a whole, since children were the most active in both the parent and friend social conditions, yet not significantly from one another, it makes sense that both conditions are beneficial. However, since the purpose of this study was to evaluate which social condition was the most beneficial at increasing physical activity and reducing sedentary activity, it is important that we consider overall motivation and preference of social condition. Previous studies have examined the effects on children's motivation to be physically active via a bonus 10-minute bout of activity immediately following the initial 30-minute activity session. Applying the same method previously utilized by Barkley, Salvy, et al. (2011), in the current study $100 \%$ of children elected to participate in the 10-minute bonus period of activity when their friend was participating with them versus only $70 \%$ and $35 \%$ in the parent participating and alone conditions, respectively. Additionally, when examining preference of social 
condition similar results were found that $65 \%$ of the children preferred to play with their friend compared to only 35\% when playing with their parent and 5\% when playing alone. These results suggest that if children find an activity to be more enjoyable it has the potential to lead to more engagement of the activity. Therefore, since the majority of children chose to engage in the additional 10-minute bout of activity (100\%) and preferred $(60 \%)$ playing with their friend, it is reasonable to conclude that the friend participating condition is the most beneficial at increasing physical activity behavior and reducing sedentary behavior.

While friends do seem to work best as hypothesized due to the greater reported preference for social condition and greater participation in the extra 10-minute bonus period, there were no differences seen in physical activity, heart rate, or sedentary behavior between the friend and parent conditions. As mentioned previously, preceding research has said that children between the ages of 6 and 14 years old are highly influenced by their peers among any other social influence (Eccles, 1999; Salvy et al., 2012; Wu \& Pender, 2002). Therefore, since the children recruited for the current study fell within that age range $(8.2 \pm 1.7$ years old $)$ it would have been expected that physical activity, heart rate, and sedentary behavior in the friend condition would have been significantly different from the parent condition; however our results proved otherwise. A possible explanation to these findings could be that perhaps 8-year-old children are still making that transition from parents serving as the biggest influence to peers serving as the biggest influence. It is possible that these children are at an intermediate step where 
both parents and peers play a large role in shaping children's physical and sedentary behaviors.

When examining sedentary time, differences were seen between boys and girls, more specifically, in the parent participating condition. On average, boy's sedentary time was 0 minutes in the parent participating condition whereas the girl's sedentary time was 5 minutes in the parent participating conditions. A possible explanation for these findings may be due to a process known as gender socialization (Elkin \& Handel, 1988). Through the process of gender socialization, boys and girls learn behaviors and attitudes that are deemed appropriate for acceptance within perceived societal norms such as some classical examples of boys playing with cars, wearing the color blue, and playing outdoors, whereas girls are playing with dolls, wearing the color pink, and doing household related-activities such as learning how to cook (Elkin \& Handel, 1988). Cheng and colleagues (2014) reported that the physical activity levels of fathers are positively associated to that of the son, and the physical activity levels of the mothers are positively associated to that of the daughter. Male adolescents usually identify more with their fathers and their behaviors, whereas female adolescents are more inclined to identify with their mothers (Cheng et al., 2014). This evidence possibly suggests that the presence of parents may not have the same influence on boys and girls as it pertains to physical activity behavior. In the present study, parents may have socialized the boys to be more physically active than the girls. In other words, boys in the present study may be modeling an expected behavior, physical activity, in the presence of their parents. This 
could be a possible explanation as to why we observed less sedentary time in boys relative to girls during the parent condition.

\section{Limitations and Future Research}

Being that this is the first experimental study that we are aware of that simultaneously examines the impact of parent and peer influence on children's physical activity behavior, it has limitations that should be addressed. First and foremost during the parent participating condition only six of the 20 parents were fathers. Due to the gender socialization theory it is possible that children playing with their fathers may be more likely to engage in more physical rather than sedentary behavior. However, when covarying for parental sex, there were no statistical differences in any of the variables examined. Future studies should investigate the differences in children's physical activity behavior when playing with a parent of the same biological sex versus when playing with a parent of the opposite biological sex. Additionally, this is the first experimental study of its kind investigating children's intensity level (i.e., average heart rate) during each of the three simulated recess conditions (playing alone, with a parent, and with a peer). Therefore, it is difficult to compare or contrast our results to other studies due to the lack of information within this body of research. Nonetheless, the significance of our findings does bring about important exercise recommendations in regards to exercise intensity for children between the ages of six and 10 years old. Furthermore, it is recommended that children accumulate at least 60 minutes of moderate intensity activity each day, being that children only had the opportunity to play for 30 minutes with the option of playing for an additional 10 minutes in each condition and 
with only one friend and/or parent. It is reasonable to question whether children would have been more active or sedentary in each condition if they were allotted a longer amount of time (i.e., $>30$-minutes) to play on the playground or allotted the opportunity to play with more than one friend or parent. To address these concerns, future investigations should allow children to play with more than one child or parent and for a longer amount of time on an outdoor playground to investigate how those changes may affect their physical activity behavior.

\section{Conclusion}

To our knowledge this was the first study to experimentally test the influence of peers versus parents on children's physical activity behavior. This study was also the first to measure children's physical activity during these various social conditions in a natural environment (i.e., playground) utilizing experimental techniques. Previous experimental studies have indicated that children's physical activity behavior increases in the presence of a peer and parent (Sanders, Peacock, et al., 2014; Rebold, Lepp, Kobak, et al., 2015). However, before this study it was unknown as to which social condition would elicit the greatest physical activity behavior. Given that peer and parental influence were manipulated in this study, we can conclude that children's physical activity behavior was increased in both the friend playing and parent playing conditions as compared to when the children played alone. This age could represent a stage in development where friends are starting to play a larger role in influencing a child's physical activity yet parents still continue to serve as significant physical activity models. However, since children reported greater motivation and preference for the friend 
condition it can be concluded that playing with a friend caused children to be more physically active (i.e., more accelerometer counts) and thus being the condition that was most beneficial. This information is advantageous in that it may aid in creating interventions in which children engage in more physical activity behaviors that they like. 


\section{CHAPTER VI}

\section{CONCLUSION AIM $1 \& 2$}

For this dissertation I set out to assess factors affecting children's physical activity behavior using experimental techniques. First, we evaluated children's physical activity, sedentary behavior, and liking in response to adding a mobile, internet-connected tablet computer (i.e., Apple iPad) into an environment that is traditionally active (i.e., gymnasium) versus when it was not included in that gymnasium. Secondly, in a separate study, children's physical activity, sedentary behavior, and liking were measured in three different social conditions: playing alone, with a parent participating, and with a friend participating. The aim of this study was to understand how active or sedentary children would be in the presence of their parent or friend compared to when they were alone. Overall, the results from these two studies indicate that children's physical and sedentary activity behavior is highly variable and are affected by the availability of popular, electronic devices (e.g., iPad) and by the social environment (in the presence of a friend, parent) in which they play.

The aim of the first study was to assess children's physical and sedentary activity with and without the presence of a mobile, internet-connected tablet computer (iPad). As predicted, children accumulated significantly more accelerometer counts and fewer sedentary minutes when playing without the iPad present versus when playing with the iPad present. Though, these children were more active and less sedentary in the condition when the iPad was not present, they did not perceive one condition to be more physically challenging (RPE) than the other, nor did they like or prefer one more than the 
other. Therefore, these results imply that introducing a mobile, internet-connected device into an active environment reduces physical activity behavior and increases sedentary behavior, without altering the enjoyment or effort perception of the activity. Therefore, it is recommended that parents consider limiting the access to such devices in environments that may promote physical activity (e.g., a gymnasium, parks, playgrounds).

The aim of the second study was to assess children's physical and sedentary activity behavior and preference of three separate simulated recess session under the following social conditions: playing alone, with their parent participating, and with their friend participating. Overall, children were more active and less sedentary when playing with their parent or friend versus the alone condition. Both playing with a friend and parent proved to increase physical activity in children; however based on the data collected, $100 \%$ of the children elected to participate in the extra 10 -minute bonus activity along with $60 \%$ of those children electing that the condition where they played with their friend as their favorite. This leads researchers to believe that, while playing with a parent elicits similar physical activity, playing in an environment with a friend present proves to be the most motivating and preferred physical activity setting for children between the ages of 6 and 10 years old.

Overall, the intention of these two studies was to evaluate and understand how manipulating an environment in specific and controlled ways such as placing a mobile, internet-connected tablet computer or another person such as a parent or peer can influence children's physical activity behavior. The results obtained in both of these studies demonstrate how easily that behavior could change when adding or subtracting those 
variables. Therefore, by conducting studies like these we continually find new and interesting results that lead us on the right path to create physical activity interventions that increase physical activity behavior and reduce sedentary behavior of children with the hopes of those interventions reducing children's risk for overweight and obesity. 
APPENDICIES 
APPENDIX A

SPECIFIC AIM \#1: RECRUITMENT FLYER 


\section{Appendix A}

Specific Aim \#1: Recruitment Flyer

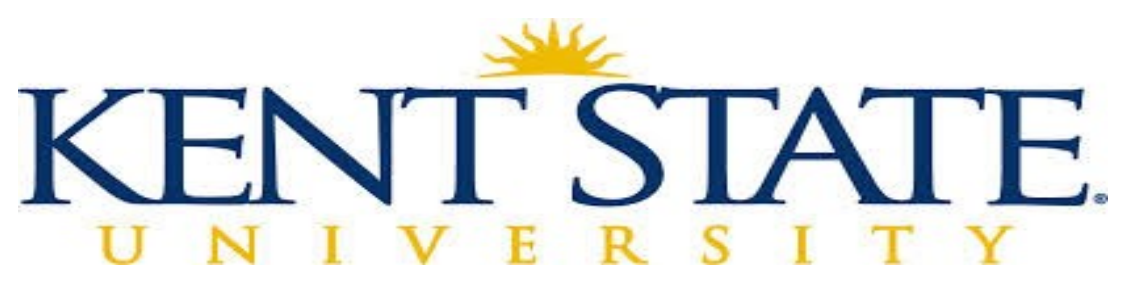

PHYSICAL ACTIVITY

RESEARCH OPPORTUNITY
FOR 5-10 YEAR OLD CHILDREN

Children will come to Kent State University on two separate conditions to complete two 30-minute activity sessions: during one session an Apple iPad will be present to play with!

Children will receive up to $\$ 20.00$ in gift cards to a local store upon completion of the study

For more information please contact either:

Dr. Jacob Barkley

Associate Professor, Exercise Science, Kent State University

Email: jbarkle1@kent.edu

Phone: 330-672-0209

OR

Mallory Kobak, MS, CSCS

Doctoral Student, Exercise Science, Kent State University

Email: mkobak2@,kent.edu

Phone: 216-570-3118 
APPENDIX B

SPECIFIC AIM \#1: INFORMED CONSENT FORM 


\section{Appendix B}

\section{Specific Aim \#1: Informed Consent Form}

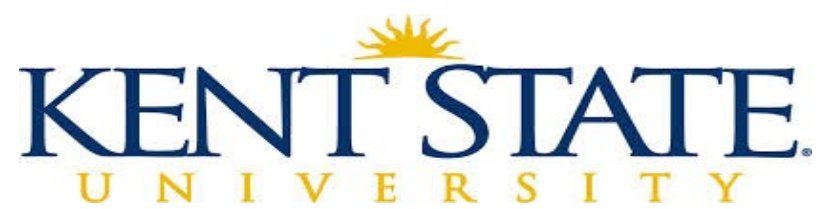

\section{Informed Consent to Participate in a Research Study}

Study Title: The effect of the presence of an internet-connected, mobile, tablet computer on physical activity behavior in children.

Principal Investigator: Dr. Jacob E. Barkley and Mallory S. Kobak

Your child is being invited to participate in a research study. This consent form will provide you with information on the research project, what your child will need to do, as well as the associated risks and benefits of the research. Your child's participation is voluntary. Please read this entire form carefully. It is imperative that you fully understand the research in order to make an informed decision. Please do not hesitate to ask questions if you have any. You will receive a copy of this document to take with you.

Purpose: We are conducting a research project to assess physical and sedentary activity behavior of school- aged children in two separate simulated recess conditions: with and without the presence of a mobile, internet-connected tablet computer (i.e., Apple iPad). As the childhood obesity epidemic continues to rise, it is essential that research is done to examine and identify environmental, social, and behavioral factors that affect physical activity participation in children.

\section{Procedures}

If you decide to allow your child to participate, you will be asked to bring your child to the Exercise Physiology Laboratory on two separate occasions for approximately 45 minutes each. During the initial visit we will measure your child's age, height, weight, and body mass index, and we will also give an explanation of the protocol in its entirety.

During each of the separate laboratory visits, your child will be taken to a 4,360 square foot gymnasium located within the same building as the Laboratory where they will be shown a variety of age-appropriate physical activity options (e.g., balls, hoops, targets, cones, obstacle courses, etc.) and a table of sedentary activities (e.g., books, Lego blocks, coloring sheets, pencils, crayons, etc.). On only one visit will the Apple iPad be included on the sedentary table. At the beginning of each session a ten-minute familiarization period will take place where your child will be shown how to access the internet and 
various games that will be pre-loaded into the iPad. Staff will explain how to play each game. The iPad will be pre-loaded with no fewer than five, popular, age appropriate game applications. These applications will be games that all children could easily have access to if they had an internet-connected tablet computer at their home.

After being shown the physical and sedentary options and undergoing the iPad familiarization your child will be fitted with an accelerometer that will be comfortably strapped around their waist. The ActiGraph is a valid and reliable device for quantifying physical activity behavior in children and adolescents. After being fitted with the accelerometers, your child will be given permission to participate in any of the sedentary and/or physical activities in the gymnasium they wish, in any pattern, for a total of 30 minutes. In the iPad condition an iPad will be present at the sedentary table and will be available to play with. If your child decides to play with the iPad they are not confined to sitting at the sedentary table, they can walk around with it or take it anywhere in the gym they would like.

In addition to accelerometry data, the time your child allocates to the sedentary table and physical activities during each 30-minute activity session will be recorded via a stopwatch. Too, the time that your child uses the iPad while seated versus standing/walking during the $i P a d$ condition will also be recorded. After both conditions are completed, your child will be asked to indicate which condition ( $i P a d$, or no iPad) was their favorite.

\section{Benefits}

This research will not benefit you or your child directly. However, your child's participation in this study will help us to better understand environmental, social, and behavioral factors that affect physical activity participation in children.

\section{Risks and Discomforts}

If your child is very physically active during the sessions, he or she may experience muscle soreness a day or two after the activity. An exercise physiologist that is CPR/First Aid certified will be present to assure that your child is exercising safely during each visit. Medical treatment by the University Health Center is provided only to currently registered students. Please be advised that for all other injuries, emergency services will be called for those occurring on the Kent State University campus. You or your medical insurance will be billed for this service. No other medical treatment or financial compensation for injury from participation in this research project is available.

\section{Privacy and Confidentiality}

Your child's study related information will be kept confidential within the limits of the law. Any identifying information will be kept in a secure location and only accessible to the research staff. Research participants will not be identified in any publication or presentation of research results; only aggregate data will be used. You and your child's 
name will not be used during the study; your child will be assigned a number that will serve as their identity.

Your research information may, in certain circumstances, be disclosed to the Institutional Review Board (IRB), which oversees research at Kent State University, or to certain federal agencies. Your child's confidentiality may not be maintained if there is an indication that if he/she may harm themselves or others.

\section{Compensation}

Your child will be awarded up to $\$ 20$ in gift cards to a local store for his or her participation in the study. If your child participates in one session and chooses not to participate in the second session they will receive one $\$ 10$ gift card. If they participate in both sessions they will receive two $\$ 10$ gift cards.

\section{Voluntary Participation}

Taking part in this research study is entirely up to you and your child. You and/or your child may choose not to participate or may discontinue their participation at any time without penalty or loss of benefits to which he/she is otherwise entitled. You will be informed of any new, relevant information that may affect your child's health, welfare, or willingness to continue participation in this study.

\section{Contact Information}

If you have any questions or concerns about this research, you may contact Dr. Jacob Barkley at 330-672-0209 or Mallory Kobak 216-570-3118. This project has been approved by the Kent State University Institutional Review Board. If you have any questions about your rights as a research participant or complaints about the research, you may call the IRB at 330.672.2704.

\section{Consent Statement and Signature}

I have read this consent form and have had the opportunity to have my questions answered to my satisfaction. I voluntarily agree to grant permission for my child to participate in this study. I understand that a copy of this consent will be provided to me for future reference.

\section{Parental Signature}

\section{Date}

I have witnessed the consent process and believe that the participants listed above have been fully informed, understand the project and what they will have to do, and have voluntarily agreed to participate. 
APPENDIX C

SPECIFIC AIM \#1: INFORMED ASSENT FORM 


\section{Appendix C}

\section{Specific Aim \#1: Informed Assent Form}

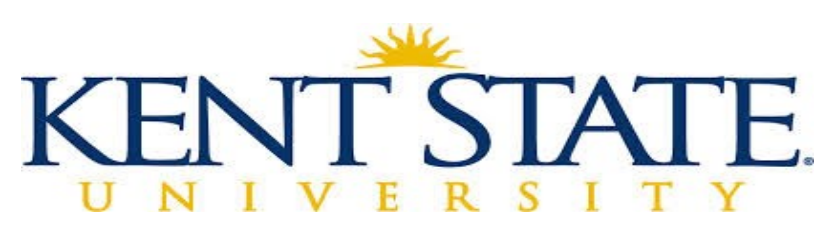

\section{Child Assent Form to Participate in a Research Study}

Title: The effect of the presence of an internet-connected, mobile, tablet computer on physical activity behavior in children.

Hello, my name is Mallory Kobak, and I am trying to learn more about how much you like to play in different activities. I would like you and one of your parents to come to the gym here at Kent State University on two days. If you choose to be in this project I will first see how tall you are and how much you weigh. After that you will get to play different activities in the gym. While playing these activities you will be asked to wear a special belt around your waist that helps me see how many times you move. It does not hurt and it will be easy for you to still play. You will play in the gym for 30 minutes each time you come here. After the 30 minutes of playing are over I will ask you how much you liked playing. After both visits are over I will ask you which time playing was your favorite.

Do you want to do this?

Do you have any questions?

When you are playing and you want to stop just tell me.

If you want to be in the study, write your name on the first line below:

\section{Child Signature}

Parent Signature

Witness Signature

\section{Date}

Date

Date 
APPENDIX D

SPECIFIC AIM \#1: MEDICAL HISTORY FORM 


\section{Appendix D}

Specific Aim \#1: Medical History Form

\section{Medical History Screen (Children)}

Name

Date

Subject \#

Address

Phone Number

Age

DOB Sex $M$ or $F$

Height in

lbs

Height cm (inches $* 2.54)$

$\mathrm{Wt}$ $\mathrm{kg}(\mathrm{lbs} / 2.2)$

BMI_ $\mathrm{kg} / \mathrm{m}^{2} \quad$ Weight percentile

\section{Which ethnic group do you most identify with (circle response):}

American Indian or Alaskan Native Asian or Pacific Islander Black, not of Hispanic

Origin Hispanic White, not of Hispanic Origin Other

$\mathbf{Y} / \mathbf{N}$

Has a doctor ever said that your child's blood pressure was too high or too low?

Have they ever had pain in their heart or chest?

Have they ever noticed extra heart beats, skipped beats or a racing heart?

Has a doctor ever said that they have heart trouble, an abnormal

electrocardiogram (ECG or EKG), heart attack, or coronary?

Do they often have trouble breathing?

_ Have they ever been diagnosed with asthma?

Have they ever been diagnosed with diabetes?

Do they have any orthopedic limitations to physical activity?

Does your child have any other medical conditions that affect your ability to safely participate in physical activity? If yes, please explain, is the condition controlled? Do you have physician clearance?

Is your child currently taking any medication(s)? $\quad \mathrm{Y}$ or $\mathrm{N}$

If yes, please describe the medication(s).

Do you have any questions?

$\mathrm{Y}$ or $\mathrm{N}$

Does the child seem eligible?

$\mathrm{Y}$ or $\mathrm{N}$

Date of first appointment 
APPENDIX E

SPECIFIC AIM \#1: GYMNASIUM CONFIGURATION 


\section{Appendix E}

\section{Specific Aim \#1: Gymnasium Configuration}

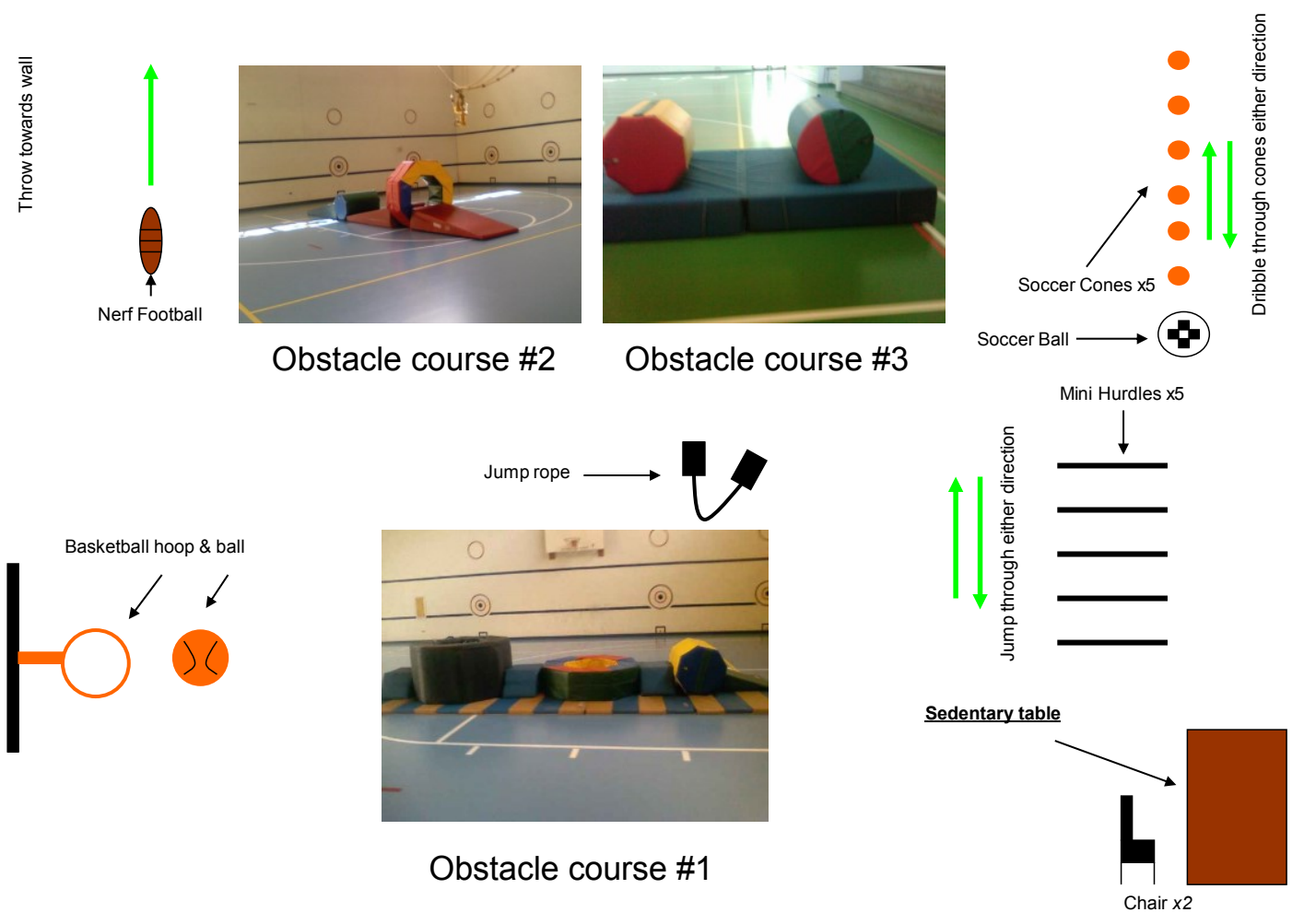


APPENDIX F

SPECIFIC AIM \#1: WORKLOAD DOCUMENTATION FORM 


\section{Appendix F}

Specific Aim \#1: Workload Documentation Form

Participant Name/\#:

Date:

Condition:

Liking:

\begin{tabular}{|c|c|c|c|c|c|c|c|c|c|c|c|}
\hline ACTIVITY & $\begin{array}{l}\text { TIME } \\
\text { SPENT }\end{array}$ & $\begin{array}{l}\text { TIME } \\
\text { SPENT }\end{array}$ & $\begin{array}{l}\text { TIME } \\
\text { SPENT }\end{array}$ & $\begin{array}{l}\text { TIME } \\
\text { SPENT }\end{array}$ & $\begin{array}{l}\text { TIME } \\
\text { SPENT }\end{array}$ & $\begin{array}{l}\text { TIME } \\
\text { SPENT }\end{array}$ & $\begin{array}{l}\text { TIME } \\
\text { SPENT }\end{array}$ & $\begin{array}{l}\text { TIME } \\
\text { SPENT }\end{array}$ & $\begin{array}{l}\text { TIME } \\
\text { SPENT }\end{array}$ & $\begin{array}{l}\text { TIME } \\
\text { SPENT }\end{array}$ & $\begin{array}{l}\text { TIME } \\
\text { SPENT }\end{array}$ \\
\hline Obstacle course 1 & & & & & & & & & & & \\
\hline Obstacle course 2 & & & & & & & & & & & \\
\hline Obstacle course 3 & & & & & & & & & & & \\
\hline Basketball shoot & & & & & & & & & & & \\
\hline Jump rope & & & & & & & & & & & \\
\hline Mini hurdles & & & & & & & & & & & \\
\hline Cones and soccer ball & & & & & & & & & & & \\
\hline Sedentary Table & & & & & & & & & & & \\
\hline $\begin{array}{l}\text { Sedentary Table/sitting: } \\
\text { iPad }\end{array}$ & & & & & & & & & & & \\
\hline Standing/Walking: iPad & & & & & & & & & & & \\
\hline
\end{tabular}




\section{APPENDIX G}

SPECIFIC AIM \#1: VISUAL ANALOG SCALE FOR LIKING (VAS) 


\section{Appendix G}

Specific Aim \#1: Visual Analog Scale for Liking (VAS)

Name:

Condition:

Date:

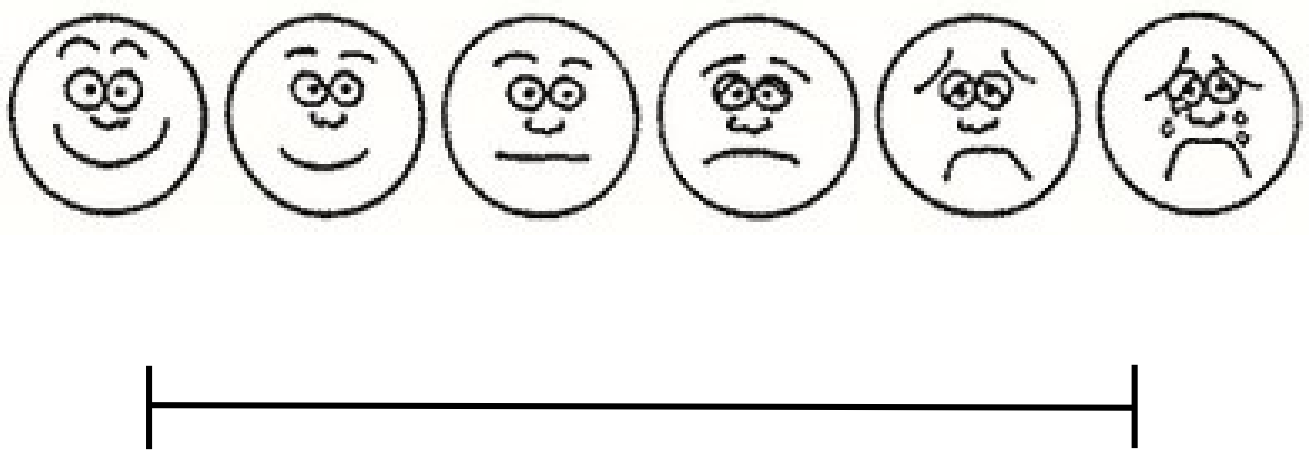

Like it very much.

Do not like it at all. 
APPENDIX H

SPECIFIC AIM \#1 : OMNI WALK/RUN SCALE OF PERCIEVED EXERTION FOR CHILDREN 
Appendix H

Specific Aim \#1: Omni Walk/Run Scale of Percieved Exertion For Children

OMNI Walk/Run Scale of Perceived Exertion (RPE) for Children

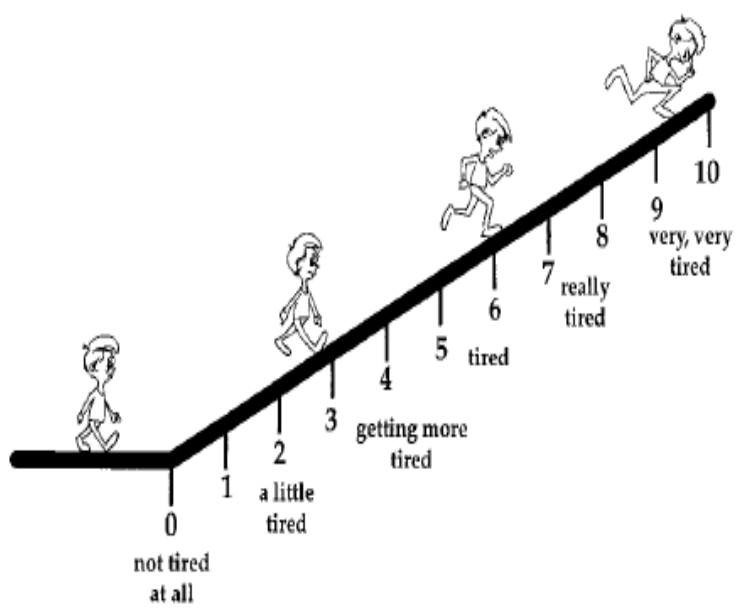

97 


\section{APPENDIX I}

SPECIFIC AIM \#2: RECRUITMENT FLYER 


\title{
Appendix I
}

Specific Aim \#2: Recruitment Flyer

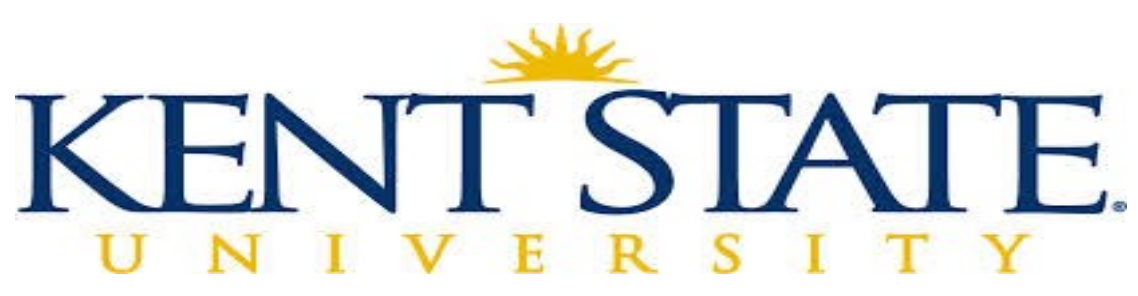

\author{
PHYSICAL ACTIVITY \\ RESEARCH OPPORTUNITY \\ FOR 6-10 YEAR OLD CHILDREN
}

Children will come to the Independence Annex Playground on three separate conditions to complete three 30 -minute activity sessions: one session they will play alone, one session with their peer, and one session with their parent/legal guardian!

Children will receive up to $\$ 30.00$ in gift cards to a local store upon completion of the study!

For more information please contact either:

Mallory Kobak, MS, CSCS

Doctoral Student, Exercise Science, Kent State University

Email: mkobak2@kent.edu

Phone: 216-570-3118

OR

Dr. Jacob Barkley

Associate Professor, Exercise Science, Kent State University

Email: jbarkle1@kent.edu

Phone: 330-672-0209 
APPENDIX J

SPECIFIC AIM \#2: INFORMED CONSENT FORM 


\title{
Appendix $\mathbf{J}$
}

\section{Specific Aim \#2: Informed Consent Form}

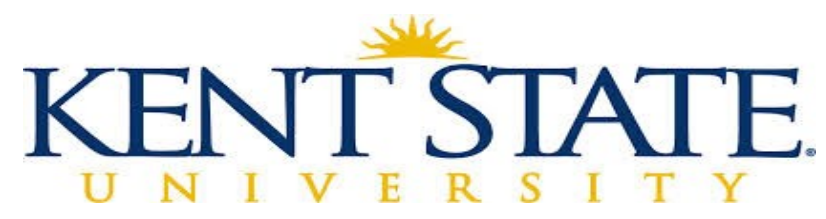

\section{Informed Consent to Participate in a Research Study}

\begin{abstract}
Study Title: The experimental effect of parent versus peer influence on children's physical activity behavior
\end{abstract}

Principal Investigator: Dr. Jacob E. Barkley and Mallory S. Kobak

Your child is being invited to participate in a research study. This consent form will provide you with information on the research project, what your child will need to do, as well as the associated risks and benefits of the research. Your child's participation is voluntary. Please read this entire form carefully. It is imperative that you fully understand the research in order to make an informed decision. Please do not hesitate to ask questions if you have any. You will receive a copy of this document to take with you.

Purpose: The purpose of this study is to assess children's physical and sedentary activity behavior and preference of three separate simulated recess conditions: playing alone, with their parent participating, and with their friend participating. No studies that we are aware of have examined the impact of peer versus parental influence on children's physical activity behavior utilizing experimental techniques. We feel that developing a better understanding of physical activity behavior in young children may lead to more effective physical activity recommendations or interventions which may decrease the occurance of childhood obesity.

\section{Procedures}

If you decide to allow your child to participate, you will be asked to bring your child to the Independence Annex Playground on three separate occasions for approximately 45 minutes each. During the initial visit we will measure your child's age, height, weight, and body mass index, and we will also give an explanation of the protocol in its entirety.

During each of the separate visits, your child will be introduced to the playground and shown a variety of age- appropriate physical activity options (e.g., monkey bars, swings, slides, crawl tubes, climbers, merry-go-round, balls) and a table of sedentary activity options (e.g., books, Lego blocks, coloring sheets, crayons, sidewalk chalk, etc.). After being shown the physical activity options your child will be fitted with an accelerometer (ActiGraph GT1M, Pensacola, FL) that will be comfortably strapped around their waist. 
The ActiGraph is a valid and reliable device for quantifying physical activity behavior in children and adolescents $(3,7)$. Your child will also be fitted with a Polar heart rate monitor (Polar V800, Lake Success, NY) that will fit comfortably around their chest at the level of the zyphoid process. After being fitted with the accelerometer and heart rate monitor, your child will be given permission to play on the playground on any structure they wish, in any pattern, for a total of 30-minutes.

During the playing alone social condition your child will play on the playground alone with no other children or parents. The parent participating social condition will consist of you actively participating with your child in the physical activity options that they choose to participate in. You will be instructed to only play with the activities your child chooses and not to select the activity nor instruct your child on what activities to play. During the friend participating social condition your child will have free access to the playground with their friend participating.

During all three sessions accelerometry data and heart rate data will be recorded. Additionally, the time your child allocates to sedentary table and physical activities during each 30-minute activity session will be recorded via a stopwatch.

At the end of each 30-minute session, your child will be asked to specify their liking of the activity and rating of perceived exertion (RPE), using a visual analog scale and the OMNI walk/run RPE scale I will provide to them. They will then be asked if they would like to play for an additional 10-minutes or if they wish to be finished for the session. If your child decides to participate in the additional 10-minutes of activity they will follow identical procedures to their initial 30-minutes. During the friend condition, both your child and friend together will be informed that if they do not both agree, then they will be done for the day. After all three conditions are completed, your child will be asked to indicate which condition (alone, with a parent participating, or with a friend participating) they preferred. They will also receive three $\$ 10.00$ gift cards to a local store upon completion of both simulated recess conditions.

\section{Benefits}

This research will not benefit you or your child directly. However, your child's participation in this study will help us to better understand environmental, social, and behavioral factors that affect physical activity participation in children.

\section{Risks and Discomforts}

If your child is very physically active during the sessions, he or she may experience muscle soreness a day or two after the activity. An exercise physiologist that is CPR/First Aid certified will be present to assure that your child is exercising safely during each visit. Please be advised that for all other injuries, emergency services will be called. You or your medical insurance will be billed for this service. No other medical treatment or financial compensation for injury from participation in this research project is available. Kent State University and/or the city of Independence are not liable for any injuries that may be sustained while participating in this study. 


\section{Privacy and Confidentiality}

Your child's study related information will be kept confidential within the limits of the law. Any identifying information will be kept in a secure location and only accessible to the research staff. Research participants will not be identified in any publication or presentation of research results; only aggregate data will be used. You and your child's name will not be used during the study; your child will be assigned a number that will serve as their identity.

Your research information may, in certain circumstances, be disclosed to the Institutional Review Board (IRB), which oversees research at Kent State University, or to certain federal agencies. Your child's confidentiality may not be maintained if there is an indication that if he/she may harm themselves or others.

\section{Compensation}

Your child will be awarded up to $\$ 30$ in gift cards to a local store for his or her participation in the study. If your child participates in one session and chooses not to participate in the second or third session they will receive one $\$ 10$ gift card. If your child participates in the two sessions but not the third session they will receive two $\$ 10$ gift cards. If they participate in all three sessions they will receive three $\$ 10$ gift cards.

\section{Voluntary Participation}

Taking part in this research study is entirely up to you and your child. You and/or your child may choose not to participate or may discontinue their participation at any time without penalty or loss of benefits to which he/she is otherwise entitled. You will be informed of any new, relevant information that may affect your child's health, welfare, or willingness to continue participation in this study.

\section{Contact Information}

If you have any questions or concerns about this research, you may contact Dr. Jacob Barkley at 330-672-0209 or Mallory Kobak 216-570-3118. This project has been approved by the Kent State University Institutional Review Board. If you have any questions about your rights as a research participant or complaints about the research, you may call the IRB at 330.672.2704.

\section{Consent Statement and Signature}

I have read this consent form and have had the opportunity to have my questions answered to my satisfaction. I voluntarily agree to grant permission for my child to participate in this study. I understand that a copy of this consent will be provided to me for future reference. 
I have witnessed the consent process and believe that the participants listed above have been fully informed, understand the project and what they will have to do, and have voluntarily agreed to participate.

Witness Signature

Date 
APPENDIX K

SPECIFIC AIM \#2: INFORMED ASSENT FORM 


\section{Appendix K}

Specific Aim \#2: Informed Assent Form

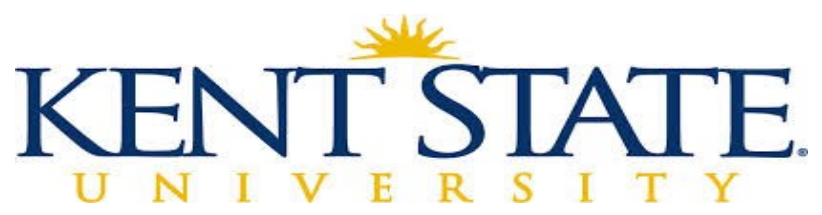

\section{Child Assent Form to Participate in a Research Study}

Title: The experimental effect of parent versus peer influence on children's physical activity behavior

Hello, my name is Mallory Kobak, and I am trying to learn more about how much you like to play in different activities. I would like you, one of your parents, and one of your friends to come to the Independence Playground to play. If you choose to be in this project I will first see how tall you are and how much you weigh. After that you will get to play different activities on the playground. While playing these activities you will be asked to wear a special belt around your waist that helps me see how many times you move. It does not hurt and it will be easy for you to still play. You will play on the playground for 30 minutes each time you come here. One time you will play by yourself, one time you will play with your parent, and one time with your friend. After the 30 minutes of playing are over I will ask you how much you liked playing. After all three visits are over I will ask you which time playing was your favorite.

Do you want to do this? Please circle one: $\quad$ YES NO

Do you have any questions? Please circle one: $\quad$ YES NO

When you are playing and you want to stop just tell me.

If you want to be in the study, write your name on the first line below:

Child Signature

Parent Signature

Witness Signature
Date

Date

Date 
APPENDIX L

SPECIFIC AIM \#2: MEDICAL HISTORY FORM (CHILD) 


\section{Appendix L}

\section{Specific Aim \#2: Medical History Form (Child)}

\section{Medical History Screen (Children)}

Name

Date

Subject \#

Address

Phone Number

Age

DOB

Sex $M$ or $F$

Height in

Height cm (inches *2.54)

Wt lbs

BMI__ $\mathrm{kg} / \mathrm{m}^{2} \quad$ Weight percentile

\section{Which ethnic group do you most identify with (circle response):}

American Indian or Alaskan Native Asian or Pacific Islander Black, not of Hispanic Origin Hispanic White, not of Hispanic Origin Other

Y/N
Has a doctor ever said that your child's blood pressure was too high or too low?
Have they ever had pain in their heart or chest?
Have they ever noticed extra heart beats, skipped beats or a racing heart?
Has a doctor ever said that they have heart trouble, an abnormal electrocardiogram (ECG
or EKG), heart attack, or coronary?
Do they often have trouble breathing?
Have they ever been diagnosed with asthma?
Have they ever been diagnosed with diabetes?
Do they have any orthopedic limitations to physical activity?

Does your child have any other medical conditions that affect your ability to safely participate in physical activity? If yes, please explain, is the condition controlled? Do you have physician clearance?

Is your child currently taking any medication(s)?

$\mathrm{Y}$ or $\mathrm{N}$

If yes, please describe the medication(s).

Do you have any questions?

$\mathrm{Y}$ or $\mathrm{N}$

To be filled out by research personnel:

Does the child seem eligible?

$\mathrm{Y}$ or $\mathrm{N}$ 
APPENDIX M

SPECIFIC AIM \#2: MEDICAL HISTORY FORM (PARENT) 


\section{Appendix M}

\section{Specific Aim \#2: Medical History Form (Parent)}

\section{Medical History Screen (Parent/Legal Guardian)}

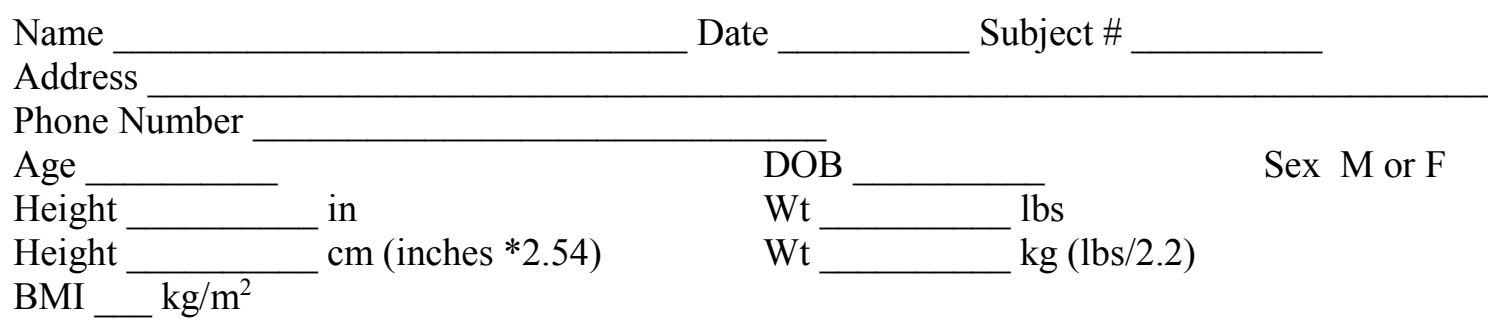

\section{Which ethnic group do you most identify with (circle response): \\ American Indian/Alaskan Native Asian/Pacific Islander Black, not of Hispanic Origin Hispanic White, not of Hispanic Origin Other}

\begin{tabular}{|c|c|}
\hline \multicolumn{2}{|l|}{$\mathbf{Y} / \mathbf{N}$} \\
\hline \multicolumn{2}{|l|}{$\mathbf{Y} / \mathbf{N}$} \\
\hline & Have you ever had pain in their heart or chest? \\
\hline & Have you ever notice extra heart beats, skipped beats or a racing heart? \\
\hline & $\begin{array}{l}\text { Has a doctor ever said that you have heart trouble, an abnormal electrocardiogram (ECG } \\
\text { or EKG), heart attack, or coronary? }\end{array}$ \\
\hline & Do you often have trouble breathing? \\
\hline & Have you ever been diagnosed with asthma? \\
\hline & Have you ever been diagnosed with diabetes? \\
\hline & Do you have any orthopedic limitations to physical activity? \\
\hline
\end{tabular}

Do you have any other medical conditions that affect your ability to safely participate in physical activity? If yes, please explain.

$\begin{array}{ll}\text { Are you currently taking any medication(s)? } & \mathrm{Y} \text { or } \mathrm{N}\end{array}$ If yes, please describe the medication(s).

Have you ever played any physical activities with your child before? $\quad \mathrm{Y}$ or $\mathrm{N}$

On average how many hours per week would you say you spend playing activities with your child?

$\begin{array}{ll}\text { Do you have any questions? } & \mathrm{Y} \text { or } \mathrm{N}\end{array}$

To be filled out by research personnel:

Does the parent seem eligible?

$\mathrm{Y}$ or $\mathrm{N}$ 
APPENDIX N

SPECIFIC AIM \#2: PRIVATE ACCESS LETTER 


\title{
Appendix N
}

Specific Aim \#2: Private Access Letter

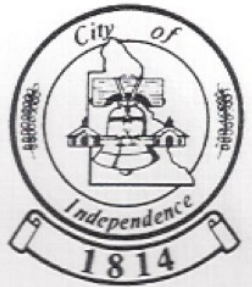

\author{
City of Independence, Ohio \\ "THE HEART OF CUYAHOGA COUNTY" \\ 6800 BRECKSVILLE ROAD INDEPENDENCE, OHIO 44131 \\ (216) $524-4131$
}

May $5^{\text {th }}, 2015$

Independence City Hall

6800 Brecksville Road

Independence, $\mathrm{OH} 44131$

To Whom It May Concern:

I write you in response to Mallory Kobak's request to use our facility to collect data for her Dissertation project. Mallory serves as a great role model for the youth of our city and we would be happy to help her in any way we can. Based on her data collection guidelines she has requested private access to the Independence Playground located on Selig Drive, across the street from City Hall in Elmwood Park. That said, we will allow her private access to this playground for a period of 4 months: June $1^{\text {st }}, 2015$ through September $30^{\text {th }}, 2015$. During that time we request that Mallory post a weekly schedule of data collection hours so that community members are aware of her hours of operation and will only allow their children to play during off hours.

Sincerely,

CITY OF INDEPENDEXCE

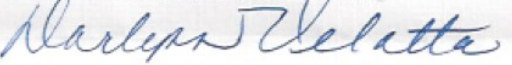

Darlynn Velotta

Administrative Assistant

Mayor's Office 


\section{APPENDIX 0}

SPECIFIC AIM \#2: VISUAL ANALOG SCALE FOR LIKING (VAS) 


\section{Appendix O}

Specific Aim \#2: Visual Analog Scale For Liking (VAS)

NAME: CONDITION:

Visual Analogue Scale for Liking

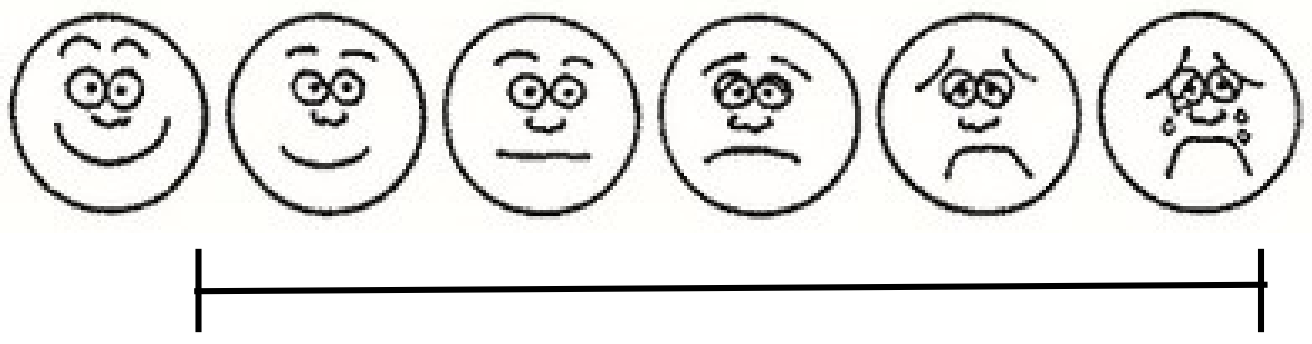

Like it very

Do not like much. it at all. 
APPENDIX P

SPECIFIC AIM \#2: OMNI WALK/RUN SCALE OF PERCIEVED EXERTION FOR CHILDREN 


\section{Appendix P}

Specific Aim \#2: OMNI Walk/Run Scale of Percieved Exertion For Children

OMNI Walk/Run Scale of Perceived Exertion (RPE) for Children

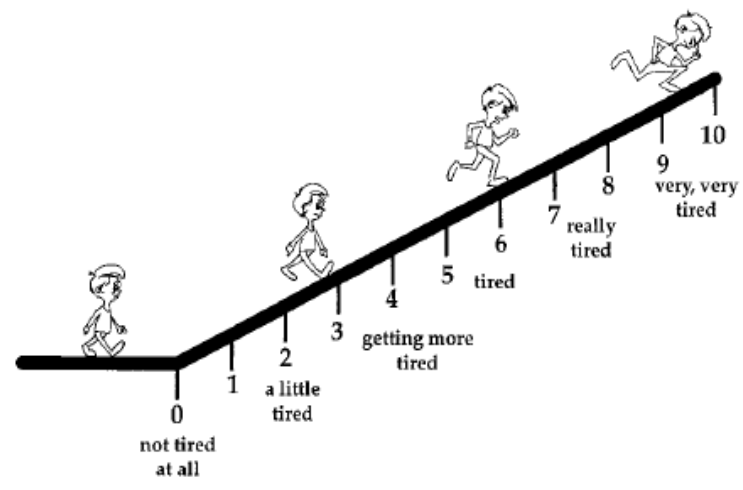




\section{APPENDIX Q}

SPECIFIC AIM \#2: PLAYGROUND ARRANGEMENT 


\section{Appendix Q}

Specific Aim \#2: Playground Arrangement

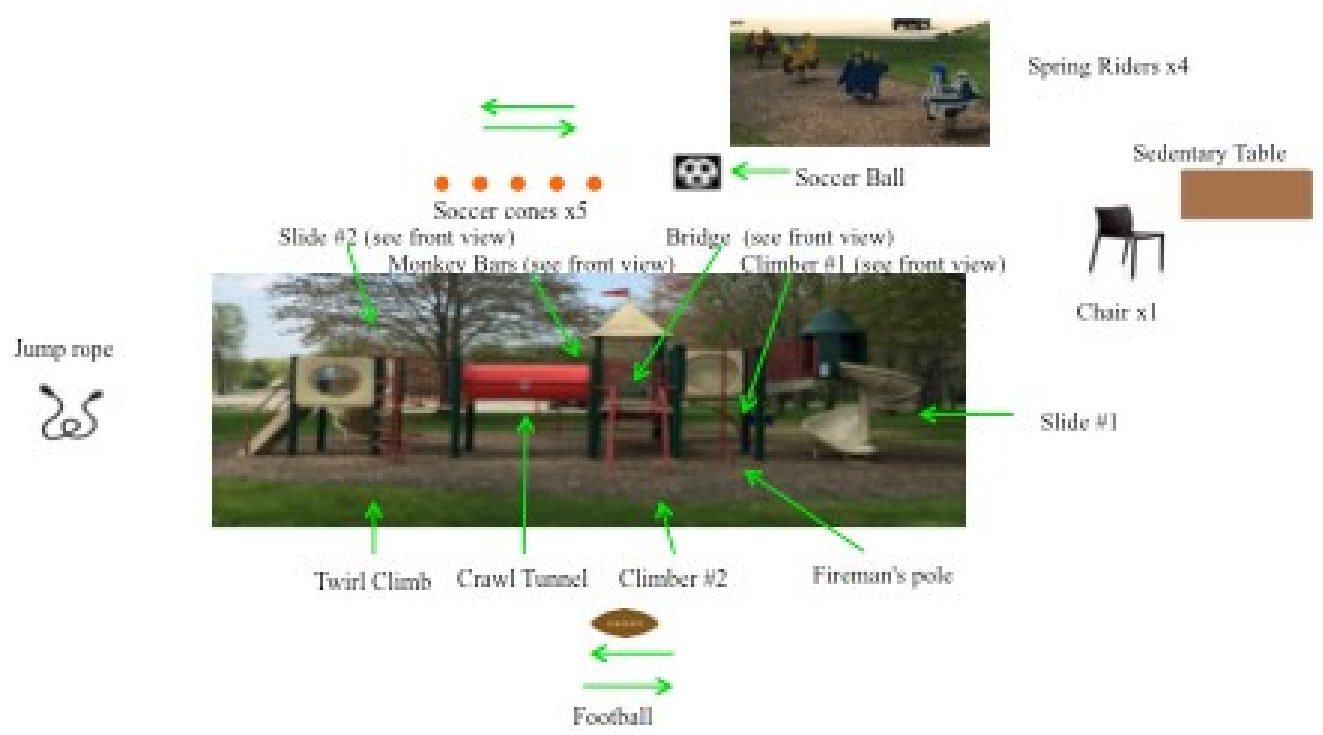




\section{REFERENCES}




\section{REFERENCES}

Anderssen, N., \& Wold, B. (1992). Parental and peer influences on leisure-time physical activity in young adolescents. British Journal of Sports Medicine, 63(4), 341-348.

Bahr, S. J., Hoffmann, J. P., \& Yang, X. (2005). Parental and peer influences on the risk of adolescent drug use. Journal of Primary Prevention, 26(6), 529-551.

Bandura, A. (1977). Self-efficacy: Toward a unifying theory of behavioral change. Psychological Review, 84(2), 191-215.

Barkley, J. E., \& Lepp, A. (2015). Cellular telephone use while walking significantly reduces average free-living walking speed. Medicine and Science in Sport and Exercise, 47(5S) Supplement: 726-732. 62 ${ }^{\text {nd }}$ Meeting of the American College of Sports Medicine, San Diego, CA.

Barkley, J. E., \& Lepp, A. (2016). Mobile phone use among college students is a sedentary leisure behavior which may interfere with exercise. Computers and Human Behavior, 56, 29-33.

Barkley, J. E., Lepp, A., \& Salehi-Esfahani, S. (2015). College students' mobile telephone use is positively associated with sedentary behavior. American Journal of Lifestyle Medicine. Published online before print July 10, 2015, doi: 10.1177/1559827615594338.*

Barkley, J. E., Salvy, S. J., \& Roemmich, J. N. (2012). The effect of simulated ostracism on physical activity behavior in children. American Academy of Pediatrics, 129, $1-8$. 
Barkley, J. E., Salvy, S. J., Sanders, G.J., Williamson, M., Dey, S., \& Von Carlowitz, K. (2011). Peer influence and physical activity in young children; A controlled study. Medicine and Science in Sports and Exercise, 43(5), S224.

Barkley, J. E., Salvy, S. J., Sanders, G. J., Dey, S., Von Carlowitz, K. P., \& Williamson, M. L. (2014). Peer influence and physical activity behavior in young children: An experimental study. Journal of Physical Activity and Health, 11, 404-409.

Beets, M. W., Cardinal, B. J., \& Alderman, B. L. (2010). Parental social support and the physical activity-related behaviors of youth: A review. Heath Education and Behavior, 37(5), 621-644.

Beets, M. W., Pitetti, K. H., \& Forlaw, L. (2007). The role of self-efficacy and referent specific social support in promoting rural adolescent girls' physical activity. American Journal of Health Behavior, 31(3), 227-237.

Benjamini, Y., \& Hochberg, Y. (1995). Controlling the false discovery rate: A practical and powerful approach to multiple testing. Journal of the Royal Statistical Society Series B, 57(1), 289-300.

Center for Disease Control and Prevention [CDC]. (2015). How much physical activity do children need? Available from Center for Disease Control and Prevention. Center for Disease Control and Prevention. Retrieved from http://www.cdc.gov/physicalactivity/basics/children/

Cheng, L. A., Mendon, G., \& de Farias Jr., J. C. (2014). Physical activity in adolescents: analysis of the social influence of parents and friends. Journal of Pediatria, 90(1), $35-4$. 
Cox, R., Skouteris, H., Rutherford, L., Fuller-Tyszkiewicz, M., Dell’ Aquila, D., \& Hardy, L. L. (2012). Television viewing, television content, food intake, physical activity and body mass index: A cross-sectional study of preschool children aged 2-6 years. Health Promotion Journal of Australia, 23(1), 58-62.

Dishman, R. K., Sallis, J. F., \& Orenstein, D. R. (1985). The determinants of physical activity and exercise. Public Health Reports, 100(2), 158-171.

Dishman, R. K., Saunders, R. P., Motl, R. W., Dowda, M., \& Pate, R. R. (2009). Selfefficacy moderates the relation between declines in physical activity and perceived social support in high school girls. Journal of Pediatric Psychology, 34, $4411-4451$.

Dunton, G. F., Liao, Y., Almanza, E., Jerrett, M., Spruijt-Metz, D., Chih-Ping, C., \& Pentz, M. A. (2012). Joint physical activity and sedentary behavior in parent-child pairs. Medicine and Science in Sports and Exercise, 1473-1480.

Eccles, J. S. (1999). The development of children ages 6 to 14. Future Child, 9(2), 30-44. Edwardson, C. L., \& Gorely, T. (2010). Parental influences on different types and intensities of physical activity in youth: A systematic review. Psychology of Sport and Exercise, 11, 522-535.

Elkin, F., \& Handel, G. (1988). The child and society: The process of socialization (5 ${ }^{\text {th }}$ ed.). New York, NY: McGraw Hill.

Epstein, L. H., \& Goldfield, G. S. (1999). Physical activity in the treatment of childhood overweight and obesity: Current evidence and research issues. Medicine and Science in Sports and Exercise, 31(11), S553-559. 
Epstein, L. H., Roemmich, J. N., Cavanaugh, M. D., \& Paluch, R. A. (2011). The motivation to be sedentary predicts weight change when sedentary behaviors are reduced. International Journal of Behavioral Nutrition and Physical Activity, 8 , 13.

Goran, M. I., Reynolds, K. D. (1999). Role of physical activity in the prevention of obesity in children. International Journal of Obesity, 3, 518-533.

Hills, A. P., Andersen, L. B., \& Byrne, N. M. (2012). Physical activity and obesity in children. British Journal of Sports Medicine, 45(11), 866-870.

Himes, J. H., \& Dietz, W. H. (1994). Guidelines for overweight in adolescent preventive services: recommendations from an expert committee. The Expert Committee on Clinical Guidelines for Overweight in Adolescent Preventive Services. The American Journal of Clinical Nutrition, 59(2), 307-316.

Jago, R., Macdonald-Wallis, K., Thompson, J. L., Page, A.S., Brockman, R., \& Fox, K.R. (2010). Better with a buddy: Influence of best friends on children's physical activity. Medicine and Science in Sports and Exercise, 43(2), 259-265.

Kimm, S. Y., Glynn, N. W., \& Kriska, A. M. (2000). Longitudinal changes in physical activity in biracial cohort during adolescence. Medicine and Science in Sports and Exercise, 32, 1445-1454.

Kirby, J., Levin, K. A., \& Inchley, J. (2011). Parental and peer influences on physical activity among Scottish adolescents: A longitudinal study. Journal of Physical Activity and Health, 9, 785-793. 
Kvaavik, E., Tell, G. S., \& Kleep K. I. (2003). Predictors and tracking of body mass index from adolescence into adulthood: Follow-up of 18 to 20 years in the Oslo Youth Study. Pediatrics and Adolescent Medicine, 157, 1212-1218.

Lepp, A., Barkley, J. E., Sanders, G. J., Rebold, M., \& Gates, P. (2013). The relationship between cell phone use, and sedentary activity, and cardiorespiratory fitness in a sample of U.S. college students. International Journal of Behavioral Nutrition and Physical Activity, 10, 79.

Lepp, A., Li, J., Barkley, J. E., \& Salehi-Esfahani, S. (2015). Exploring the relationships between college students' cell phone use, personality and leisure. Computers in Human Behavior, 43, 210-219.

Macdonald-Wallis, K., Jago, R., Page, A. S., Brockman, R., \& Thompson, J. L. (2011). School-based friendship networks and children's physical activity: A spatial analytical approach. Social Science and Medicine, 73(1), 6-12.

O’Keeffe, G. S., Clarke-Pearson, K., \& Council on Communications and Media. (2011). The impact of social media on children, adolescents, and families. The Journal of Pediatrics, 127(4), 800-804.

Ormrod, J. E. (1999). Human learning (3 ${ }^{\text {rd }}$ ed.). Upper Saddle River, NJ: Prentice-Hall. Penko, A. L., \& Barkley, J. E. (2010). Motivation and physiologic responses of playing a physically interactive video game relative to a sedentary alternative in children. Annals of Behavioral Medicine, 39(2), 162-169. 
Peterson, M. S., Lawman, H. G., Wilson, D. K., Fairchild, A., \& Van Horn, M. L. (2013). The association of self-efficacy and parent social support on physical activity in male and female adolescents. Health Psychology, 32, 666-674.

Pradinuk, M., Chanoine, J. P., \& Goldman, R. D. (2011). Obesity and physical activity in children. Canadian Family Physician, 57(7), 779-782.

Prochaska, J. J., Rodgers, M. W., \& Sallis, J. F. (2002). Association of parent and peer support with adolescent physical activity. Quarterly for Exercise and Sport, 73(2), 206-210.

Pugliese, J., \& Tinsley, B. (2007). Parental socialization of child and adolescent physical activity: A meta-analysis. Journal of Family Psychology, 21, 331-343.

Rebold, M. J., Lepp, A., Kobak, M. S., McDaniel, J., \& Barkley, J. E. (2015). The effect of parental involvement on children's physical activity. The Journal of Pediatrics, in press.

Rebold, M. J., Lepp, A., Sanders, G. J., \& Barkley, J. E. (2015). The impact of cell phone use on the intensity and liking of a bout of treadmill exercise. Plos One, 10(5), 112.

Rebold, M. J., Sheehan, T., Dirlam, M., Maldonado, T., \& O’Donnell, D. (2015). The impact of cell phone texting on the amount of time spent exercising at different intensities. Computers in Human Behavior, 55, 167-171.

Rittenhouse, M. A., \& Barkley, J. E. (2013). Self-reported peer victimization and objectively measured physical activity behavior in boys; a quasi-experimental study. Journal of Exercise Physiology Online, 16(3), 84-92. 
Rittenhouse, M., Salvy, S. J., \& Barkley, J. E. (2011). The effect of peer influence on the amount of physical activity performed in 8 - to 12 -year-old boys. Pediatric Exercise Science, 23(1), 49-60.

Robertson, R. J., Goss, F. L., Andreacci, J. L., Dube, J. J., Rutkowski, J. J., \& Snee, B. M. (2005). Validation of the children's OMNI RPE scale for stepping exercise. Medicine and Science in Sports and Exercise, 37(2), 290-298.

Rodriguez, D. A., Brown, A. L., \& Troped, P. J. (2005). Portable global positioning units to complement accelerometry-based physical activity monitors. Medicine and Science in Sports and Exercise, 37(11), S572-S581.

Rodriguez, D. A., Brown, A. L., \& Troped, P. J. (2005). Portable global positioning units to complement accelerometry-based physical activity monitors. Medicine and Science in Sports and Exercise, 37(11), S572-S581.

Roemmich, J. N., Barkley, J. E., Kuo, C., Epstein, L. H., White, T. M., Foster, J. H., \& Paluch, R. (2006). Validity of PCERT and OMNI-walk/run Ratings of Perceived Exertion During Treadmill Exercise. Medicine and Science in Sport and Exercise 38(5), 1014-1019.

Roemmich, J. N., Barkley, J. E., Lobarinas, C. L., Foster, J. H., White, T. M., \& Epstein, L. H. (2008). Association of liking and reinforcing value with children's physical activity. Physiology \& Behavior, 93, 1011-1018.

Sallis, J. F. (2001). Progress in behavioral research on physical activity. Annals of Behavioral Medicine, 23(2), 77-78. 
Sallis, J. F., Alcaraz, J. E., McKenzie, T. L., \& Hovell, M. F. (1999). Predictors of change in children's physical activity over 20 months. Variations by gender and level of adiposity. American Journal of Preventive Medicine, 16(3), 222-229.

Sallis, J. F., Alcaraz, J. E., McKenzie, T. L., Hovell, M. F., Kolody, B., \& Nader, P. R. (1992). Parental behavior in relation to physical activity and fitness in 9-year-old children. American Journal of Diseases of Children, 146, 1383-1388.

Sallis, J. F., Berry, C. C., Broyles, S. L., McKenzie, T. L., \& Nader, P. R. (1995). Variability and tracking of physical activity over 2 years in young children. Medicine and Science in Sports and Exercise, 27, 1042-1049.

Sallis, J. F., \& Nader P. R. (Eds.). (1988). Family determinants of health behaviors. New York, NY: Plenum Press.

Sallis, J. F., Prochaska, J. J., Taylor, W. C., Hill, J. O., \& Geraci, J. C. (1999). Correlates of physical activity in a national sample of girls and boys in grades 4 through 12. Health Psychology, 18(4), 410-415.

Sallis, J. F., Simons-Morton, B. G., Stone, E. J., Corbin, C. B., Epstein, L. H., \& Faucette, N. (1992). Determinants of physical activity and interventions in youth. Medicine and Science in Sports and Exercise, 24(6), S248-257.

Sallis, J. F., Taylor, W. C., Dowda, M., Freedson, P. S., \& Pate, R. R. (2002). Correlates of vigorous physical activity for children in grades 1 through 12: Comparing parent-reported and objectively measured physical activity. Pediatric and Exercise Science, 14(1), 30-44. 
Salvy, S. J., Bowker, J. C., Nitecki, L.A., Kluczynski, M. A., \& Barkley, J. E. (2012). Influence of peers and friends on overweight/obese youths' physical activity. Exercise and Sport Sciences Reviews, 40(3), 127-132.

Salvy, S. J., Roemmich, J. N., Bowker, J. C., Romero, N. D., Stadler, P. J., \& Epstein, L. H. (2009). Effect of peers and friends on youth physical activity and motivation to be physically active. Journal of Pediatric Psychology, 34(2), 217-225.

Salvy, S. J., Romero, N., Paluch, R., \& Epstein, L. H. (2007). Peer influence on preadolescent girls' snack intake: Effects of weight status. Appetite, 49(1), 177-182.

Sanders, G. J., Peacock, C. A. Williamson, M. L., Wilson, K., Carnes, A., \& Barkley, J. E. (2014). The effect of friendship groups on children's physical activity: An experimental study. Journal of Behavioral Health, 3(2), 95-100.

Sanders, G. J., Rebold, M., Peacock, C. A. Williamson, M. L., Santo, A. S., \& Barkley, J. E. (2014). The physiologic and behavioral implications of playing active and sedentary video games in a seated and standing position. International Journal of Exercise Science, 7(3), 194-201.

Sanders, G. J., Santo, A. S., Peacock, C. A., Williamson. M. L., Von Carlowitz, K. P., \& Barkley, J. E. (2012). Physiologic responses, liking and motivation for playing the same video game on an active versus a traditional, non-active gaming system. International Journal of Exercise Science, 5(2), 160-169.

Seabra, A. F., Mendonca, D. M., Thomis, M. A., Anjos, L. A., \& Maia, J. A. (2008). Biological and sociocultural determinants of physical activity in adolescents. Cad Saude Publica, 24, 721-736. 
Shields, C., Spink, K., Chad, K., Muhajarine, N., Humbert, L., \& Odnokon, P. (2009). Examining self-efficacy as a mediator of the relationships between family social influence and physical activity. Journal of Health Psychology, 13, 121-130.

Sigmund, L. A., Naylor, J., Santo, A. S., \& Barkley, J. E. (2014). The effect of a peer on $\mathrm{VO}_{2}$ and game choice in 6-10 year old children. Frontiers in Exercise Physiology, 5(202), 1-9.

Trost, S. G., \& Loprinzi, P. D. (2011). Parental influences on physical activity behavior in children and adolescents: a brief review. American Journal of Lifestyle Medicine, 5, 171-181.

Trost, S. G., Pate, R. R., Freedson, P. S., Sallis, J. F., \& Taylor. W. C. (2000). Using objective physical activity measures with youth: How many days of monitoring are needed? Medicine and Science in Sport and Exercise, 32, 426-431.

Trost, S. G., Sallis, J. F., Pate, R. R., Freedson, P. S., Taylor, W. C., \& Dowda, M. (2003). Evaluating a model of parental influence on youth physical activity. American Journal of Preventive Medicine, 25(4), 277-282.

Trost, S. G., Ward, D. S., Moorehead, S. M., Watson, P. D., Riner, W., \& Burke, J. R. (1998). Validity of the computer science and applications (CSA) activity monitor in children. Medicine and Science in Sports and Exercise, 30(4), 629-633.

Verloigne, M., Veitch, J., Carver, A., Salmon, J., Cardon, G., De Bourdeaudhuij, I., \& Timpero, A. (2014). Exploring associations between parental and peer variables, personal variables and physical activity among adolescents: A mediation analysis. BMC Public Health, 14(966), 1-11. 
Weiss, M. R. (2000). Motivating kids in physical activity. President's Council on Physical Fitness and Sports, Research Digest, 3(11), 1-10.

Weiss, M. R., McCullagh, P., Smith, A. L., \& Berlant, A. R. (1998). Observational learning and the fearful child: Influence of peer models on swimming skill performance and psychological responses. Research Quarterly for Exercise and Sport, 69(4), 380-394.

Wu, T. Y., \& Pender, N. (2002). Determinants of physical activity among Taiwanese adolescents: An application of the health promotion model. Research in Nursing $\&$ Health, 25(1), 25-36.

Zecevic, C. A., Tremblay, L., Lovsin, T., \& Michel, L. (2011). Parental influence on young children's physical activity. International Journal of Pediatrics, 2010, 468526. 